\title{
Genetic reduction of PERK-elF2 $\alpha$ signaling in dopaminergic neurons drives cognitive and age-dependent motor dysfunction
}

\author{
Francesco Longo ${ }^{1}$, Maria Mancini ${ }^{2}$, Pierre L. Ibraheem ${ }^{1}$, Sameer Aryal ${ }^{1,3}$, Caterina Mesini ${ }^{1}$, \\ Jyoti C. Patel ${ }^{2,4}$, Elena Penhos ${ }^{2,4}$, Nazia Rahman ${ }^{2,4}$, Maggie Donohue ${ }^{1}$, Emanuela Santini ${ }^{1,5}$ \\ Margaret E. Rice ${ }^{2,4}$, and Eric Klann ${ }^{10}$
}

\author{
${ }^{1}$ Center for Neural Science, New York University, New York, NY \\ ${ }^{2}$ Department Neuroscience and Physiology, NYU School of Medicine, New York, NY \\ ${ }^{3}$ Sackler Institute of Graduate Biomedical Sciences, NYU School of Medicine, New York, NY \\ ${ }^{4}$ Department of Neurosurgery, NYU School of Medicine, New York, NY \\ ${ }^{5}$ Department of Neuroscience, Biomedicum, Karolinska Institute, Stockholm, Sweden
}

- To whom correspondence should be addressed:

Dr. Eric Klann

Center for Neural Science

New York University

4 Washington Place, Room 809

New York, NY 10003

eklann@cns.nyu.edu 


\section{Abstract}

3 An array of phenotypes in animal models of neurodegenerative disease have been shown to 4 be reversed by neuronal inhibition of PERK, an elF2 $\alpha$ kinase that modulates the unfolded 5 protein response (UPR). This suggests that targeting PERK therapeutically could be beneficial 6 for treatment of human disease. Herein, using multiple genetic approaches we show that 7 selective deletion of the PERK in mouse midbrain dopaminergic (DA) neurons results in 8 multiple cognitive and age-dependent motor phenotypes. Conditional expression of phospho9 mutant elF2 $\alpha$ in DA neurons recapitulated the phenotypes caused by deletion of PERK, 10 consistent with a causal role of decreased elF2 $\alpha$ phosphorylation. In addition, deletion of 11 PERK in DA neurons resulted in altered de novo translation, as well as age-dependent changes in axonal DA release and uptake in the striatum that mirror the pattern of motor changes observed. Taken together, our findings show that proper regulation of PERK-elF2 $\alpha$ signaling in DA neurons is required for normal cognitive and motor function across lifespan, and also highlight the need for caution in the proposed use of sustained PERK inhibition in 


\section{Introduction}

Altered proteostasis and the aggregation of misfolded proteins represent a shared pathological trait across many neurodegenerative diseases ${ }^{1}$. The sustained and inappropriate accumulation of damaged proteins constitutes a pathological load for the endoplasmic reticulum (ER), which results in ER-stress ${ }^{2}$ and activation of the unfolded protein response (UPR), an integrated signaling pathway that protects cells by restoring normal proteostasis. UPR signaling controls the overall burden of misfolded proteins through general translational arrest and increased translation of transcriptional genes that enhance ER protein-folding capacity and quality control through the degradation of proteins with aberrant conformation. Multiple pieces of evidence suggest that the UPR plays a key role in maintaining neuronal function at the level of synapses, connectivity, and brain development ${ }^{3}$.

A critical component of the UPR is protein kinase R-like endoplasmic reticulum kinase (PERK), which phosphorylates the eukaryotic initiation factor $2 \alpha$ (elF2 $\alpha$ ) at serine 51 , thereby controlling the initiation step of protein synthesis and subsequently preventing an overload of proteins in the ER lumen ${ }^{4}$. Paradoxically, elF2a phosphorylation via PERK increases the synthesis of transcription factors that contain unread open reading frames (uORFs) in the 5'UTR of their mRNAs, including activating transcription factor 4 (ATF4), which is involved in the expression of several UPR target genes ${ }^{5}$. However, when ER stress is sustained and the adaptive mechanisms of the UPR are not sufficient to recover cellular protein homeostasis, a switch to pro-apoptotic signals triggers the death of damaged cells ${ }^{6}$, which occurs in neurodegenerative disorders including Parkinson's disease (PD) and Alzheimer's disease $(\mathrm{AD})^{1}$. In vitro and in vivo studies indicate that UPR activation is a "double-edged sword", as evidence suggests that short-term activation plays a protective role whereas long-term activation results in synaptic failure, impaired synaptic plasticity, and ultimately, cell death ${ }^{7,8}$. Together, these studies reinforce the idea that proper ER proteostasis is key for sustaining neuronal connectivity and function.

The functional link between ER stress, the UPR, and neurodegeneration has been extensively investigated over the last decade ${ }^{9}$. Activation of the UPR has been reported in post mortem brain tissues from patients with a number of neurodegenerative disorders. Increases in markers of UPR activation, in particular, the increased phosphorylation of PERK and elF2 $\alpha$, 
have been observed in PD, AD, and other tauopathies ${ }^{9,10}$. Selective neuronal populations seem to be especially vulnerable to ER stress ${ }^{11}$, so it is perhaps unsurprising that the clinical manifestation of neurodegenerative diseases is initiated by the selective alteration in the function of distinct neuronal populations. Activation of PERK-eIF2 $\alpha$ signaling and a colocalization of phosphorylated PERK and a-synuclein, a disease-specific misfolded protein, have been reported in dopaminergic (DA) neurons of the substantia nigra in brain tissue of PD patients $^{10,12}$. Beyond its critical role in the control of voluntary movement via the nigrostriatal pathway, DA signaling contributes to synaptic plasticity underlying learning and memory in specific brain regions, including the hippocampus, amygdala, and prefrontal cortex, and altered DA modulation affects the encoding and maintenance of memories ${ }^{13-15}$.

The findings described above suggest that modulation of the UPR in specific subpopulations of neurons may supply therapeutic benefits in the treatment of neurodegenerative disorders. Consistent with this idea, genetic and pharmacological modulation of PERK-elF2 $\alpha$ signaling has emerged as a therapeutic target in neurodegenerative diseases, primarily due to its role in mediating elF2-dependent protein synthesis $^{16-18}$. However, these studies have proved to be as controversial as promising ${ }^{19,20}$, indicating a new layer of complexity to the involvement of UPR in neurodegeneration. In the current study, we explored the cell type-specific modulation of PERK-elF2 $\alpha$ signaling in DA neurons. We used genetic approaches that included Cre-Lox recombination technology to selectively delete PERK in DA neurons of both the nigrostriatal and mesocorticolimbic pathways to investigate the consequences of manipulating the UPR on motor and cognitive function. Notably, we found that genetic disruption of PERK-elF2 $\alpha$ signaling in DA neurons in mice resulted in multiple age-dependent motor and cognitive phenotypes. In addition, de novo translation studies revealed dysregulated protein synthesis in DA neurons, and fast-scan cyclic voltammetry (FSCV) in ex vivo striatal slices showed an age-dependent alteration in DA release and DAT-mediated uptake that contribute to the behavioral phenotypes caused by the deletion of PERK in DA neurons. Overall, our findings show that proper cell type-specific regulation of PERK-elF2 signaling in DA neurons is required for normal motor and cognitive function, and that the UPR plays a critical role in maintaining DA neuron function during development and aging. These findings highlight the need for careful evaluation of the effects of sustained PERK inhibition in neurons, which has been proposed as a therapeutic strategy in the treatment of several neurodegenerative disorders. 


\section{Results}

\section{Conditional deletion of PERK in DA neurons leads to multiple age-dependent motor and} cognitive phenotypes in mice.

In order to evaluate whether proper cell type-specific regulation of PERK-elF2 $\alpha$ signaling in DA neurons is required for normal cognitive and motor function, we generated mice containing a DA transporter (DAT) promoter-driven Cre transgene (DAT-Cre; Jackson Laboratory, stock number: 006660 $)^{21}$ and a conditional allele of Perk (Perk ${ }^{\text {loxP }}$; termed PERK ${ }^{\mathrm{f} / \mathrm{f}}$; Fig. 1a) ${ }^{22}$. The expression of the Cre transgene and the Perk ${ }^{\text {loxP }}$ allele was determined using PCR-specific primers (Fig. 1b). The resulting conditional knockout mice (PERK $\left.{ }^{\mathrm{f} / \mathrm{f}} \mathrm{DAT}-\mathrm{Cre}\right)$, which lack PERK in DA neurons of both the ventral tegmental area (VTA) and the substantia nigra pars compacta (SNc) represent the primary experimental mouse line used here, along with their littermate control mice (WT DAT-Cre).

Cell-specific deletion of PERK in DA neurons was first verified at the protein expression level by treating coronal midbrain slices containing the VTA and SNc with thapsigargin, which inhibits $\mathrm{ER} \mathrm{Ca}^{2+}$ sequestration and is a potent inducer of ER stress and elF2 $\alpha$ phosphorylation. Immunostaining for PERK after thapsigargin exposure was clearly seen in tyrosinehydroxylase positive (TH+) DA neurons in both SNc and VTA in WT DAT-Cre mice, whereas PERK staining was not detected in SNc or VTA DA neurons of PERK ${ }^{f / f}$ DAT-Cre mice, although PERK expression in non-DA (TH-) cells remained intact (Fig. 1c-d). Consistent with these results, downstream UPR targets of PERK such as p-elF2a (Supplementary Fig. 1a-d) and ATF4 (Supplementary Fig. 1e-f) were significantly reduced in both SNc and VTA DA neurons of PERK ${ }^{\mathrm{f} / \mathrm{f}}$ DAT-Cre mice compared to thapsigargin-treated controls. Taken together, these results demonstrate a reduced UPR after thapsigargin-induced ER-stress in midbrain DA neurons of $P E R K^{f / f}$ DAT-Cre mice, confirming positive targeting of DA neurons for the deletion of PERK. specificity of Cre transgene expression in $\mathrm{DAT}^{+}$neurons, we generated a separate mouse line containing the DAT-Cre transgene, the Perk ${ }^{\text {loxP }}$ allele and Ai14, a Cre reporter allele that has a loxP-flanked STOP cassette preventing transcription of a CAG promoter-driven red fluorescent 
133 protein variant (tdTomato), all inserted into the Gt(ROSA)26Sor locus (B6; 129S6134 Gt(ROSA)26Sor ${ }^{\text {tm14(CAG-tdTomato)Hze; Jackson Laboratory, stock number: 007914) }}{ }^{23}$ that express 135 tdTomato fluorescence following Cre-mediated recombination (Supplementary Fig. 2a). Thus, 136 along with the deletion of PERK from in neurons in which Cre is expressed (DAT ${ }^{+}$neurons), 137 the STOP cassette is removed and the tdTomato protein is expressed. We found a complete 138 overlap between cells expressing tdTomato fluorescence (Cre-reporter expression) and the DA 139 neuronal marker tyrosine hydroxylase (TH; Supplementary Fig. 2b) in both $140 \mathrm{PERK}^{\mathrm{f} / \mathrm{f}} / \mathrm{CAG}^{\text {floxStop-tdTomato }}{ }^{\mathrm{DAT}-C r e}$ and wild-type (WT)/CAG ${ }^{\text {floxStop-tdTomato }}{ }^{\mathrm{DAT}-C r e}$ mice. 141 Moreover, we found no staining for PERK in tdTomato co-stained neurons (Supplementary 142 Fig. 2c,e) of PERK ${ }^{\mathrm{f} / \mathrm{f}} / \mathrm{CAG}^{\text {floxStop-tdTomato } D A T-C r e ~ m i c e, ~ c o n f i r m i n g ~ t h e ~ s p e c i f i c i t y ~ o f ~ t h e ~ C r e-~}$ 143 recombinase system for the DA neurons. Along with these results, we detected a significant 144 reduction in p-elF2 $\alpha$ levels in DA neurons in both SNc and VTA of PERK $/$ CAG $^{\text {floxStop- }}$

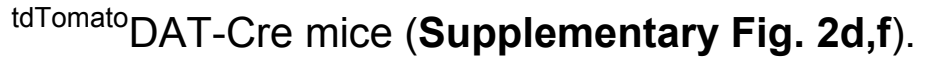
neurons on motor ability in mice across ages, we examined PERK ${ }^{\mathrm{f} / f}$ DAT-Cre mice and their age-matched WT DAT-Cre littermate controls in a series of behavioral tests at 3, 8, and 12 months of age. Mice were tested for different motor skills, including akinesia (bar test), bradykinesia (drag test), general motor activity (rotarod test), locomotor activity induced by novelty (NHC), and spontaneous horizontal and vertical locomotor activity in the open field (OF). PERK ${ }^{\mathrm{f} / \mathrm{f}}$ DAT-Cre mice displayed a striking biphasic change in motor performance as the mice aged. Specifically, compared to age-matched controls, mice lacking PERK in DA neurons generally exhibited a hyperactive motor phenotype at 3 months of age, had motor behavior that was similar to controls at 8 months, but then showed reversal to a hypoactive phenotype at 12 months of age (Fig. 1e-j). In the bar test, young PERK ${ }^{\mathrm{f} / \mathrm{f}}$ DAT-Cre mice showed a trend for reduced immobility time versus WT DAT-Cre, whereas 8 and 12-month old PERK ${ }^{\mathrm{f} / \mathrm{f}}$ DATCre mice showed increased akinesia compared to WT DAT-Cre mice (Fig. 1e). Consistent with a hyperactive phenotype at 3 months, young PERK ${ }^{\mathrm{f} / \mathrm{f}}$ DAT-Cre mice showed significantly greater stepping activity than WT DAT-Cre mice in the drag test (Fig. 1f). Although overall stepping activity decreased with age for both genotypes in this test, the performance of $P E R K^{\mathrm{f} / \mathrm{f}}$ DAT-Cre mice exhibited a more pronounced decline at 12 months compared to control mice. Motor facilitation was also seen in the rotarod test for young PERK mutant mice, with significantly enhanced motor skill acquisition compared to WT DAT-Cre mice at 3 months (Fig. 
1g). This motor difference was normalized at 8 months, then reversed at 12 months, with a marked drop in rotorod performance in PERK ${ }^{\mathrm{f} / \mathrm{f}}$ DAT-Cre compared to that of age-matched controls (Fig. 1g). Novelty-induced (Fig. 1h) and spontaneous (Fig. 1i) horizontal locomotor activity followed similar patterns, with hyperactivity motor phenotype in PERK ${ }^{\mathrm{f} / \mathrm{f}}$ DAT-Cre mice at 3 months, but a significant decline associated with aging in DAT-Cre versus WT at 12 months (Fig. 1h,i). Moreover, PERK ${ }^{\mathrm{f} / \mathrm{f}}$ DAT-Cre mice displayed a significantly enhanced vertical locomotor activity in the OF arena compared with their controls at 3 months of age, although the difference was lost as the mice aged (Fig. 1j).

PERK is a key regulator of elF2-dependent translation, which is a key molecular process underlying learning and memory formation ${ }^{24-26}$. To determine whether the conditional deletion of PERK in DA neurons impacts cognitive, as well as motor function, we examined 3and 12-month old PERK ${ }^{\mathrm{f} / \mathrm{f}}$ DAT-Cre mice and age-matched littermate WT DAT-Cre mice in a series of behavioral tasks to test learning and memory. First, we tested spatial learning and memory in 3-month old mice in the Morris water maze (MWM), a hippocampus-dependent water escape task. During the acquisition of the hidden platform phase of the water maze task, both genotypes showed a day-to-day decrease in escape latency, although the daily improvement was less in PERK ${ }^{\mathrm{f} / \mathrm{f}}$ DAT-Cre mice which consistently exhibited longer escape latencies than WT DAT-Cre controls (Fig. 2a). In the probe test when the platform was removed, PERK ${ }^{\mathrm{f} / \mathrm{f}}$ DAT-Cre mice spent less time in the target quadrant (Fig. 2b) and crossed the platform location fewer times (Fig. 2c) compared to WT DAT-Cre mice, with representative swim paths shown in Fig. 2d. Notably, 12-month old PERK ${ }^{\mathrm{fff}}$ DAT-Cre mice displayed learning and memory deficits that paralleled those seen in the 3-month old mice, including longer escape latencies during training (Fig. 2h), reduced time in the target quadrant (Fig. 2i), and fewer crossings of the platform location (Fig. $2 \mathbf{j}$ ) during the probe test compared to their WT DAT-Cre counterparts. The impaired performance seen in mice lacking PERK in midbrain DA neurons suggest that the sustained disruption of PERK-elF2 $\alpha$ signaling alters a DA-dependent contribution to this hippocampus-dependent spatial memory task.

To confirm our findings that PERK-elF2 $\alpha$ signaling disruption in DA neurons impacts learning and memory, we tested PERK ${ }^{f / f}$ DAT-Cre mice and their WT DAT-Cre littermates on two additional tasks: novel object recognition and an associative threat memory task (Fig. 2). In the novel object recognition task, we found that 3-month old PERK mutant mice exhibited 
199 similar interactions with familiar objects during training to age-matched WT DAT-Cre mice (Fig. 20), but showed a decreased preference for the novel object, indicating a significantly impaired short-term memory (STM) performance during the test versus controls (Fig. 2p). Moreover, young PERK ${ }^{\mathrm{f} / \mathrm{f}}$ DAT-Cre mice also demonstrated a significantly reduced preference for the novel object versus controls when long-term memory (LTM) was examined 24 hours after the test (Fig. 2q). Representative heat maps are shown in Fig. 2r. Again, 12-month old PERK ${ }^{\mathrm{f} / \mathrm{f}}$ DAT-Cre mice recapitulated the phenotype exhibited by the 3-month old mice, with impaired STM (Fig. 2p) and LTM (Fig. 2q) during the novel object recognition task (Fig. 20-r). Combined, these results suggest that PERK in DA neurons is important for frontal and temporal cortex-dependent sensory information processing. Similar to the novel object recognition task, 3-month old PERK ${ }^{\mathrm{f} / \mathrm{f}}$ DAT-Cre mice exhibited altered associative learning and memory when tested with a threat memory task (Fig. 2e-g). Both genotypes performed similarly during training, showing a similar freezing behavior (Fig. 2e). However, PERK ${ }^{\mathrm{fff}}$ DATCre mice displayed significantly reduced freezing 24 hours after training for both the context (Fig. 2f) and the cue (Fig. 2g) compared to their WT DAT-Cre littermates. Similarly, 12-month old PERK ${ }^{f / f}$ DAT-Cre mice showed no difference in freezing compared to the WT DAT-Cre mice during training (Fig. 2I), but displayed a significant decrease in freezing time to both the context (Fig. 2m) and the cue (Fig. 2n). These behavioral studies indicate that the deletion of PERK in DA neurons not only affects hippocampal and frontal cortex-dependent function, but also results in amygdala-dependent memory impairments, suggesting functional alterations of the mesocorticolimbic pathways ${ }^{27}$.

\section{Deletion of PERK in DA neurons alters de novo translation and multiple behaviors via} elF2 $\alpha$ signaling disruption

As mentioned above, phosphorylation of elF $2 \alpha$ on serine 51 is a mechanism through which PERK downregulates global protein synthesis under a variety of cellular stress conditions. Consistent with blocked expression of PERK, the phosphorylation of elF2 $\alpha$ was reduced in DA neurons of 3-month old PERK ${ }^{\mathrm{f} / \mathrm{f}}$ DAT-Cre mice (Supplementary Fig. 2d). Given that elF2 $\alpha$ phosphorylation is a key step in translational control under normal physiological conditions and during ER-stress, we investigated the effect of removing PERK on de novo protein synthesis in DA neurons (Fig 3). Coronal midbrain slices containing SNc and VTA DA neurons were subjected to fluorescent non-canonical amino acid tagging (FUNCAT) of newly synthesized proteins (Fig. 3a). We observed an increase in de novo translation in DA neurons 
232 of the SNc of PERK ${ }^{\mathrm{f} / \mathrm{f}}$ DAT-Cre mice compared to wild-type DAT-Cre littermates (Fig. 3 b,c).

233 Similar to SNc, VTA DA neurons of PERK ${ }^{\mathrm{f} / \mathrm{f}}$ DAT-Cre mice also exhibited a net increase in 234 newly synthesized proteins (Fig. 3b,d).

To confirm that the behavioral results obtained by deleting PERK in DA neurons are due to decreased elF2 $\alpha$ phosphorylation and not due to other cellular functions of PERK, we bred DAT-Cre mutant mice (Jackson Laboratory, stock number: 006660) ${ }^{21}$ with conditional phospho-mutant elF2 $\alpha$ mice ${ }^{28}$ (knock-in elF2 $\alpha^{(\mathrm{S} 51 \mathrm{~A} / \mathrm{S} 51 \mathrm{~A})}$ mice), where the serine 51 residue has been mutated to alanine (S51A; Fig. 4a). As a result, both the floxed wild-type and the mutated elF2 $\alpha$ gene were expressed in all cells of elF2 $\alpha^{(\mathrm{S} 51 \mathrm{~A} / \mathrm{S} 51 \mathrm{~A})}$ DAT-Cre mice, except for the DA neurons (DAT ${ }^{+}$neurons), where only the mutated elF2 $\alpha^{(\mathrm{S} 51 \mathrm{~A} / \mathrm{S} 51 \mathrm{~A})}$ form is expressed (see Methods section for details). The expression of the Cre transgene and the elF2 $2 \alpha^{(\mathrm{S} 51 \mathrm{~A} / \mathrm{S} 51 \mathrm{~A})}$ allele was determined using PCR-specific primers (Fig. 4b). Then, we verified the cell-specificity of the Cre system by treating coronal slices containing the midbrain with thapsigargin to induce ER stress and elF2 $\alpha$ phosphorylation. Levels of p-elF2 $\alpha$ detected by immunofluorescence were significantly reduced $(\sim 90 \%)$ in both SNc and VTA DA neurons of elF2 $\alpha^{(\mathrm{S} 51 \mathrm{~A} / \mathrm{S} 51 \mathrm{~A})}$ DATCre mice compared to thapsigargin-treated controls (Fig. 4c-d). These data also are consistent with western blotting results showing significantly lower levels of p-elF2a in both VTA and SNc of elF2 $\alpha^{(\text {S51A/S51A) }}$ DAT-Cre mice (Fig. 4e,j). As mentioned above, phosphorylation elF2 $\alpha$ on serine 51 is a mechanism through which PERK downregulates global protein synthesis under a variety of cellular stress conditions. To further confirm the cellspecificity expression of the phospho-mutant elF2 $\alpha\left(\right.$ elF2 $\left.\alpha^{(\mathrm{S} 51 \mathrm{~A} / \mathrm{S} 51 \mathrm{~A})}\right)$ in DA neurons, we investigated de novo translation in DA neuron from thapsigargin-treated midbrain coronal slices with surface sensing of translation (SUnSET). We found a robust increase in de novo protein synthesis in both VTA ( 50\%; Fig. 4f) and SNc ( $80 \%$; Fig. 4k) DA neurons of elF2 $\alpha^{(\mathrm{S} 51 \mathrm{~A} / \mathrm{S} 51 \mathrm{~A})}$ DAT-Cre mice compared to controls. Collectively, these data confirm positive targeting of $\mathrm{DA}\left(\mathrm{DAT}^{+}\right)$neurons for the expression of elF2 $\alpha^{(\mathrm{S} 51 \mathrm{~A} / \mathrm{S} 51 \mathrm{~A})}$ and the disruption of the elF2 $\alpha$ translational control pathway.

We then used the elF2 $\alpha^{(\mathrm{S51A/S51A)})}$ DAT-Cre mice and their WT DAT-Cre littermates to investigate whether the motor phenotypes exhibited by PERK ${ }^{\mathrm{f} / \mathrm{f}} \mathrm{DAT}-\mathrm{Cre}$ mice is due to the selective reduction of elF2 $\alpha$ phosphorylation in DA neurons. We tested 3-month old elF2 $\alpha^{(\mathrm{S} 51 \mathrm{~A} / \mathrm{S} 51 \mathrm{~A})}$ DAT-Cre mice and their WT DAT-Cre littermates for different motor skills (Fig. 
265 4g-I, I-n). Consistent with the findings with the PERK ${ }^{\mathrm{f} / \mathrm{f}}$ DAT-Cre mice, we found that conditional phospho-mutant elF2 $\alpha$ mice displayed decreased immobility time in the bar test (Fig. 4g) and greater stepping activity in the drag test (Fig. 4h) than their WT DAT-Cre counterparts. Although we found no effect of the elF2 $\alpha$ conditional phospho-mutation in the rotarod test (Fig. 4i), elF2 $\alpha^{(\mathrm{S} 51 \mathrm{~A} / \mathrm{S} 51 \mathrm{~A})}$ DAT-Cre mice exhibited significantly enhanced horizontal locomotor activity in both the novel home cage (Fig. 4I) and open field arena (Fig. 4m) tasks, as well as greater vertical locomotor activity compared with WT DAT-Cre littermates (Fig. 4n). These findings support the hypothesis that altered general motor ability displayed by the PERK $^{\mathrm{f} / \mathrm{f}}$ DAT-Cre mice (Fig. 1) is due to the disruption of PERK-elF2a signaling in DA neurons.

To test the hypothesis that PERK regulates learning and memory via elF2 $\alpha$ phosphorylation control in DA neurons, elF2 $\alpha^{(\mathrm{S} 51 \mathrm{~A} / \mathrm{S} 51 \mathrm{~A})} \mathrm{DAT}-\mathrm{Cre}$ mice were trained in the same cognitive tasks as the PERK ${ }^{\mathrm{f} / \mathrm{f}}$ DAT-Cre mice. During MWM training, both genotypes showed a day-to-day decrease in escape latency, but the elF2 $\alpha^{(\mathrm{S} 51 \mathrm{~A} / \mathrm{S} 51 \mathrm{~A})}$ DAT-Cre mice spent significantly longer times to locate the hidden platform (Fig. 5a). elF2 $\alpha^{(\mathrm{S} 51 \mathrm{~A} / \mathrm{S} 51 \mathrm{~A})}$ DAT-Cre mice not only spent less time in the target quadrant (C; Fig. 5b), but also, they exhibited higher preference for the adjacent quadrant (D; Fig. 5b) and crossed the platform location fewer times (Fig. 5c) than their littermate controls in the probe test. We then tested elF2 $\alpha^{(\mathrm{S} 51 \mathrm{~A} / \mathrm{S} 51 \mathrm{~A})}$ DAT-Cre mice and their littermate controls in the novel object recognition (Fig. 5h-k) and associative threat memory tasks (Fig. 5e-g). During novel object recognition training, 3-month old conditional phospho-mutant elF2 $\alpha$ mice and their controls exhibited similar interaction profile with familiar objects (Fig. 5h). No difference in the preference for the novel object was observed between the genotypes during the short-term memory task (Fig. 5i), suggesting intact short-term memory in those mice. However, elF2 $\alpha^{(\mathrm{S} 51 \mathrm{~A} / \mathrm{S} 51 \mathrm{~A})}$ DAT-Cre mice exhibited a reduced preference for the novel object when long-term memory (LTM) was examined 24 hours testing (Fig. 5j). Representative heat maps are shown in Fig. 5k. The 3-month old conditional phospho-mutant elF2 $\alpha$ mice also had impaired LTM in the associative threat memory task (Fig. 5e-g). The elF2 $\alpha^{(\mathrm{S} 51 \mathrm{~A} / \mathrm{S} 51 \mathrm{~A})}$ DAT-Cre mice displayed significantly reduced freezing time during contextual (Fig. 5f) and cued (Fig. 5g) testing compared with WT DATCre mice. Taken together, these findings are consistent with the cognitive phenotypes exhibited by the PERK ${ }^{\mathrm{f} / \mathrm{f}}$ DAT-Cre mice and are consistent with the hypothesis that PERKelF2 $\alpha$ signaling disruption in DA neurons impacts motor functions and multiple cognitive domains in mice. 
Deleting PERK in DA neurons leads to a dysregulation of striatal DA release, DAT activity, synaptic plasticity and DA signaling, without affecting DA content

Midbrain DA neurons project to and modulate multiple highly interconnected modules of the basal ganglia, limbic system, and frontal cortex. Alterations in the DA transmission have been reported not only in $\mathrm{PD}^{29}$, but also in $A D^{27}$ and Huntington's disease (HD) ${ }^{30}$, and have been linked to motor as well as cognitive symptoms. Our observation of opposite agedependent patterns of motor and cognitive changes in PERK ${ }^{\mathrm{f} / \mathrm{f}}$ DAT-Cre mice led us to hypothesize that the role of PERK in DA neuron function may change as a mouse ages, rather than simply contributing to a degenerative process later in life. As noted, SNc DA neurons project primarily to dStr and play a critical role in motor function and dysfunction via basal ganglia circuitry ${ }^{29}$, whereas VTA DA project to ventral striatum (nucleus accumbens) as well as $\operatorname{cortex}^{14,31}$ and hippocampus ${ }^{27}$. To provide an index of age-dependent effects of selective disruption of the PERK-elF2 $\alpha$ signaling in DA neurons, we used FSCV to quantify single-pulse evoked increases in extracellular DA concentration ([DA $\left.]_{0}\right)$ and DA uptake in ex vivo striatal slices from 3-month old and 12-month old PERK ${ }^{\mathrm{f} / \mathrm{f}}$ DAT-Cre mice and their littermate controls. Data from the NAc serve as a proxy for expected changes in DA release in other VTAinnervated regions, including the hippocampus. Consistent with motor hyperactivity in 3-month old PERK ${ }^{\mathrm{f} / \mathrm{f}}$ DAT-Cre mice (Fig. 1e-j), peak evoked [DA] in dStr, NAc core, and NAc shell was significantly higher than in littermate controls (Fig. 6a-d). In striking contrast, in 12-month old PERK $^{\mathrm{f} / \mathrm{f}}$ DAT-Cre mice showed significantly lower peak evoked [DA] compared to control in each region (Fig. 6e-h) that was consistent with the motor hypoactivity phenotype seen in PERK mutants at 12 months (Fig. 1e-j). Given that net [DA]。 reflects both DA release and uptake, we determined maximum DA uptake rate, $V_{\max }$, from evoked [DA]。 records. Increased peak evoked [DA] o could reflect a decrease in $V_{\max }$, for example. However, we found the opposite, with a significantly higher DA uptake rate in 3-month old PERK ${ }^{\mathrm{f} / \mathrm{f}}$ DAT-Cre mice in dStr and NAc core (Fig. 6i-I; dStr: $3.23 \pm 0.12 \mu \mathrm{M} / \mathrm{s}$ PERK ${ }^{\mathrm{f} / \mathrm{f}}$ DAT-Cre versus $2.29 \pm 0.13 \mu \mathrm{M} / \mathrm{s}$ in WT DAT-Cre; NAc: $2.28 \pm 0.11 \mu \mathrm{M} / \mathrm{s}$ PERK $^{\mathrm{f} / \mathrm{f}}$ DAT-Cre vs $1.66 \pm 0.10 \mu \mathrm{M} / \mathrm{s}$ control). In contrast, $V_{\max }$ for DA uptake was significantly lower in slices from 12-month-old PERK ${ }^{\mathrm{f} / \mathrm{f}}$ DATCre mice compared to those from littermate WT DAT-Cre (Fig. 6i-I; dStr: $1.84 \pm 0.12 \mu \mathrm{M} / \mathrm{s}$ PERK $^{\mathrm{f} / \mathrm{f}}$ DAT-Cre vs $3.20 \pm 0.20 \mu \mathrm{M} / \mathrm{s}$ WT DAT-Cre; NAc: $1.02 \pm 0.07 \mu \mathrm{M} / \mathrm{s}$ PERK ${ }^{\mathrm{f} / \mathrm{f}}$ DAT-Cre vs $2.14 \pm 0.10 \mu \mathrm{M} / \mathrm{s}$ WT DAT-Cre). 
Given that altered $[D A]_{0}$ could reflect changes in DA tissue content, we also determined striatal tissue DA content in the PERK ${ }^{f / f}$ DAT-Cre mice to verify possible changes in DA synthesis that might underlie altered DA availability for release. However, striatal DA levels, quantified using HPLC, did not differ significantly between PERK ${ }^{\mathrm{flf}}$ DAT-Cre mice versus their respective controls at either 3 or 12 months (Supplementary Fig. 3a-c). Collectively these data show that PERK-eIF2 $\alpha$ signaling plays a fundamental role in the dynamic regulation of DA release and uptake as the mice age, independent of changes in DA synthesis.

Although regulation of axonal DA release in the striatum is often linked to the firing patterns of midbrain DA neurons, the activity of striatal cholinergic interneurons (Chls) can also trigger axonal DA release independently of DA neuron activity via the activation of nicotinic acetylcholine receptors ( $\mathrm{nAChRs)}$ on DA axons ${ }^{32,33}$. nAChRs on DA axons are formed by different $\alpha$ and $\beta$ subunits; previous studies have demonstrated that $n A C h R s$ containing $\beta 2$ subunits mediate Chl-driven DA release ${ }^{50,34,35}$. To verify whether the effects of PERK deletion might involve Chls and altered nAChR-dependent regulation of DA release, we applied dihydro- $\beta$-erythroidine $(\mathrm{DH} \beta \mathrm{E} ; 1 \mu \mathrm{M})$ a selective antagonist for $\beta 2^{*}$ subunit-containing $n A C h R s^{50}$, and again evoked DA release in dStr, NAc core and shell in the same slices recorded under control conditions. The differences in mean peak evoked [DA] in 3-month and 12-month-old PERK ${ }^{\mathrm{f} / \mathrm{f}}$ DAT-Cre mice versus WT DAT-Cre mice persisted in the presence of $\mathrm{DH} \beta E$, showing that the effect of PERK deletion in DA neurons on axonal DA release is direct and cell-autonomous, and not an indirect effect of altered regulation by Chls and nAChR activation (Supplementary Fig. 4).

The parallel between age-dependent changes in locomotor activity in PERK ${ }^{f / f}$ DAT-Cre mice (Fig 1) and age-dependent changes in evoked DA release (Fig. 6) and uptake in these mice strongly suggests that the changes in DA release drive the changes in motor behavior. We therefore tested the DA dependence of the behaviors seen in 3-month old PERK ${ }^{\mathrm{f} / \mathrm{f}}$ DATCre and WT DAT-Cre. Each genotype was challenged with two different doses $(0.01 \mathrm{mg} / \mathrm{kg}$, $0.2 \mathrm{mg} / \mathrm{kg}$; i.p.) of the D1 receptor antagonist SCH 23390. We found that acute SCH 23390 $(0.01 \mathrm{mg} / \mathrm{kg})$ injection, which previously was shown to cause motor impairments in naive mice ${ }^{36}$, was sufficient to induce a reduction in locomotor activity in control mice, but was ineffective in PERK ${ }^{\mathrm{f} / \mathrm{f}}$ DAT-Cre mice, consistent with enhanced DA release in PERK mutants (Fig. 7a-c). Similarly, PERK ${ }^{\text {f/f }}$ DAT-Cre mice treated with low-dose SCH 23390 showed no 
364 differences in their stepping activity (Fig. 7a), rotarod performance (Fig. 7b), or distance 365 moved (Fig. 7c), whereas control mice treated with SCH 23390 (0.01 mg/kg) had reduced 366 locomotor activity (Fig. 7a-c). Confirming the DA dependence of motor hyperactivity in PERK ${ }^{\mathrm{f} / \mathrm{f}}$ 367 DAT-Cre, high-dose SCH $23390(0.2 \mathrm{mg} / \mathrm{kg})$ reduced locomotor activity in PERK ${ }^{\mathrm{f} / \mathrm{f}}$ DAT-Cre 368 mice to levels seen in untreated controls (Fig. 7a-c). In addition to showing increased DA 369 release at 3 months of age, $\mathrm{PERK}^{\mathrm{f} / \mathrm{f}}$ DAT-Cre mice also exhibit a significant increase in $V_{\max }$ for 370 DA uptake via the DAT (Fig. 6i-I), possibly to compensate for elevated DA release. , We 371 challenged 3-month old PERK ${ }^{\mathrm{f} / \mathrm{f}}$ DAT-Cre mice and their age-matched WT DAT-Cre littermate 372 controls with the DAT inhibitor GBR-12783 (6 mg/kg; $10 \mathrm{mg} / \mathrm{kg}$; i.p.) and examined motor 373 performance. We found that acute DAT blockade with a low dose of GBR-12783 (6 mg/kg) did 374 not change the behavioral responses of the PERK ${ }^{\mathrm{f} / \mathrm{f}}$ DAT-Cre mice, but significantly increased 375 the locomotor activity of WT DAT-Cre mice, as expected (Fig. 7d-f). Inhibition of the DAT by 376 GBR-12783 (6 mg/kg) also increased stepping activity in the drag test (Fig. 7d), facilitated 377 rotarod motor performance (Fig. 7e) and increased the distance travelled (Fig. 7f) in WT DAT378 Cre, but not PERK ${ }^{\mathrm{f} / \mathrm{f}}$ DAT-Cre mice. Consistent with the observed increase in $V_{\text {max }}$ in PERK 379 mutants, we found that a higher dose of GBR-12783 (10 mg/kg) was effective in increasing 380 locomotor activity in both PERK ${ }^{\mathrm{f} / \mathrm{f}}$ DAT-Cre and control mice, as well as, in the drag (Fig. 7d), 381 the rotarod (Fig. 7e) and the open field (Fig. 7f) test. Lastly, in one further test of DA 382 involvement in the motor consequences of PERK deletion in DA neurons, we examined 383 consequence of inhibition of the vesicular monoamine transporter 2 (VMAT2), which is also 384 potentially relevant for pathophysiology in DA neurons, given that the ratio between DAT and 385 VMAT2 is a vulnerability factor in DA neurons ${ }^{37}$. Interestingly, VMAT2 inhibition by low-dose 386 reserpine $(1 \mathrm{mg} / \mathrm{kg})$ was sufficient to induce a variety of motor impairments in WT DAT-Cre 387 mice (Fig. 7d-f), but affected only motor activity in the open field test (Fig. 7f) in PERK ${ }^{f / f} D A T-$ 388 Cre mice. However, high-dose reserpine $(1.5 \mathrm{mg} / \mathrm{kg})$ administration resulted in altered motor 389 behavior in both PERK ${ }^{\mathrm{f} / \mathrm{f}}$ DAT-Cre mice and controls (Fig. 7d-f) resulting in impaired stepping 390 activity (Fig. 7d) rotarod performance (Fig. 7e) and distance moved (Fig. 7f). These data 391 indicate that basic vesicular storage and release of dopamine is not impaired in PERK ${ }^{\mathrm{f} / \mathrm{f}} \mathrm{DAT}$ 392 Cre mice. Taken together, these findings provide strong evidence that the changes in motor 393 activity exhibited by the PERK ${ }^{\mathrm{f} / \mathrm{f}}$ DAT-Cre mice depends primarily on enhanced DA, and 394 support the notion that similar patterns of DA release alteration may also underlie the changes 395 in cognitive tests observed in PERK ${ }^{\mathrm{f} / \mathrm{f}}$ DAT-Cre mice. 
Previous studies have suggested that DA plays a crucial role in the induction and the modulation of striatal long-term depression (LTD), ${ }^{38}$ one of the two main forms of striatal synaptic plasticity ${ }^{39,40}$ at corticostriatal synapses, which depends on the activation of DA receptors. ${ }^{41}$ In addition, reduction of evoked DA overflow in the striatum results in a failure to express $\mathrm{LTD}^{42}$. Therefore, we determined whether the altered de novo translation expressed in PERK-depleted SNc DA neurons underlying the changes in DA release, alters striatal LTD in cortico-striatal slices from 3 month-old PERK ${ }^{\mathrm{f} / \mathrm{f}}$ DAT-Cre and WT DAT-Cre mice. We recorded locally-evoked field excitatory postsynaptic potentials (fEPSPs) in the dorsolateral striatum, then delivered three trains of high-frequency stimulation (HFS) locally to induce LTD. We found that striatal LTD was enhanced in slices from PERK ${ }^{\mathrm{f} / \mathrm{f}}$ DAT-Cre compared to those from control mice (Supplementary Fig. 5a,b). DA plays a key role in the modulation of hippocampal synaptic plasticity and memory encoding, mostly through its binding to DA receptor ${ }^{14}$. Among the different sub-cortical inputs, VTA represents the major source of DA that the hippocampus receives $^{43}$. Because our data from the NAc suggested changes in DA release in other VTAinnervated regions, such as the hippocampus and our behavioral results indicated that the disruption of PERK-elF2 $\alpha$ signaling in DA neurons alters hippocampus-dependent learning and memory in the PERK ${ }^{\mathrm{f} / \mathrm{f}}$ DAT-Cre mice (Fig. 2), we then examined late-phase long-term potentiation (L-LTP) in hippocampal slices from 3 month-old PERK ${ }^{f / f}$ DAT-Cre and control mice. We found that L-LTP, was enhanced in PERK ${ }^{f / f}$ DAT-Cre mice compared to WT DATCre mice (Supplementary Fig. 5c,dn). Taken together, these findings suggest that PERK deletion in DA neurons significantly increases de novo protein synthesis in both striatonigral and mesocorticolimbic DA neuron populations, alters DA release and results in aberrant expression of both cortico-striatal LTD and hippocampal L-LTP, respectively.

Selective disruption of PERK/elF2a signaling in SNc DA neurons causes motor phenotypes similar to those exhibited by PERK ${ }^{\mathrm{f} / \mathrm{f}}$ DAT-Cre mice

DA neurons in the SNc and the VTA play pivotal roles in various brain functions, including the control of motor actions and higher cognitive functions such as learning and memory, motivation, decision-making, and reward processes ${ }^{29}$. These motor functions and cognitive abilities primarily involve two main DA pathways: the nigrostriatal and the mesocorticolimbic pathway, respectively. Thus, we determined whether disrupting PERKelF2 $\alpha$ signaling in either the DA neurons of the nigrostriatal or the mesocorticolimbic pathway differentially impacted motor function and learning and memory at different ages. 
We first investigated motor behavior following the selective deletion of PERK in SNc DA neurons. To conditionally delete PERK from DA neurons of the nigrostriatal pathway, we injected either AAV-TH-iCre ${ }^{44,45}$ or a control AAV expressing dsRED under TH promoter (AAV-Control) ${ }^{44}$ into the SNc of 3-month old PERK ${ }^{\mathrm{f} / \mathrm{f}}$ mice (Fig. 8a). To verify the efficacy of PERK deletion, we examined co-expression of PERK and TH in PERK ${ }^{\mathrm{f} / \mathrm{f}}$ TH-dsRED AAV (control) and PERK ${ }^{f / f}$ TH-Cre AAV mice (Fig. 8b-d). In PERK ${ }^{\mathrm{fff}}$ TH-Cre AAV mice, PERK immunofluorescence was observed in $\sim 35 \%$ of $\mathrm{TH}^{+}$cells (Fig. 8c). Notably, no difference was detected in the total number of $\mathrm{TH}+$ cells between groups (Fig. 8d). We subjected PERK ${ }^{\mathrm{f} / \mathrm{f}} \mathrm{TH}-$ Cre AAV mice and their controls to bar, drag, rotarod, NHC, and OF tasks (Fig. 8) 3 weeks after surgery. We found that 3-month old mice lacking PERK selectively in DA neurons of the nigrostriatal pathway exhibited a hyperactive motor phenotype expressed as reduced immobility time in the bar test (Fig. 8e) and higher stepping activity in the drag test (Fig. 8f). In addition, PERK ${ }^{f / f}$ TH-Cre AAV mice performed better than PERK ${ }^{f / f}$ TH-dsRED AAV mice in the rotarod task (Fig. 8g). Moreover, PERK ${ }^{\mathrm{ff}} \mathrm{TH}-\mathrm{Cre}$ AAV mice exhibited a significant increase in horizontal activity in the NHC task (Fig. 8h) when compared with the control mice. Although spontaneous locomotor activity in the OF task did not differ between PERK ${ }^{\mathrm{f} / \mathrm{f}} \mathrm{TH}-\mathrm{Cre}$ AAV mice and controls (Fig. 8i), PERK ${ }^{\mathrm{f} / \mathrm{f}}$ DAT-Cre mice did show an increase in vertical locomotor activity versus controls (Fig. 8j). We next determined whether deleting PERK in DA neurons of the SNc could affect learning and memory in 3-month old mice. We found a similar day-to-day decrease in escape latency between genotypes, during the acquisition of the hidden platform version of Morris water maze (Supplementary Fig. 6a). Also, no difference between groups was found in the time spent in the target quadrant (Supplementary Fig. 6b) and in the number of platform crossings (Supplementary Fig. 6e) in the probe test (Supplementary Fig. 6a-b,e), suggesting that hippocampus-dependent spatial memory deficits displayed by the PERK ${ }^{\mathrm{f} / \mathrm{f}}$ DAT-Cre mice (Fig. 2) is not due to disrupted PERK-elF2 $\alpha$ signaling in SNc DA neurons. Moreover, PERK ${ }^{\mathrm{f} / \mathrm{T}} \mathrm{TH}-\mathrm{Cre}-\mathrm{AAV}$ mice exhibited similar performance compared to the PERK ${ }^{\mathrm{f} / \mathrm{f}}$ TH-dsRED-AAV control mice when tested in the novel object recognition (Supplementary Fig. 6) and in the LTM contextual threat memory (Supplementary Fig. 6n) tasks. Notably, PERK ${ }^{\mathrm{f} / \mathrm{f}}$ TH-Cre-AAV mice displayed a significant decrease in freezing when compared to the controls during the auditory cue (Supplementary Fig. 6o), denoting that selective deletion of PERK in SNc DA neurons plays a critical role in cognitive processes and affects amygdala-dependent associative memory in mice. Taken together, these results indicate that 3-month PERK ${ }^{\mathrm{f} / \mathrm{f}}$ DAT- 
463 Cre mice exhibit motor phenotypes due to altered function of the nigrostriatal pathway, and 464 impaired associative threat memory that may be related to altered function of the central amygdala (CeA)-SNc-dorsal striatum (dStr) circuitry ${ }^{46}$.

466

We next determined whether PERK-elF2 $\alpha$ signaling disruption in the SNc DA neurons impacted motor and cognitive processes in 12-month old mice. We selectively ablated PERK in DA neurons of the nigrostriatal pathway in 12-month old PERK ${ }^{\mathrm{f} / \mathrm{f}}$ mice, using the same protocol described above. To our surprise, PERK deletion in SNc DA neurons did not affect motor function in these older mice (Fig. 8). $\mathrm{PERK}^{\mathrm{f} / \mathrm{f}} \mathrm{TH}-\mathrm{Cre}-\mathrm{AAV}$ mice and their PERK ${ }^{\mathrm{f} / \mathrm{f}} \mathrm{TH}-$ dsRED-AAV controls exhibited similar locomotor activity expressed as immobility time (Fig. 8e), stepping activity (Fig. 8f), and time on the rotarod (Fig. 8g) at 12 months of age. Moreover, no differences between groups were found in either horizontal (Fig. 8h,i) or vertical (Fig. 8j) locomotor activity in those mice. We then tested learning and memory in PERK ${ }^{\mathrm{flf}} \mathrm{TH}-$ Cre-AAV mice and their PERK ${ }^{\mathrm{fff}}$ TH-dsRED-AAV controls at 12 months of age. We found that PERK deletion in SNc DA neurons in adult mouse brain affected neither hippocampus- and frontal cortex-dependent functions nor amygdala-dependent associative memory (Supplementary Fig. 2). Then, we examined striatal DA release in 12-month-old PERK ${ }^{\mathrm{f} / \mathrm{f}} \mathrm{TH}-$ Cre AAV animals in which PERK omission was selectively restricted to either SNc or VTA DA neurons (e.g., Fig. 8). Single-pulse evoked increases in [DA]。 were similar between control (PERK ${ }^{f / f}$ TH-dsRED AAV) and PERK ${ }^{\mathrm{fff}} \mathrm{TH}-\mathrm{Cre} \mathrm{AAV}$, in dStr, NAc core and shell, whether PERK was deleted selectively in SNc or VTA (Supplementary Fig. 7). Accordingly, no differences in the $V_{\max }$ for DA uptake were seen between genotypes for either injection site (data not shown). Similarly, midbrain DA levels were unaltered in PERKf/f TH-Cre AAV compared to the littermates at either age (Supplementary Fig. 3d-f). Collectively, these data suggest that the lack of PERK in DA neurons of SNc during early life alters control of motor function and importantly, that the age-dependent switch in motor performance in the PERK ${ }^{\mathrm{f} / \mathrm{f}}$ DAT-Cre mice requires PERK deletion during the aging process. Notably, alterations in the nigrostriatal pathway due to the selective deletion of PERK early in life might be detrimental for specific cognitive domains, such as associative threat memory.

\section{Selective disruption of PERK/elF2 $\alpha$ signaling in VTA DA neurons impairs learning and} memory 
Midbrain DA neurons of the VTA encode multiple signals that influence cognitive processes via diverse projections along mesolimbic and mesocortical pathways. Indeed, VTA projections to prefrontal cortex, hippocampus, amygdala and the ventral striatum are thought to regulate and contribute to various types of learning and memory ${ }^{14,31}$. To conditionally delete PERK from DA neurons of the mesocorticolimbic pathway, we injected AAV-TH-iCre or the control AAV expressing dsRED under TH promoter (AAV-Control) into the VTA of 3-month old PERK $^{\mathrm{f} / \mathrm{f}}$ mice (Fig. 8k). We verified the efficacy of PERK deletion by co-expression of PERK and $\mathrm{TH}$ in PERK ${ }^{\mathrm{f} / \mathrm{f}} \mathrm{TH}-\mathrm{dsRED}$ AAV (control) and PERK ${ }^{\mathrm{f} / \mathrm{f}} \mathrm{TH}-\mathrm{Cre}$ AAV mice (Fig. 8I-m). We observed PERK immunofluorescence in only $\sim 30 \%$ of $\mathrm{TH}^{+}$cells of PERK ${ }^{\mathrm{f} / \mathrm{f}} \mathrm{TH}-\mathrm{Cre}$ AAV mice

(Fig. 8m) and no difference was detected in the total number of $\mathrm{TH}^{+}$cells between groups (Fig. 8n). activity in 3-month old mice. Indeed, PERK ${ }^{\mathrm{f} / \mathrm{f}} \mathrm{TH}-\mathrm{Cre}-\mathrm{AAV}$ mice exhibited similar performance compared to the PERK ${ }^{\mathrm{f} / \mathrm{f}}$ TH-dsRED-AAV controls when examined in the bar (Fig. 80), drag (Fig. 8p) and rotarod (Fig. 8q) tests. In addition, no difference was detected between genotypes in either horizontal (Fig. 8r,s) or vertical (Fig. 8t) locomotor activity. We proceeded to examine learning and memory in the 3-month PERK ${ }^{\mathrm{f} / \mathrm{f}} \mathrm{TH}-\mathrm{Cre}$ AAV and PERK ${ }^{\mathrm{f} / \mathrm{f}}$ TH-dsRED AAV mice. We found that PERK ${ }^{f / f}$ TH-Cre AAV mice displayed longer escape latencies (Supplementary Fig. 6a) compared to controls in the training phase of the MWM task. During the probe test, there was no difference between groups in the time spent in the target quadrant (Supplementary Fig. 6b), but the PERK ${ }^{\mathrm{f} / \mathrm{f}} \mathrm{TH}-\mathrm{Cre}$ AAV mice crossed the platform location significantly fewer times than PERK ${ }^{\mathrm{f} / \mathrm{f}}$ TH-dsRED AAV mice (Supplementary Fig. 6e). Moreover, we found that PERK ${ }^{\mathrm{f} / \mathrm{f}} \mathrm{TH}-\mathrm{Cre}$ AAV mice exhibited reduced preference for the novel object in both STM (Supplementary Fig. 6h) and LTM (Supplementary Fig. 6i) tests in the novel object recognition task. The selective deletion of PERK in the VTA DA neurons also recapitulated impaired associative memory deficits exhibited by the 3-month old PERK ${ }^{\mathrm{f} / \mathrm{f}} \mathrm{DAT}$ Cre mice in the associative threat memory tasks (Supplementary Fig. 6). PERK ${ }^{\mathrm{f} / \mathrm{f}} \mathrm{TH}^{\mathrm{C}} \mathrm{Cre}$ AAV mice displayed significantly decreased freezing time when exposed to the context (Supplementary Fig. 6n) and the auditory cue (Supplementary Fig. 6o) compared to their controls, consistent with the idea the disruption of PERK-elF2 $\alpha$ signaling in VTA DA neurons impacts several cognitive domains in a similar manner to 3-month old mice. 
We proceeded to determine the effect of selective deletion of PERK via TH-Cre AAV injection in VTA DA neurons of the 12-month old PERK ${ }^{\mathrm{f} / \mathrm{f}}$ mice. PERK deletion in VTA DA neurons in these older mice also did not affect locomotor performance (Fig. 8o-t). Interestingly, however, the PERK ${ }^{\mathrm{f} / \mathrm{f}} \mathrm{TH}-\mathrm{Cre} \mathrm{AAV}$ mice exhibited mild learning and memory impairments, mostly hippocampus-dependent, when compared to their controls (Supplementary Fig. 6). PERK ${ }^{\mathrm{f} / \mathrm{f}} \mathrm{TH}-\mathrm{Cre}$ AAV mice were trained to localize the hidden platform in the MWM tasks and they showed longer escape latencies (Supplementary Fig. 6c) compared to controls. Nevertheless, no difference between groups was found during the probe test (Supplementary Fig. 6d,f). The 12-month old PERK ${ }^{\mathrm{flf}} \mathrm{TH}-\mathrm{Cre}$ AAV mice showed altered STM (Supplementary Fig. 6k) and LTM (Supplementary Fig. 6I) in the novel object recognition task when compared with the PERK ${ }^{\mathrm{f} / \mathrm{f}} \mathrm{TH}$-dsRED AAV mice. Finally, we examined PERK $^{\mathrm{flf}} \mathrm{TH}-\mathrm{Cre} \mathrm{AAV}$ mice and their controls in the associative threat memory task. Both genotypes performed similarly during training, showing a similar freezing behavior (Supplementary Fig. 6p). However, PERK ${ }^{\mathrm{f} / \mathrm{f}}$ TH-Cre AAV mice exhibited a significant reduction in freezing time than controls when exposed to the context (Supplementary Fig. $6 q$ ), but no differences between groups were detected when the mice were exposed to the auditory cue (Supplementary Fig. 6r). These data suggest that hippocampus- but not amygdala-dependent memory processes were affected in the mice.

\section{Discussion}

The upregulation of PERK-dependent UPR markers has emerged as a consistent feature of multiple neurodegenerative diseases over the last decade ${ }^{9,47}$. There is evidence of dysregulated PERK-eIF2 $\alpha$ signaling in post-mortem brain tissues of PD and AD patients ${ }^{10}$, as well as in preclinical models ${ }^{48,49}$ of neurodegenerative disease. These studies marked a turning point in the recent research strategy on neurodegenerative disorders, bringing into focus the therapeutic value of UPR modulation across the spectrum of these diseases. Chronic activation of PERK signaling via elF2 $\alpha$ phosphorylation is thought to alter neuronal function by repressing global protein synthesis, particularly the synthesis and expression of a cluster of proteins important for the establishment of synapses and neuronal plasticity ${ }^{18}$. This type of PERK-elF2 $\alpha$-dependent translation might account not only for synaptic failure, but also for and subsequent cognitive decline observed in most neurodegenerative disorders ${ }^{24,50,51}$. Thus, it is perhaps unsurprising that modulation of the PERK-elF2 $\alpha$ signaling has emerged as a promising therapeutic target for neurodegenerative disease. Much of the research focus 
561 regarding either pharmacological or genetic inhibition of PERK signaling to reduce p-elF2 $\alpha$ 562 levels has been placed on models of pathology, suggesting a neuroprotective effect of restored 563 elF2 $\alpha$-dependent translation in mice ${ }^{18,52-54}$. However, there is other evidence from studies of 564 preclinical models of neurodegenerative disorders that depict a complex scenario where, depending on the disease context, modulation of PERK-branch mediated translational control may result in contrasting and even opposite effects ${ }^{19,20,55}$. Thus, to fully understand the role of the UPR in pathology and normal brain function, dissecting the impact of modulating the PERK-elF2 $\alpha$ translational control pathway in a cell type-specific manner is necessary, especially if this pathway is to be harnessed as a therapeutic target to treat neurodegenerative diseases. In this study, we provide evidence that cell type-specific deletion of PERK in midbrain DA neurons results in multiple, age-dependent motor and cognitive phenotypes in mice. Our current study is the first demonstrating that sustained reduction of PERK-elF2 $\alpha$ signaling in DA neurons affects DA release and subsequently, DA signaling that impacts both nigrostriatal and mesocorticolimbic pathways.

Classically, elF2a-mediated translational control in the brain has been studied in the context of synaptic plasticity as well as learning and memory processes ${ }^{5,56}$, with most of the studies focusing on molecular manipulation in excitatory neurons ${ }^{17,25,26}$. Our findings reveal a previously unrecognized role of PERK-elF2 $\alpha$-mediated translation in DA neurons and provide molecular insights into the pathophysiology of motor and cognitive impairments when this type of translational control is disrupted. We found that reduced elF2 $\alpha$ phosphorylation in midbrain DA neurons leads to increased de novo translation, which results in DA dysfunction as well as multiple motor and cognitive impairments. Notably, there is an extensive body of literature describing the differential gene and protein expression between different DA neuron populations, which could underlie their selective vulnerability in the context of different neurodegenerative disorders ${ }^{27,57}$. De novo protein synthesis was markedly increased in $\mathrm{TH}^{+}$ neurons of both the SNc and the VTA at 3 months of age, consistent with a clear dysfunction in both nigrostriatal and mesocorticolimbic pathways. Both pre- and postsynaptic protein synthesis is required for striatal $\operatorname{LTD}^{39,40}$, which depends on the activation of DA receptors ${ }^{40,41}$, as does locomotor behaviors, action selection, and associative learning ${ }^{58}$. The hyperactive motor phenotype exhibited by $\mathrm{PERK}^{\mathrm{f} / \mathrm{f}}$ DAT-Cre mice at 3-months of age is correlated with enhanced cortico-striatal LTD, likely via D2 receptor activation ${ }^{59}$ and elevated DA release in the dorsolateral striatum, as indicated by FSCV data (Fig. 6) and the pharmacological 
594 behavioral experiments targeting DA receptors and transporters (Fig. 7). Notably, preclinical 595 models of PD, where degeneration of SNc DA neurons leads to striatal DA depletion, show 596 impairment in indirect pathway mGluR-LTD ${ }^{60}$. The inhibition of indirect pathway LTD causes a 597 shift of balance toward direct pathway LTP in the striatum, which ultimately inhibits 598 movement ${ }^{40}$. Although DA binds to both D1 and D2 receptors, the relative activation of either 599 subtype depends on the DA release levels and the respective affinities of the receptors for $600 \mathrm{DA}^{29}$. Either a hyper-dopaminergic state or a hypodopaminergic state can drive the system to 601 become imbalanced, leading to unidirectional changes in plasticity that could underlie network 602 pathology and symptoms ${ }^{60}$.

603

Despite no changes in DA content, PERK-deficient DA neurons showed increased DA 605 release and uptake in the dStr and NAc of young PERK ${ }^{f / f}$ DAT-Cre mice that correlated with a 606 marked hyperactive motor phenotype and required higher doses of SCH-23390 and GBR12783 to block D1 receptors and DAT, respectively, than those sufficient to induce changes in behavior in WT DAT-Cre mice (Fig. 7). Conversely, a decrease in DA release and uptake in the dStr in older PERK ${ }^{\mathrm{f} / f}$ DAT-Cre mice was associated with a marked decrease in locomotor ability, without affecting DA content (Supplementary Fig. 3). Our findings suggest that PERK not only is important for the regulation of DA release and DAT activity early in life, but sustained repression of PERK activity is detrimental for proper neuronal activity of SNc DA neurons during aging. Consistent with this notion, selectively deleting PERK from SNc DA neurons postnatally using a viral approach led to enhanced locomotor activity at 3 months of age, whereas no alteration in DA release and uptake, or in motor activity were detected when PERK was deleted in SNc DA neurons in 12-month old mice (Supplementary Fig. 7). Curiously, selective deletion of PERK in SNc DA neurons in young mice resulted in an amygdala-dependent memory impairment (Supplementary Fig. 6), which is consistent with the dense interconnections between the SNc and CeA identified as part of a CeA-SNc-CPu loop that underlies associative learning ${ }^{46}$.

It is well established that DA regulation of basal ganglia circuitry occurs mainly in striatum, the major input nucleus that also plays a central role in processing motivational, associative and sensorimotor information ${ }^{61}$. The increase in elF2 $\alpha$-dependent translation via PERK deletion in VTA DA neurons is correlated with an increase DA release and uptake in the NAc of young mice (Fig. 6), whereas we detected an opposite outcome in the NAc when 
PERK was deleted in VTA DA neurons of 12-month old mice (Supplementary Fig. 7). DA plays a key role in the modulation of multiple forms of learning and memory by acting upon specific brain regions, including the hippocampus, amygdala, and prefrontal cortex, and altered DA signaling has been shown to impair the encoding and maintenance of memories ${ }^{13-15}$. Altered DA signaling resulting from PERK deletion in VTA DA neurons in both young and old mice may compromise the role of DA in the modulation of those target structures, ultimately resulting in impaired learning and memory. Indeed, DA is required for late-phase long-term potentiation (LTP) and spike timing-dependent plasticity in the hippocampus ${ }^{62}$, and DA receptor signaling regulates aversive memory retention ${ }^{14}$. Consistent with these observations, we found that hippocampal L-LTP is enhanced in young PERK ${ }^{\mathrm{f} / \mathrm{f}}$ DAT-Cre mice (Supplementary Fig. 5) and hippocampus-dependent contextual memory is altered in PERK ${ }^{\mathrm{f} / \mathrm{f}}$ DAT-Cre mice (Fig. 2), indicating that PERK activity in DA neurons is critical for encoding contextual information. Pharmacological activation of D1/D5 receptors, gates long-term changes in synaptic strength and facilitates induction and duration of LTP at CA1 and dentate gyrus synapses of the dorsal hippocampus in vivo ${ }^{63}$ and DAT re-uptake blockade, which increases DA availability, results in increased LTP magnitude in the CA1 region of rat hippocampus $^{64}$. PERK deletion, specifically in DA VTA neurons in both young and old mice, results in spatial learning and memory impairments in the MWM task (Supplementary Fig. 6). In agreement with these findings, it has been shown that proper mesocorticolimbic DA neuronal function promotes hippocampal network dynamics associated with memory persistence $^{65}$ and $\mathrm{DA}$ in the hippocampus has been shown to play a role in plasticity underlying spatial novelty ${ }^{66}$. The main DA input to the hippocampus arises from the VTA, which has been postulated to form a loop with the hippocampus that then regulates the activity of the VTA to control hippocampal activity through the release of DA ${ }^{67}$.

Moreover, deletion of PERK in excitatory neurons in the forebrain was shown previously to cause impaired cognitive function, especially in behavioral flexibility ${ }^{25}$. Finally, a reduction of elF2 $\alpha$ phosphorylation in either mice lacking the elF2 $\alpha$ kinase GCN2 ${ }^{50}$ or in elF2-S51A mutant mice $^{24}$ results in a lowered threshold for the consolidation of long-term memory, impairments in long-term memory in standard learning and memory paradigms.

We also found that PERK ${ }^{\mathrm{f} / \mathrm{f}}$ DAT-Cre mice exhibit a preference for the familiar rather 
deficits. DA modulation in the prefrontal cortex is crucial for object recognition memory and the dysfunction of the dopaminergic system contributes to age-related cognitive decline in $A D$ model mice ${ }^{68}$. Consistent with this notion, we showed that deleting PERK selectively in VTA DA neurons with a viral approach results in impaired spatial, associative, and discriminative memory in old mice (Supplementary Fig. 6). Our results suggest that PERK-elF2 $\alpha$ signaling is essential for proper function of mesecorticolimbic DA neurons as the mice age, and, therefore, it also plays a key role in the regulation of VTA DA neuron function in the adult DA system. Moreover, a sustained reduction of elF2 $\alpha$ phosphorylation, as is the case in aged mice, is detrimental for the integrity of DA signaling and either an increase or a reduction of DA outflow levels negatively affects DA neurons modulation of target structures. Notably, a recent study on cognitive deficits displayed by AD model mice pointed out the link between alteration in VTA DA neurons and deficits of hippocampus-dependent memory and synaptic plasticity ${ }^{27}$. It has been shown that a decrease in DA in the hippocampus and NAc shell of AD model mice due to VTA DA neuronal degeneration results in impaired synaptic plasticity, memory performance, and food reward processing, which suggests that altered VTA DA neuron function contributes to cognitive deficits in $A D^{27}$.

UPR activation has been described as a "double-edged sword" because short-term activation plays a protective role whereas sustained activation results in synaptic failure, impaired synaptic plasticity, and ultimately, cellular death ${ }^{7,8}$. Interestingly, multiple studies on neurodegenerative disease support the notion that prolonging, rather than inhibiting, PERKelF2 $\alpha$ signaling results in neuroprotective effects. For example, in the A53T alpha-synuclein mutation model of PD, activation of the PERK branch mediates a pro-survival response ${ }^{69}$ and blocking elF2 $\alpha$ dephosphorylation in mutant SOD1 G93A mice, an amyotrophic lateral sclerosis (ALS) mouse model, prevents motor neuron degeneration and aggregation of mutant SOD $1^{70}$. Thus, enhancing the PERK pathway by selectively inhibiting GADD34-mediated dephosphorylation of elF $2 \alpha$ in mutant model of SOD1 mice appears to significantly ameliorate the disease condition ${ }^{71}$. Finally, a recent study on multiple forms of dystonia, a brain disorder associated with involuntary movement and DA deficiency, demonstrated reduced elF2 $\alpha$ signaling in DYT1 dystonia patient-derived cells and that enhancing elF2 $\alpha$ signaling restored abnormal corticostriatal synaptic plasticity in a DYT1 mutant mouse model ${ }^{55}$. 
In closing, our findings reveal the importance of PERK-elF2 $\alpha$-mediated translational control in DA neurons and its role in normal motor function and in learning and memory. Moreover, given the general agreement that preventing translational repression caused by increased elF2 $\alpha$ phosphorylation might be beneficial for treatment of cognitive deficits associated with neurodegenerative disorders, our study sheds light on the consequences of long-term disruption of PERK in DA neurons for motor and cognitive function, suggesting that cell type-specific dissection of the role of PERK, as well as the UPR, in different neurodegenerative diseases is required. Finally, our study is not merely limited to the evaluation of the effect of PERK-elF2 $\alpha$-mediated translational control repression, but uncovers an entirely new biological link between PERK and DA neuronal function that is involved in motor behavior and cognitive processes. Further investigation is needed to elucidate how disruption of PERK-elF2 $\alpha$ signaling affects general and gene-specific translation in DA neurons to alter DA release and uptake and ultimately, motor and cognitive behavior.

\section{Methods}

Animals. All mice were housed in groups of 3-4 animals per cage in the Transgenic Mouse Facility of New York University and maintained in accordance with the US National Institutes of Health Guide for Care and Use of Laboratory Animals. The facility was kept under regular lighting conditions (12 h light/dark cycle) with a regular feeding and cage-cleaning schedule. Mice were all maintained on a C57/BL6 genetic background and all genotypes were determined by polymerase chain reaction (PCR).

Transgenic mice obtained by selective ablation of PERK in midbrain DA neurons were generated by crossing mice harboring floxed PERK gene, Eif2ak3 (PERK ${ }^{\mathrm{fff}}$; generated as previously described; Zhang et al. 2002) with heterozygous DAT-Cre recombinase mouse line (Jackson Laboratory, stock number: 006660) ${ }^{21}$ expressing Cre recombinase inserted upstream of the first coding ATG of the dopamine transporter gene (S/c6a3; DAT). The resulting heterozygous mice $\left(\mathrm{PERK}^{\mathrm{f} /+}\right.$ DAT-Cre) were crossed with $\mathrm{PERK}^{\mathrm{f} /+}$ mice in order to obtain PERK DA conditional knockout (PERK ${ }^{\mathrm{flf}}$ DAT-Cre) mice and, the respective wild-type (WT DAT-Cre) littermates mice used as a control.

Knock-in elF2 $\alpha^{(\mathrm{S} 51 \mathrm{~A} / \mathrm{S} 51 \mathrm{~A})}$ mice expressing transgenic floxed wild-type elF2s1 gene were kindly provided by Dr. Randal J. Kaufman and generated as previously described ${ }^{72}$. The generation 
724 of elF2 $\alpha^{(\mathrm{S} 51 \mathrm{~A} / \mathrm{S} 51 \mathrm{~A})}$ DAT-Cre mice, where the serine 51 residue has been mutated to alanine 725 (S51A) selectively in DA neurons required two stages of breeding. First, elF2 $\alpha^{(\mathrm{S} 51 \mathrm{~A} /+)}$ DAT-Cre 726 mice were obtained by crossing elF2 $\left.\alpha^{(\mathrm{S} 51 \mathrm{~A} /} \mathrm{S51A}\right)$ mice with heterozygous DAT-Cre 727 recombinase mouse line (Jackson Laboratory, stock number: 006660). Second, elF2 $\alpha^{(\mathrm{S} 51 \mathrm{~A} /+)}$ 728 DAT-Cre mice were crossed with elF2 $\alpha^{(\mathrm{S} 51 \mathrm{~A} /+)}$ to generate conditional phospho-mutant elF2 $\alpha$ 729 mice elF2 $\alpha^{(\mathrm{S} 51 \mathrm{~A} / \mathrm{S} 51 \mathrm{~A})}$ DAT-Cre mice and, the respective wild-type (WT DAT-Cre) littermates 730 mice used as a control. The resulting elF2 $\alpha^{(\mathrm{S} 51 \mathrm{~A} / \mathrm{S} 51 \mathrm{~A})}$ DAT-Cre mice express both the floxed 731 wild-type and the mutated elF2 $\alpha$ gene in all cells except for DA neurons (DAT+ neurons), 732 where only the mutated elF2a(S51A/S51A) form is expressed since the wild-type elF2 $\alpha$ gene 733 is excised by Cre.

734 CAG ${ }^{\text {floxStop-tdTomato }}(\mathrm{Ai} 14)$ conditional reporter line (B6; 129S6-Gt(ROSA)26Sor ${ }^{\text {tm14(CAG-tdTomato)Hze; }}$ 735 Jackson Laboratory, stock number: 007914) ${ }^{23}$ and PERK ${ }^{\mathrm{f} /+}$ DAT-Cre mice were crossed to 736 generate $\mathrm{PERK}^{\mathrm{f} / \mathrm{f}} / \mathrm{CAG}^{\text {floxStop-tdTomato } D A T-C r e}$ mice and $\mathrm{PERK}^{+/+} / \mathrm{CAG}^{\text {floxStop-tdTomato }}$ DAT-Cre 737 (named CAG ${ }^{\text {floxStop-tdTomato }}$ DAT-Cre) mice expressing tdTomato fluorescence following Cre738 mediated recombination in $\mathrm{DAT}^{+}$neurons. Mice generated from this cross were used 739 exclusively to confirm the specificity of the Cre-recombinase system for the $\mathrm{DAT}^{+}$neurons and 740 the consequential deletion of PERK in dopaminergic neurons by immunofluorescence.

741 AAVs infusion. AAV2/10-TH-iCre and AAV2/10-TH-dsRED adeno-associated viruses $\left(\sim 10^{12}\right.$ 742 infectious units $\mathrm{ml}^{-1}$ ) were kindly provided by Dr. Caroline Bass and were generated as 743 previously described ${ }^{44}$. Briefly, mice were anesthetized with a solution of ketamine 744 hydrochloride (100 mg/kg, i.p.) and xylazine (10 mg/kg, i.p.), mounted onto a stereotaxic 745 apparatus and viruses were infused bilaterally at the rate of $0.1 \mu \mathrm{l} / \mathrm{min}$. Microinjection needles 746 were left in place for an additional $5 \mathrm{~min}$ to allow for diffusion of viral particles. $\mathrm{PERK}^{\mathrm{f} / \mathrm{f}} \mathrm{mice}$ 747 were injected at either 2 or 11 months of age and allowed three weeks to recover after surgery. 748 Injection coordinates targeting the SNc or the VTA were as follows (with reference to bregma): $749-3.1 \mathrm{AP}, \pm 1.2 \mathrm{ML},-4.3 \mathrm{DV}(\mathrm{SNc})$ or $-3.50 \mathrm{AP}, \pm 0.35 \mathrm{ML},-4.50 \mathrm{DV}$ (VTA).

750 Experimental design. For all behavioral and molecular experiments, mice of either sex were 751 used. Mice subjected to locomotor activity analysis were tested at 3, 8 and 12 months whereas 752 cognitive skills were tested in 3 and 12-month old mice. PERK ${ }^{\mathrm{f} / \mathrm{f}}$ mice (3 or 12 months of age) 753 were subjected to intracranial injections of AAV-TH-Cre or AAV-dsRED in either the SNc or the 754 VTA and tested for both motor and cognitive skills 3 weeks after AAV infusions. All mice were 
755 acclimated to the testing room 30 min prior to each behavioral experiment and all behavioral apparatuses were cleaned with $30 \%$ ethanol between each trial. The experimenter was blind to genotype. All behavioral tests were performed starting with the least aversive (locomotor activity) and ending with the most aversive (associative threat memory task) task.

Mouse behavior: bar test. Originally developed to quantify morphine-induced catalepsy, this test measures the ability of the animal to respond to an externally imposed static posture. It can also be used to quantify akinesia (i.e. time to initiate a movement) also under conditions that are not characterized by increased muscle tone (i.e. rigidity) as in the cataleptic/catatonic state. Mice were gently placed on a table and forepaws were placed alternatively on blocks of increasing heights $(1.5,3$ and $6 \mathrm{~cm}$ ). The time (in seconds) that each paw spent on the block (i.e. the immobility time) was recorded (cut-off time of $20 \mathrm{~s}$ ). Performance was expressed as total time spent on the different blocks. The test was performed in two consecutive days ${ }^{73}$.

Mouse behavior: drag test. This test gives information regarding the time to initiate (akinesia) and execute (bradykinesia) a movement. It is a modification of the 'wheelbarrow test', and measures the ability of the animal to balance its body posture with the forelimbs in response to an externally imposed dynamic stimulus (backward dragging). Animals were gently lifted from the tail leaving the forepaws on the table, and then dragged backwards at a constant speed (about $20 \mathrm{~cm} / \mathrm{s}$ ) for a fixed distance $(100 \mathrm{~cm}$ ). The number of steps made by each paw was recorded. Five determinations were collected for each animal. The test was performed on two consecutive days ${ }^{73}$.

Mouse behavior: rotarod test. The accelerating rotarod task (UGO BASILE, Biological Research Apparatus) was used to test balance and motor coordination. The rotarod test was performed by placing mice on a rotating drum $(3 \mathrm{~cm}$ of diameter), and measuring the time that each mouse was able to achieve walking on the top of the rod. The time at which each animal fell from the drum, touching the plate at the base of the rod, was recorded automatically. If the mouse stopped walking, the session was considered ended at the third full turn of the drum without movement. The speed of the rotarod accelerated from 4 to 40 RPM over a 5 min (300 sec) period. Mice were given 4 consecutive trials with a maximum time of $300 \mathrm{sec}$ and a minimum of $15 \mathrm{~min}$ inter-trial for two consecutive days. The fall latency (expressed in sec) obtained from each of 4 trials of the two days was used for statistical analysis ${ }^{74}$. 
Mouse behavior: novel home cage test (NHC). The NHC test was used to assess the spontaneous horizontal motor activity as novelty-induced exploratory response. Mice were placed in a $35 \times 22 \times 22 \mathrm{~cm}$ experimental cage with the floor covered with bedding. Locomotor activity (expressed in $\mathrm{cm}$ ) was recorded over a 60 min period by using a computerized video tracking system (Noldus, EthoVision XT 13) ${ }^{75}$. The parameter tested was the total distance traveled during the test and in each of the 6 intervals of $10 \mathrm{~min}$.

Mouse behavior: open field (OF) test. The OF test was used to measure the spontaneous general locomotor activity and anxiety-like behavior ${ }^{76}$. Mice were placed in the center of a clear Plexiglas open field $(40 \times 40 \times 30 \mathrm{~cm})$ for $15 \mathrm{~min}$ and a computer-operated optical system (Activity Monitor software for Open Field) monitored the movement of the mice as they explored in the open field. The parameters tested were: total distance traveled, vertical counts (expressed as \% of control). The data were pooled according to genotype, and a mean value was determined for each group.

Mouse behavior: novel object recognition task. The novel object recognition task was performed to analyze both STM and $\mathrm{LTM}^{74}$. Two familiar objects with same shape $(2.5 \times 2.5 \times$ $2.5 \mathrm{~cm})$ and color were used during habituation days. Objects with different shape $(2.5 \times 2.5 \times$ $5 \mathrm{~cm}$ ) and color from the familiar object, were used as novel objects. STM novel object was rectangular shaped and LTM novel object was round shaped. Mice were habituated to the arena and to the two familiar objects (FO) for 2 consecutive days and for 10 min each day. The following day, mice were exposed to the arena with the same two identical objects for the third time and the interaction time with both the objects was recorded (Noldus, EthoVision XT 13) during a 10 min period. After 1 hour, mice were tested for STM and they were exposed to the arena with one FO and the novel object (NO) replaced the non-preferred familiar object. Interaction time with both the objects was recorded for 5 min period. On day 4, mice were tested for LTM and the STM novel object was replaced with the LTM novel object; interaction time with both the objects was recorded for 5 min period and analyzed with the computer program. Interaction parameters were defined as contact with the object (noise-point detector; distance $\leq 2.54 \mathrm{~cm}$ ). The Preference Index (PI) was calculated using the following equation:

$P I=($ time interacting with $\mathrm{NO}) /($ time interacting with $\mathrm{NO}+$ time interacting with $\mathrm{FO})$ 
816 diameter) filled with water, and colored with white non-toxic paint to increase the water's opacity. The pool was separated into four virtual quadrants. There were both proximal as well as distant visual cues in place. There were visual cues placed both on the pool and around the room to mark the position of the different quadrants and a hidden platform was placed in one quadrant. The diameter of the platform was $10.5 \mathrm{~cm}$, which was $1 \mathrm{~cm}$ beneath the surface of the water. On days 1-5, mice were trained to locate the hidden platform. The training phase consisted of four (day 1) or 3 (day 2-4) trials per day with a cutoff of $60 \mathrm{sec}$ and 15 min of intertrials interval. On each day, the swim start positions for each trial were placed sequentially and counterclockwise in the quadrants, allowing mice to start from all the positions at the end of the training phase. The latency to find the platform was recorded. On day 5 mice were subjected to a $60 \mathrm{sec}$ probe trial where the platform was removed from the pool. The parameters measured during the probe trial (also referred as test), were the number of platform crossings and time spent in each quadrant. One hour and a half after the probe trial, visible platform test was performed to ensure that none of the mice were impaired in their visual acuity. The platform was replaced in the same position as the training phase and a small flag was placed on the top of it to indicate the platform position, and the latency to find the visible platform was measured $^{74}$. On day 6 , the reversal learning task was performed. The hidden platform was placed in the opposite quadrant and the latency to find the new location of the platform was recorded. The reversal learning task continued for three days exactly as the initial training protocol (three trials each day; maximum duration of $60 \mathrm{sec}$ for each trial) ${ }^{77}$. Escape latency, number of previous platform position crossings, time spent in each quadrant, and trajectories of the mice in both Morris water maze and water-based reversal learning task were recorded with a computerized video tracking system (Noldus, EthoVision XT 13).

Mouse behavior: associative threat memory task. Contextual and cued threat conditioning (TC) was used to measure associative fear memory ${ }^{78}$. Mice were subjected to a neutral stimulus or context called "conditional stimulus" (CS), a $30 \mathrm{sec} 80 \mathrm{~dB}$ tone; and an aversive stimulus called "unconditional stimulus" (US), a 2 sec $0.5 \mathrm{~mA}$ foot shock. Mice received two day of habituation (900 sec) to the training context, consisting of a white house light and metal conducting grid floor. On the training day mice were placed in the TC chamber (570 sec) and then given two sequences of CS-US, the first at $270 \mathrm{sec}$ and the second at $420 \mathrm{sec}$. In this session mice associated the aversive experience (US) to the noise (CS). Freezing time was measured for intervals: from the start to the first CS-US (270 sec), during the first CS-US (30 
$848 \mathrm{sec}$ ), from the end of first CS-US to the second one (120 sec), during the second CS-US (30 $\mathrm{sec})$ and from the end of second CS-US to the end (120 sec). On day 3, mice were probed first for context TC and then for cued TC, with one hour and a half interval. In context TC, mice were exposed to the training context as the habituation day (without foot shock and tone), and recorded for $300 \mathrm{sec}$; freezing time was measured every interval of $60 \mathrm{sec}$. In this session mice remembered the environment where they received the aversive stimulus. Cued TC was measured by placing mice in a novel context consisting of a red house light, a white Plexiglass floor and vanilla flavored bedding; cleaning solvents also was changed with $30 \%$ isopropanol. Mice were recorded for $720 \mathrm{sec}$ and they were given three CS at $270 \mathrm{sec}, 440 \mathrm{sec}$ and 570 sec. Freezing time was measured in intervals: from $0 \mathrm{sec}$ to $270 \mathrm{sec}$, during the first CS (30 $\mathrm{sec})$, from the end of the first CS to the second CS (140 sec), during the second CS (30 sec), from the end of the second CS to the third CS (100 sec), during the third CS (30 sec), and finally from the end of the third CS to $720 \mathrm{sec}(120 \mathrm{sec})$. Habituation, context TC and cued TC protocols, videos recording and freezing time analysis were performed with FreezeFrame ${ }^{\mathrm{TM}}$ software (version 4.08, Actimetric Inc).

Behavioral pharmacology. Three-month-old PERK ${ }^{\mathrm{f} / \mathrm{f}}$ DAT-Cre and WT DAT-Cre mice were acutely administered i.p. with the DAT inhibitor GBR-12783 dihydrochloride (Tocris Bioscience, cat no: 0421 ) at a doses of 6 or $10 \mathrm{mg} / \mathrm{kg}$, the VMAT2 inhibitor reserpine (Tocris Bioscience, cat no: 2742) at a dose of 1 or $1.5 \mathrm{mg} / \mathrm{kg}$, or the D1 receptor antagonist SCH 23390 hydrochloride (Tocris Bioscience, cat no: 0925) at a dose of 0.01 or $0.2 \mathrm{mg} / \mathrm{kg}$, and motor activity was assessed using the drag, the rotarod, and the open field tests. Mice were tested 20 min (GBR-12783; SCH 23390) or 24 hr (reserpine) after drug administration. Experimenters were blind to the genotype and treatment.

Fluorescent labeling of de novo protein synthesis in DA neurons. A fluorescent noncanonical amino acid tagging (FUNCAT) method was used to detect changes in de novo protein synthesis in DA neurons and it was performed as previously described ${ }^{79}$ with minor modifications. Briefly, $400 \mu \mathrm{m}$ transverse slices were incubated with azido-homoalanine (AHA) at $32^{\circ} \mathrm{C}$ for 2.5 hours. At the end of the incubation slices were transferred into ice-cold $4 \%$ PFA for overnight fixation at $4^{\circ} \mathrm{C}$. The following day, slices were mounted in $3 \%$ agarose and sliced using a vibratome (Leica VT1200S; Leica Microsystems; Bannockburn, IL) to a thickness of 30 $\mu \mathrm{m}$. Free floating sections were collected in Tris-buffered saline (TBS), washed, blocked and permeabilized with $5 \%$ bovine serum albumin (BSA), 5\% normal goat serum (NGS), $0.3 \%$ 
880 Triton-X-100 in TBS for 90 minutes (at RT). Slices were then washed with TBS and incubated 881 with $500 \mu \mathrm{l}$ of cyclo-addition reaction mix (Click-iT TM Cell Reaction Buffer Kit, Invitrogen, Ltd, 882 Paisley, UK) for overnight cyclo-addition at $4^{\circ} \mathrm{C}$ with gentle rocking. Then, slices were rinsed 883 in TBS, blocked in 1\% NGS solution in TBS, and incubated with anti-tyrosine hydroxylase (TH) 884 antibody (Millipore, MA, United States, cat no: MAB318). Slices were then rinsed in TBS and incubated with Alexa Fluor ${ }^{\mathrm{TM}} 488$ goat anti-mouse secondary antibody (Invitrogen, Carlasbad, 886 CA, USA). Finally, slices were rinsed with TBS and mounted using DAPI fluoromount-G ${ }^{\mathrm{TM}}$ 887 (Electron Microscopy Sciences, Hatfield, PA, USA). AHA was detected using an Alexa Fluor ${ }^{\mathrm{TM}}$ 888 647 Alkyne, Triethylammonium Salt (Invitrogen, Carlasbad, CA, USA) and subsequent 889

890 891 fluorescence imaging.

Immunofluorescence and confocal microscopy. Mice were perfused intracardially with phosphate-buffered saline (PBS) followed by $4 \%$ paraformaldehyde. Brains were removed and stored in the same fixative o.n. at $4^{\circ} \mathrm{C}$. The immunofluorescent staining was performed on $40-$ $\mu \mathrm{m}$ thick free-floating coronal midbrain slice containing VTA and SNc DA neurons that were prepared using a vibratome (Leica VT1200S; Leica Microsystems; Bannockburn, IL). For identification of DAT-specific deletion of PERK and consequential reduction of phosphorylated elF2 $\alpha$ ( $p$ - elF2 $\alpha$ ) levels in VTA and SNc DA neurons, sections were blocked in $0.1 \%$ Triton-X$100,5 \%$ NGS in TBS for $1 \mathrm{~h}$ and incubated with primary antibodies o.n. at $4^{\circ} \mathrm{C}$. The following primary antibodies were used: anti-tyrosine hydroxylase $(\mathrm{TH})$ antibody (Millipore, MA, United States, cat no: MAB318) phospho-elF2 $\alpha$ (Ser51; Cell Signaling Technology, cat no: 33985), PERK (Cell Signaling Technology, cat no: 3192), anti-dsRED antibody (Thermofisher, cat no: 632496), anti-ATF4 (Santa Cruz, cat no: sc-390063). Alexa Fluor ${ }^{\mathrm{TM}} 488$ or 647 secondary antibodies (Invitrogen, Carlasbad, CA, USA) were used. Sections were mounted using ProLong TM Gold Antifade mounting medium without DAPI (Invitrogen, Thermo Scientific, cat no: P36930). The sections were imaged using a Leica TCS SP8 confocal microscope (Leica, Germany) at $10 \mathrm{X}$ or $20 \mathrm{X}$ objective lens. All parameters (pinhole, contrast, gain and offset) were held constant for all sections from the same experiment. For analysis of AHA-Alexa-647 signal, 40 regions of interest $(\mathrm{ROI})$ corresponding to soma size were selected from $20 \mathrm{x} \mathrm{TH}-$ Alexa-488 images and were then measured in AHA-Alexa-647 images. Arbitrary fluorescent units (a.u.) were taken from Z-stack acquired images from the minimum value in the ROI to preserve the dynamic range as the increase in fluorescence between PERK ${ }^{\mathrm{f} / \mathrm{f}}$ DAT-Cre vs. WT DAT-Cre mice. For de novo protein synthesis in DA neurons detection the $n$ refers to the 
912 number of mice per group (average of 40 somas per slice, 2 slices per mouse, from three 913 independent experiments). All cell counting experiments were conducted blind to experimental 914 group. All images were subsequently processed using ImageJ (NIH, USA).

915 Protein synthesis assay. Proteins were labeled using a protocol adapted from the SUnSET 916 method $^{80}$. Briefly, $400 \mu$ m-thick brain slices containing SNc and VTA from 3-month old 917 elF2 $\alpha^{(\mathrm{S} 51 \mathrm{~A} / \mathrm{S} 51 \mathrm{~A})}$ DAT-Cre mice and control mice were prepared using a vibratome. Slices were 918 allowed to recover in artificial cerebral spinal fluid (ACSF) at $32^{\circ} \mathrm{C}$ for 1 hour and subsequently 919 treated with puromycin (P8833, Sigma-Aldrich, $5 \mu \mathrm{g} / \mathrm{mL}$ ) for 45 mins. Newly synthesized 920 proteins were end-labeled with puromycin. SNc and VTA were micro-dissected from the brain 921 slices and flash frozen on dry ice. Protein lysates were prepared for western blotting. Protein 922 synthesis levels were determined by taking total lane density in the molecular weight range of $92310 \mathrm{kDa}$ to $250 \mathrm{kDa}$. Comparisons of protein synthesis levels between both genotypes were made by normalizing to the average WT DAT-Cre signal.

Thapsigargin-induced ER stress assay. To induce ER stress, $400 \mu \mathrm{m}$-thick brain slices containing SNc and VTA from 3-month old mice were allowed to recover in ACSF at $32^{\circ} \mathrm{C}$ for 1 $\mathrm{hr}$ and subsequently treated with $1 \mu \mathrm{M}$ Thapsigargin (Sigma-Aldrich, cat no: T9033) at $32^{\circ} \mathrm{C}$ for $2 \mathrm{hrs}$. ER stress was measured using either western blotting or immunofluorescent staining to detect PERK, p-eIF2 $\alpha$ and ATF4 levels. SNc and VTA were punched out from the brain slices and processed by western blotting, whereas slices processed for immunofluorescence were embedded in 3\% agarose solution and re-sliced at 40- $\mu$ m thickness using a vibratome (Leica VT1200S; Leica Microsystems; Bannockburn, IL).

Western blotting. SNc and VTA were separately micro-dissected from the brain slices and sonicated in ice-cold homogenization buffer (10 mM HEPES, $150 \mathrm{mM} \mathrm{NaCl}, 50 \mathrm{mM} \mathrm{NaF}, 1$ mM EDTA, 1 mM EGTA, 10 mM Na4P2O7, 1\% Triton X-100, 0.1\% SDS and 10\% glycerol) that was freshly supplemented with HALT protease and phosphatase inhibitor cocktail (Thermo Scientific, cat no: $78441,1 / 10$ total volume). Aliquots $(2 \mu \mathrm{l})$ of the homogenate were used for protein determination with a BCA (bicinchoninic acid) assay kit (GE Healthcare). Samples were prepared with $5 \mathrm{X}$ sample buffer $(0.25 \mathrm{M}$ Tris-HCl pH6.8, 10\% SDS, 0.05\% bromophenol blue, $50 \%$ glycerol and $25 \%$ - $\beta$ mercaptoethanol) and heat denatured at $95^{\circ} \mathrm{C}$ for $5 \mathrm{~min} .40 \mu \mathrm{g}$ protein per lane was run in pre-cast 4-12\% Bis-Tris gels (Invitrogen) and subjected to SDSPAGE followed by wet gel transfer to polyvinylidene difluoride (PVDF; Immobilon-Psq, Millipore Corporation, Billerica, USA) membranes. The membranes were probed overnight at $4^{\circ} \mathrm{C}$ using 
944 primary antibodies against p-elF2 $\alpha$ S51 (rabbit, Cell Signaling cat no: 9721, 1:500), anti-t945 elF2 $\alpha$ (rabbit, Cell Signaling, cat no: 9722, 1:500), anti-puromycin (mouse, Millipore, cat no: 946 MABE343, 1:1000). An antibody against $\beta$ tubulin (mouse, Sigma, cat no: T8328, 1:1000) was 947 used to estimate the total amount of protein. The membranes were probed with horseradish 948 peroxidase-conjugated secondary IgG (1:7000, Promega) for $1 \mathrm{hr}$ at room temperature. 949 Signals from membranes were detected with ECL chemiluminescence (GE Healthcare 950 Amersham $^{\mathrm{TM}}$ ) using Alpha Imager 3.4 software and the FluorChem Protein Simple instrument. 951 Exposures were set to obtain signals at the linear range and then normalized by total protein 952 and quantified via densitometry using ImageJ software (NIH, USA).

953 Electrophysiology. Striatal and hippocampal slice preparation and the recording of 954 extracellular field excitatory postsynaptic potentials (fEPSPs) were performed as described 955 previously $^{76}$. Briefly, striatal and hippocampal slices from mice 3 to 4 months of age were 956 isolated and transferred to recording chambers (preheated to $32{ }^{\circ} \mathrm{C}$ ), where they were 957 superfused with oxygenated artificial cerebrospinal fluid (ACSF). In all experiments, basal 958 fEPSPs were stable for at least $20 \mathrm{~min}$ before the start of each experiment and all slices 959 recovered in the recording chamber at least $1 \mathrm{hr}$ before recordings began. Briefly, three trains 960 of high-frequency stimulation (3 sec duration, $100 \mathrm{~Hz}$ frequency at $20 \mathrm{sec}$ intervals) were used 961 to induced LTD in striatal slices, while hippocampal L-LTP was induced with three $1 \mathrm{~s} 100-\mathrm{Hz}$ 962 high-frequency stimulation trains, with an intertrain interval of $60 \mathrm{sec}^{81}$. After induction of either 963 striatal LTD or hippocampal L-LTP, fEPSPs were collected for an additional 70 min and $964140 \mathrm{~min}$, respectively. Slope values of fEPSP were expressed as percent of the baseline 965 average before LTD or L-LTP induction.

966 Voltammetric monitoring of DA release using FSCV. Mice were deeply anesthetized with 967 isoflurane, decapitated and brains were sliced with a Leica VT1200S vibratome (Leica 968 Microsystems; Bannockburn, IL). Coronal forebrain slices (300 $\mu \mathrm{m}$ thickness) were cut in an 969 ice cold HEPES-buffered artificial cerebrospinal fluid (aCSF) that contained (in $\mathrm{mM}$ ): $\mathrm{NaCl}$ 970 (120), $\mathrm{NaHCO}_{3}(20)$, glucose (10), HEPES acid (6.7), $\mathrm{KCl}$ (5), $\mathrm{HEPES}$ sodium salt (3.3), $\mathrm{CaCl}_{2}$ 971 (2), and $\mathrm{MgSO}_{4}(2)$, bubbled with a $95 \% \mathrm{O}_{2} / 5 \% \mathrm{CO}_{2}$ gas mixture and recovered in this solution 972 for $1 \mathrm{~h}$ at room temperature prior to recordings. Slices were transferred to the recording 973 chamber, maintained at $32{ }^{\circ} \mathrm{C}$ and superfused $(1.5 \mathrm{~mL} / \mathrm{min}$ ) with aCSF that contained (in $\mathrm{mM}$ ): $974 \mathrm{NaCl}$ (124), $\mathrm{KCl}$ (3.7), $\mathrm{NaHCO}_{3}$ (26), $\mathrm{CaCl}_{2}$ (2.4), $\mathrm{MgSO}_{4}$ (1.3), $\mathrm{KH}_{2} \mathrm{PO}_{4}$ (1.3), glucose (10) 975 equilibrated with $95 \% \mathrm{O}_{2} / 5 \% \mathrm{CO}_{2}$. Recordings were started after 30 min stabilization in the 
976 chamber. A Millar Voltammeter (available from Dr. Julian Millar, University of London, UK) was 977 used for FSCV detection of evoked increased in $[\mathrm{DA}]_{0}$, as described previously ${ }^{1,82}$. Locally 978 evoked DA release was detected using carbon fiber microelectrodes, constructed in house 979 from 7- $\mu \mathrm{m}$ diameter carbon fibers (Goodfellow Corporation, Berwyn, PA, USA), with 30-70 $\mu \mathrm{m}$ 980 exposed length. For FSCV, a triangular voltage ramp (from -0.7 to $+1.3 \mathrm{~V}$, then back to $-0.7 \mathrm{~V}$ 981 vs. $\mathrm{Ag} / \mathrm{AgCl}$ ) was applied every $100 \mathrm{~ms}$ at a scan rate of $800 \mathrm{~V} / \mathrm{s}$. Increases in [DA]。 in $\mathrm{CPu}$ 982 and NAc core and shell were evoked using a concentric stimulating electrode positioned within $983100 \mu \mathrm{m}$ of the recording site. Single-pulse stimulation (400 $\mu \mathrm{A}, 0.1 \mathrm{~ms}$ duration) was used in $984 \mathrm{CPu}$ and NAc core, and a brief high-frequency pulse train (5 pulses at $100 \mathrm{~Hz}$ ) was used in 985 NAc shell to amplify evoked DA release. The currents resulting from DA oxidation were 986 converted to DA concentration according to calibration with known concentrations of DA. To 987 compare DA release in slices from control and PERK ${ }^{\mathrm{f} / \mathrm{f}}$ DAT-Cre or PERK ${ }^{\mathrm{f} / \mathrm{f}} \mathrm{TH}-\mathrm{Cre}$ mice, DA 988 release was evoked in 4-5 sites in each striatal subregion in two slices per mouse. In all 989 experiments after initial sampling under control conditions, a nAChR antagonist, DHßE (1 $\mu \mathrm{M})$ 990 was applied. A maximal drug effect was seen within 15 min, and multiple site sampling was 991 repeated.

992 DAT-mediated dopamine uptake analysis. The evaluation of changes in DAT activity was 993 done using a MATLAB尺 script. $C_{\text {peak }}$ values (peak concentration) and $V_{\max }$ values (maximum 994 uptake velocity) for DAT-mediated dopamine uptake, derived from Michaelis-Menten analysis 995 of single pulse evoked [DA] $996 K_{m}$ of $0.9 \mu \mathrm{M}^{84}$ for each brain region and genotype. Data from the CPu and NAc core were 997 used for this analysis because it was developed to extract uptake terms from [DA] transients 998 evoked by single-pulse stimulation, which was used in these regions. It should be noted that all 999 mice were heterozygous DAT-cre, which exhibit a small but significant impairment in DAT 1000 function ${ }^{85}$.

1001 HPLC analysis of striatal DA content. Quantification of DA content in experimental striatal 1002 slices was performed using HPLC with electrochemical detection, as described previously ${ }^{82}$. 1003 The dorsal and ventral striatum were dissected from each slice, with careful removal of 1004 overlying cortex and white matter. Samples (3-7 mg) were weighed, then frozen immediately 1005 on dry ice and stored at $-80^{\circ} \mathrm{C}$ until processing. On the day of analysis, samples were diluted 1006 1:10 in ice-cold mobile phase deoxygenated with argon, sonicated, centrifuged at $13,000 \times \mathrm{g}$ 1007 for 2 min and then the supernatant injected onto the HPLC. 
1008 Statistical analysis. All data are presented as the mean \pm SEM. Data was analyzed using 1009 GraphPad Prism 8. For behavioral experiments the experimenter was blinded to the genotype 1010 of the animals during behavioral testing. For two-group comparisons, statistical significance 1011 was determined by parametric and nonparametric two-tailed Student's t tests. Multi-groups 1012 were analyzed using one-way ANOVA or two-way ANOVA. P values less than 0.05 were 1013 considered statistically significant. Extreme outliers were detected by applying Grubbs' method 1014 with $\alpha=0.05$ to each experimental group and eliminated from further analysis (GraphPad 1015 software). Data distribution was assumed to be normal but this was not formally tested. For 1016 voltammetry experiments and $C_{\text {peak }} / V_{\text {max }}$ analysis $n$ represents the number of recorded sites 1017 sampled from 3 to 5 mice per genotype. Statistically significant differences measured for WT 1018 vs. KO were assessed with two-tailed unpaired $t$-test with Welch's correction for unequal 1019 variance in 12 month-oldmice during the $\mathrm{C}_{\text {peak }} / \mathrm{V}_{\max }$ analysis. For this latter, values with $R^{2}<$ 10200.95 indicating goodness-of-fit were excluded from the data reported here. For the HPLC 1021 analysis, $n$ is the number of samples analyzed for each region, with two to six samples per 1022 animal. Significance of differences was calculated using unpaired Student's $t$-test. Statistical 1023 significance was considered to be $P<0.05$.

1024 Data availability. The data that support the findings of this study are available from the 1025 corresponding author upon request.

1026

1027

1028

1029

1030

1031

1032

1033

1034

1035

1036

1037

1038

1039

\section{Acknowledgement}

We thank Dr. C. E Bass (University of Buffalo) for providing the AAV2/10-TH-iCre and AAV2/10-TH-dsRED adeno-associated viruses and Dr. R. Kaufman (Sanford Burnham Prebys Medical Discovery Institute) for the Eif2(S51A) mouse line; We wish to acknowledge C. Farb for exceptional technical assistance and $\mathrm{Dr} \mathrm{P}$. Shrestha for critical advice and review of this manuscript. We thank all members of the Klann laboratory for critical feedback and discussions. The MATLAB script for Vmax analysis was written and provided by Dr. Charles Nicholson at NYU Grossman School of Medicine. This study was supported by National Institute of Health Grants (nos. NS034007 and NS047384) to E.K.

\section{Author contributions}

F.L. carried out and analysed behavioral experiments, slice electrophysiology, and collected and analysed all in vivo and ex vivo data. M.M. carried out and analyzed FSCV experiments. 
1040 S.A. carried out western blotting, and collected ex vivo data. P.L.I. and C.M. carried out 1041 behavioral experiments and collected in vivo and ex vivo data. J.C.P. performed DAT1042 mediated dopamine uptake analysis. M.E.R. coordinated, performed, and analyzed HPLC 1043 experiments. E.P. and N.R. carried out HPLC experiments. M.D. performed genotype 1044 detection. F.L., E.K., E.S. conceived the study. M.M. and M.E.R. participated in the design of 1045 the study. F.L. and E.K. designed and coordinated all the experiments and wrote the 1046 manuscript. All authors read and commented on the paper.

\section{Competing financial interests}

1049 The authors declare no competing financial interests.

1050

1051

1052

1053

1054

1055

1056

1057

1058

1059

1060

1061

1062

1063

1064

1065

1066

1067

1068

1069

1070

1071

1072

Figure Legends

\section{Figure 1. Deletion of PERK from DA neurons induces motor facilitation at early ages,} but worsens motor performance in older mice. (a) Schematic representation of DATneuron specific deletion of PERK in PERK ${ }^{\mathrm{flf}}$ mice crossed with WT DAT-Cre mice. (b) PCR identification of alleles of Perk ${ }^{\text {loxP }}$ and DAT-driven Cre. (c) Immunofluorescent detection of $\mathrm{TH}^{+}$ (green) neurons and PERK (red) expression in SNc and VTA DA neurons of PERK ${ }^{\mathrm{flf}}$ DAT-Cre and WT DAT-Cre mice, confirming positive targeting of dopaminergic $\left(\mathrm{TH}^{+}\right)$neurons for the deletion of PERK (scale bars represent $50 \mu \mathrm{m}$ ). White arrows indicate dopaminergic neurons (green) and PERK (red) co-staining; yellow arrows indicate non dopaminergic neurons and PERK (red) staining (d) Summary plot showing the ratio of TH+ cells in both the SNc and the VTA that co-labeled for PERK in PERK ${ }^{\mathrm{fff}}$ DAT-Cre vs. WT DAT-Cre control mice $(\mathrm{n}=6$ mice each, unpaired $\mathrm{t}$ test, SNc: $\mathrm{t}_{(10)}=15.85, P<0,0001$; VTA: $\left.\mathrm{t}_{(10)}=16.86, P<0,0001\right)$ after treatment with thapsigargin. PERK ${ }^{\mathrm{flf}}$ DAT-Cre and their WT DAT-Cre littermates mice were subjected to a set of tests, including the bar $(\mathbf{e})$, drag $(\mathbf{f})$, rotarod $(\mathbf{g})$, novel home cage $(\mathbf{h})$, and open field $(\mathbf{i}, \mathbf{j})$ tests to investigate locomotor activity, from 3 up to 12 months of age. (e) Summary plot of immobility time (sec) during bar test in PERK ${ }^{\mathrm{fff}}$ DAT-Cre versus WT DAT-Cre mice (two-way RM ANOVA, time $x$ genotype, $\mathrm{F}_{(2,93)}=6.80, P<0.01$ ). (f) Summary plot of average number of steps during drag test (two-way RM ANOVA, time $x$ genotype, $F_{(2,93)}=$ 10.31, $P<0.001)$. (g) Summary plot of latency to fall from the rotating rod measured as average of two days (4 trials/day) test (two-way RM ANOVA, time $x$ genotype, $F_{(2,44)}=14.93$, $P<0.001$ ). (h) Summary plot of the novelty-induced locomotor activity expressed as a novel 
1073 home cage (NHC) distance moved $(\mathrm{cm})$ in the first 10 minutes interval of a 60 minutes test 1074 during novel home cage test (two-way RM ANOVA, time $x$ genotype, $\mathrm{F}_{(2,58)}=6.52, P<0.01$ ). 1075 (i,j) Summary plot of (i) spontaneous locomotor activity expressed as distance moved (cm) 1076 and (j) vertical activity (number of counts) during the open field test over 15 min (two-way RM 1077 ANOVA, time x genotype; $\left.\mathbf{i}, \mathrm{F}_{(2,38)}=4.18, P<0.05 ; \mathbf{j}, \mathrm{F}_{(2,38)}=18.89, P<0.001\right)$. Mice were 1078 analyzed using two-way RM ANOVA followed by the Bonferroni's test for multiple 1079 comparisons. ${ }^{*} P<0.05,{ }^{* *} P<0.01,{ }^{* * *} P<0.001$ different from age-matched littermates. All 1080 data are shown as mean \pm s.e.m. of $n=18-15, n=17-13$ and $n=19-17$ mice/genotype at 3, 8 1081 and 12 months of age, respectively $(\mathbf{e}, \mathbf{f}) ; n=12$ mice/genotype $(\mathbf{g}) ; n=15-16$ mice/genotype 1082 (h) $n=10-11$ mice/genotype $(\mathbf{i}, \mathbf{j})$.

1083 1084 Figure 2. Deletion of PERK from DA neurons results in multiple cognitive phenotypes in 1085 1086 mice. (a-c) Summary plots of (a) average latency to find the hidden platform during a 4-day 1087 training protocol, (b) percentage time spent in each zone, and (c) average number of times 1088 crossing the location of the previously hidden platform during probe test in 3- month old PERK $^{\mathrm{f} / \mathrm{f}}$ DAT-Cre versus WT DAT-Cre mice in the MWM test (a, two-way RM ANOVA, followed by Bonferroni's multiple comparisons test, time $x$ genotype, $\mathrm{F}_{(3,75)}=3.53, P<0.05$; $\mathbf{b}$, two-way 1090 RM ANOVA, followed by Bonferroni's multiple comparisons test, quadrant $x$ genotype, $F_{(3,75)}=$ 1091 $3.77, P<0.05 ;$ c, unpaired $t$ test, $\mathrm{t}_{(25)}=2.607, P=0.02 ; n=12$ PERK $^{\mathrm{f} / \mathrm{f}}$ DAT-Cre mice; $n=15$ WT DAT-Cre mice). (d) Representative swim paths in the MWM test. (e-g) Summary plots of 1093 average percentage of freezing during (e) training, (f) exposure to the context 24 hours after 1094 training, and (g) exposure to $3 \mathrm{CS}$ presentations in a novel context in the associative threat 1095 memory test in 3-month old PERK ${ }^{\mathrm{f} / \mathrm{f}}$ DAT-Cre versus WT DAT-Cre mice (e, two-way RM 1096 ANOVA, followed by Bonferroni's multiple comparisons test, time $x$ genotype, $\mathrm{F}_{(1,25)}=0.76, P=$ 1097 0.39; f, two-way RM ANOVA, followed by Bonferroni's multiple comparisons test, genotype, $\mathrm{F}_{(1 \text {, }}$ $25)=20.45, P=0.0001 ; \mathbf{g}$, two-way RM ANOVA, followed by Bonferroni's multiple comparisons 1099 test, genotype, $\mathrm{F}_{(1,25)}=28.53 P<0.0001 ; n=12 \mathrm{PERK}^{\mathrm{f} / \mathrm{f}} \mathrm{DAT}-\mathrm{Cre}$ mice; $n=15$ WT DAT-Cre mice). (h-j) Summary plots of (h) average latency to find the hidden platform during a 4-day training protocol, (i) percentage time spent in each zone and (j) average number of times crossing the location of the previously hidden platform during probe test in 12- month old PERK $^{\mathrm{f} / \mathrm{f}}$ DAT-Cre versus WT DAT-Cre mice in the MWM test (h, two-way RM ANOVA, followed by Bonferroni's multiple comparisons test, time $x$ genotype, $\mathrm{F}_{(4,56)}=2.61, P<0.05$; $\mathbf{i}$, two-way 
1106

1107

1108

1109

1110

1111

1112

1113

1114

1115

1116

1117

1118

1119

1120

1121

1122

1123

1124

1125

1126

1127

1128

1129

1130

1131

1132

1133

1134

1135

1136

1137

22.84, $P<0.001 ; \mathbf{j}$, unpaired $t$ test, $\mathrm{t}_{(14)}=2.392, P=0.03 ; n=9$ PERK ${ }^{\mathrm{fff}}$ DAT-Cre mice; $n=7$ WT DAT-Cre mice). (k) Representative swim paths in the MWM test. (I-n) Summary plots of average percentage of freezing during (I) training, $(\mathbf{m})$ exposure to the context 24 hours after training, and (n) exposure to3 CS presentations in a novel context in the associative threat memory test in 12-month old PERK ${ }^{f / f}$ DAT-Cre versus WT DAT-Cre mice (I, two-way RM ANOVA, followed by Bonferroni's multiple comparisons test, time $x$ genotype, $\mathrm{F}_{(1,14)}=0.19, P=$ 0.67; m, two-way RM ANOVA, followed by Bonferroni's multiple comparisons test, genotype, $\mathrm{F}_{(1,14)}=31.13, P<0.0001 ; \mathbf{n}$, two-way RM ANOVA, followed by Bonferroni's multiple comparisons test, genotype, $\mathrm{F}_{(1,14)}=22.98 P<0.001 ; n=9$ PERK $^{\mathrm{f} / \mathrm{f}}$ DAT-Cre mice; $n=7 \mathrm{WT}$ DAT-Cre mice). (o-q) Summary plots of (o) interaction time with familiar objects, and (p,q) preference indices of mice towards a novel object introduced in the novel object recognition test in 3- month and 12-month old PERK ${ }^{\mathrm{t} / \mathrm{f}}$ DAT-Cre versus WT DAT-Cre mice (unpaired $t$ test; $o, \mathrm{t}_{(25)}=0.513, P=0.61$ and $\mathrm{t}_{(14)}=1.074, P=0.30$ respectively in 3-month and 12-months old mice; $\mathbf{p}, \mathrm{t}_{(25)}=3.079, P<0.01$ and $\mathrm{t}_{(14)}=2.417, P<0.05$ respectively in 3-month and 12months old mice; $\mathbf{q}, \mathrm{t}_{(25)}=3.433, P<0.01$ and $\mathrm{t}_{(14)}=2.427, P<0.05$ respectively in 3-month and 12-months old mice; 3-month old mice: $n=12$ PERK $^{\mathrm{fff}}$ DAT-Cre mice, $n=15$ WT DATCre mice; 12-month old mice: $n=9$ PERK $^{\mathrm{f} / \mathrm{f}}$ DAT-Cre mice, $n=7$ WT DAT-Cre mice). (r) Representative heat maps of the interaction with the objects for each genotype in the novel object recognition test. All data are shown as mean \pm s.e.m. ${ }^{*} P<0.05$, ${ }^{* *} P<0.01$ and ${ }^{* * *} P<$ 0.001 PERK $^{\mathrm{fff}}$ DAT-Cre versus WT DAT-Cre mice.

Figure 3. Deletion of PERK in DA neurons causes dysregulated de novo translation in mice. (a) Schematic for FUNCAT experiments. (b) Representative immunofluorescence images of TH-IR (green) and incorporation of AHA (magenta) detected by FUNCAT with alkyne-Alexa 647 in SNc and VTA DA neurons from midbrain coronal slices of 3-month old PERK $^{\mathrm{fff}}$ DAT-Cre mice and their WT DAT-Cre littermates. Insets in the first and third rows are magnified in the second and fourth rows, respectively (scale bars represent $50 \mu \mathrm{m}$ ). (c,d) Quantification of increased AHA-alkyne-Alexa 647 signal in fluorescent arbitrary units (a.u.) expressed as \% of control in $\mathrm{TH}^{+}$neurons (Green) from SNc (c) and VTA (d) of PERK ${ }^{\mathrm{f} / \mathrm{f}}$ DATCre vs. WT DAT-Cre mice. Cell soma intensity was measured in ImageJ. Statistical significance was determined by using Student's $t$ test (PERK ${ }^{\mathrm{t} / \mathrm{f}}$ DAT-Cre vs. WT DAT-Cre mice; unpaired $t$ test; $\left.\mathbf{c}, \mathrm{t}_{(14)}=2.933, P=0.011 ; \mathbf{d}, \mathrm{t}_{(10)}=4.215, P=0.002\right)$. Data are shown as mean 
$1138 \pm$ s.e.m. of $n=6 / 8$ mice per group (average of $n=40$ somas per slice, $n=2$ slices per mouse, 1139 from three independent experiments) ${ }^{*} P<0.05,{ }^{* *} P<0.01$.

Figure 4. elF2 $\alpha^{(\mathrm{S51A} / \mathrm{S51A})}$ DAT-Cre mice display enhanced locomotor activity. (a) 1142 Schematic representation of DAT-neuron specific expression of phospho-mutant elF2 $\alpha$ in 1143 elF2 $\alpha^{(\mathrm{S} 51 \mathrm{~A} / \mathrm{S} 51 \mathrm{~A})}$ mice crossed with WT DAT-Cre mice. (b) PCR identification of alleles of 1144 elF2 $\alpha^{(\mathrm{S} 51 \mathrm{~A} / \mathrm{S} 51 \mathrm{~A})}$ and DAT-driven Cre. (c) Immunofluorescent detection of $\mathrm{TH}^{+}$(green) neurons 1145 and phospho-elF2 $\alpha$ (p-elF2 $\alpha$; red) expression in SNc and VTA DA neurons of elF2 $\alpha^{(\mathrm{S} 51 \mathrm{~A} / \mathrm{S} 51 \mathrm{~A})}$ 1146 DAT-Cre and WT DAT-Cre mice, confirming positive targeting of dopaminergic $\left(\mathrm{TH}^{+}\right)$neurons 1147 for the expression of phospho-mutant elF2 $\alpha$ (scale bars represent $50 \mu \mathrm{m}$ ). Arrows indicate 1148 dopaminergic neurons (green) and p-elF2 $\alpha$ (red) co-stain. (d) Summary data showing the ratio 1149 of TH+ cells in both the SNc and the VTA that co-labeled for $p$-elF2 $\alpha$ in elF2 $\alpha^{(\mathrm{S} 51 \mathrm{~A} / \mathrm{S} 51 \mathrm{~A})}$ DAT1150 Cre vs. WT DAT-Cre control mice $\left(n=5\right.$ mice each, unpaired $\mathrm{t}$ test, SNc: $\mathrm{t}_{(8)}=19.61, P$ $1151<0,0001$; VTA: $\left.\mathrm{t}_{(8)}=17.19, P<0,0001\right)$

$1152(\mathbf{e}, \mathbf{j})$ Representative western blots (right panel) and quantification of phosphorylation of elF2 $\alpha$ 1153 in VTA $(\mathbf{e})$ and SNc (j) of elF2 $\alpha^{(\mathrm{S} 51 \mathrm{~A} / \mathrm{S} 51 \mathrm{~A})}$ DAT-Cre and WT DAT-Cre mice. Summary plot 1154 showed a robust decrease in the phosphorylation of elF2 $\alpha$ in both VTA (e; unpaired $t$ test, $\mathrm{t}_{(6)}=$ $11554.79, P=0.003 ; n=4$ independent lysates from 4 mice per group) and SNc (j; unpaired $t$ test, $1156 \mathrm{t}_{(6)}=4.54, P=0.004 ; n=4$ independent lysates from 4 mice per group) of elF2 $\alpha^{(\mathrm{S} 51 \mathrm{~A} / \mathrm{S} 51 \mathrm{~A})}$ DAT1157 Cre mice compared with controls. (f,k) Representative western blots (right panel) and 1158 quantification of newly synthesized brain proteins in VTA $(\mathbf{f})$ and SNc $(\mathbf{k})$ of elF2 $\alpha^{(\mathrm{S} 51 \mathrm{~A} / \mathrm{S} 51 \mathrm{~A})}$ 1159 DAT-Cre and WT DAT-Cre mice, labelled with puromycin using the SUnSET method (see 1160 Methods). Summary plot of puromycilation indicated increased de novo translation in both VTA 1161 (f; unpaired $t$ test, $\mathrm{t}_{(6)}=3.18, P=0.019 ; n=4$ independent lysates from 4 mice per group) and 1162 SNc $\left(\mathbf{k}\right.$; unpaired $t$ test, $\mathrm{t}_{(6)}=5.72, P=0.0012 ; n=4$ independent lysates from 4 mice per 1163 group) of elF2 $\alpha^{(\mathrm{S} 51 \mathrm{~A} / \mathrm{S} 51 \mathrm{~A})}$ DAT-Cre mice compared with controls. 3-month old elF2 $\alpha^{(\mathrm{S} 51 \mathrm{~A} / \mathrm{S} 51 \mathrm{~A})}$ 1164 DAT-Cre mice and their WT DAT-Cre littermates mice were subjected to a set of tests 1165 including the bar $(\mathbf{g})$, drag $(\mathbf{h})$, rotarod $(\mathbf{i})$, novel home cage, (I) and open field $(\mathbf{m}, \mathbf{n})$ tests to 1166 investigate locomotor activity. (g) Summary plot of immobility time (sec) during bar test in 1167 elF2 $\alpha^{(\mathrm{S} 51 \mathrm{~A} / \mathrm{S} 51 \mathrm{~A})} \mathrm{DAT}-C r e$ versus WT DAT-Cre mice (unpaired $t$ test, $\left.\mathrm{t}_{(19)}=5.21, P<0.001\right)$. (h) 1168 Summary plot of average number of steps during drag test (unpaired $t$ test, $\mathrm{t}_{(19)}=3.67, P<$ 1169 0.01). (i) Summary plot of latency to fall from the rotating rod measured as average of two 1170 days (4 trials/day) test (unpaired $t$ test, $\mathrm{t}_{(19)}=1.30, P=0.20$ ). (I) Summary plot of the novelty- 
1171 induced locomotor activity expressed as a distance moved (cm) in the first 10 minutes interval

1172 of a 60 minutes test during novel home cage test (unpaired $t$ test, $\left.\mathrm{t}_{(19)}=5.76, P<0.001\right)$. (m,n) 1173 Summary plot of $(\mathbf{m})$ spontaneous locomotor activity expressed as distance moved (cm) and 1174 (n) vertical activity (number of counts) during the open field test (unpaired $t$ test; $\mathbf{m}, \mathrm{t}_{(19)}=2.78$ $\left.1175 P<0.001 ; \mathbf{n}, \mathrm{t}_{(19)}=5.71 P=0.012\right)$. All data are shown as mean \pm s.e.m. of $n=9$ 1176 elF2 $\alpha^{(\mathrm{S} 51 \mathrm{~A} / \mathrm{S} 51 \mathrm{~A})}$ DAT-Cre mice and $n=12$ WT DAT-Cre mice. ${ }^{*} P<0.05,{ }^{* *} P<0.01$ and ${ }^{* * *} P<$ 11770.001 elF2 $\alpha^{(\mathrm{S} 51 \mathrm{~A} / \mathrm{S51A})}$ DAT-Cre versus WT DAT-Cre mice.

1178

1179

Figure 5. elF2 $\alpha^{(\mathrm{S51A} / \mathrm{S} 51 \mathrm{~A})}$ DAT-Cre mice display multiple cognitive phenotypes. (a-c) 1180 Summary plots of (a) average latency to find the hidden platform during a 4-day training 1181 protocol, (b) percentage spent in each zone and (c) average number of times spent crossing 1182 the location of the previously hidden platform during probe tests in 3 - month old elF2 $\alpha^{(\mathrm{S} 51 \mathrm{~A} / \mathrm{S} 51 \mathrm{~A})}$ 1183 DAT-Cre versus WT DAT-Cre mice in the MWM test (a, two-way RM ANOVA, followed by 1184 Bonferroni's multiple comparisons test, time $\mathrm{F}_{(3,57)}=67.07, P<0.001$, genotype $\mathrm{F}_{(1,19)}=9.49$, $1185 P<0.01 ;$ b, two-way RM ANOVA, followed by Bonferroni's multiple comparisons test, 1186 quadrant $x$ genotype, $\mathrm{F}_{(3,57)}=17.65, P<0.001$; c, unpaired $t$ test, $\left.\mathrm{t}_{(19)}=4.193, P<0.001\right)$. (d) 1187 Representative swim paths in the MWM test. (e-g) Summary plots of average percentage of 1188 freezing during (e) training, (f) exposure to the context 24 hours after training, and (g) 1189 exposure to $3 \mathrm{CS}$ presentations in a novel context in the associative threat memory test in 31190 month old elF2 $\alpha^{(\mathrm{S} 51 \mathrm{~A} / \mathrm{S} 51 \mathrm{~A})}$ DAT-Cre versus WT DAT-Cre mice (e, two-way RM ANOVA, 1191 followed by Bonferroni's multiple comparisons test, time, $\mathrm{F}_{(1,19)}=78.34, P<0.001$; f, two-way 1192 RM ANOVA, followed by Bonferroni's multiple comparisons test, genotype, $\mathrm{F}_{(1,19)}=18.69, P<$ 1193 0.001; g, two-way RM ANOVA, followed by Bonferroni's multiple comparisons test, genotype, $\left.1194 \mathrm{~F}_{(1,19)}=26.76 P<0.001\right) .(\mathbf{h}-\mathbf{j})$ Summary plots of $(\mathbf{h})$ interaction time with familiar objects, and $1195(\mathbf{i}, \mathbf{j})$ preference indices of mice towards a novel object introduced in the novel object 1196 recognition test in 3-month old elF2 $\alpha^{(\mathrm{S} 51 \mathrm{~A} / \mathrm{S} 51 \mathrm{~A})}$ DAT-Cre versus WT DAT-Cre mice (unpaired $\mathrm{t}$ 1197 test; $\left.\mathbf{h}, \mathrm{t}_{(19)}=0.702, P=0.49 ; \mathbf{i}, \mathrm{t}_{(19)}=1.967, P=0.06 ; \mathbf{j}, \mathrm{t}_{(19)}=6.017, P<0.001\right) .(\mathbf{k})$ 1198 Representative heat maps of the interaction with the objects for each genotype in the novel 1199 object recognition test. All data are shown as mean \pm s.e.m. of $n=9$ elF2 $\alpha^{(\mathrm{S} 51 \mathrm{~A} / \mathrm{S} 51 \mathrm{~A})}$ DAT-Cre 1200 mice and $n=12$ WT DAT-Cre mice. ${ }^{*} P<0.05,{ }^{* *} P<0.01$ and ${ }^{* * *} P<0.001$ elF2 ${ }^{(\mathrm{S} 51 \mathrm{~A} / \mathrm{S} 51 \mathrm{~A})}$ 1201 DAT-Cre versus WT DAT-Cre mice.

1202 
1203 Figure 6. Deletion of PERK in DA neurons alters striatal DA release and DAT activity differently at 3 and 12 months of age in mice. (a,e) Average single-pulse (1p) evoked [DA]。

1205 transients recorded in CPu, NAc core, and NAc shell in PERK ${ }^{\mathrm{f} / \mathrm{f}}$ DAT-Cre versus control DATCre mice at 3 (a) and 12 months of age (e). (b-d) Summary plot of evoked [DA] peak expressed as \% mean control in CPu (unpaired $t$-test, $\mathrm{t}_{(98)}=5.345, P<0.001$ ), NAc core (unpaired $t$-test, $\mathrm{t}_{(91)}=2.954, P<0.01$ ), and NAc shell (unpaired $t$-test, $\mathrm{t}_{(97)}=3.807, P<0.001$ ) in 3-month old mice. (f-h) Summary plot of evoked [DA] peak expressed as \% of mean control in CPu (unpaired $t$-test, $\mathrm{t}_{(58)}=6.525, P<0.001$ ), NAc core (unpaired $t$-test, $\mathrm{t}_{(58)}=6.090, P<$ 0.001 ), and NAc shell (unpaired $t$-test, $\mathrm{t}_{(58)}=5.444, P<0.001$ ) in 12-month old mice. $V_{\max }$ values (maximum uptake velocity; $\mathbf{i , k}$ ) and $C_{\text {peak }}$ values (peak concentration; j,I) for DATmediated DA uptake derived from Michaelis-Menten analysis of single pulse evoked [DA]。 records determined using a fixed $K_{\mathrm{m}}$ of $0.9 \mu \mathrm{M}$ for each brain region and genotype. (i) Summary plot of $V_{\max }$ values in CPu of WT DAT-Cre versus PERK ${ }^{\mathrm{f} / f}$ DAT-Cre mice at 3 months of age. (j) Summary plot of $C_{\text {peak }}$ values in CPu of WT DAT-Cre versus PERK ${ }^{\mathrm{f} / \mathrm{f}}$ DATCre mice at 3 (unpaired $t$-test, $\mathrm{t}_{(94)}=5.113, P<0.001$ ) and 12 (unpaired $t$-test, $\mathrm{t}_{(54)}=4.476, P<$ $0.001)$ months of age. (k) Summary plot of $V_{\max }$ values in NAc core of WT DAT versus PERK ${ }^{\mathrm{f} / \mathrm{f}}$ DAT-Cre mice at 3 (unpaired $t$-test, $\mathrm{t}_{(90)}=3.616, P<0.001$ ) and 12 (unpaired $t$-test, $\mathrm{t}_{(54)}=$ 4.476, $P<0.001)$ months of age. (I) Summary plot of $C_{\text {peak }}$ values in NAc core of WT DAT versus PERK $^{\mathrm{f} / \mathrm{f}}$ DAT-Cre mice at 3 (unpaired $t$-test, $\mathrm{t}_{(90)}=3.554, P<0.001$ ) and 12 (unpaired $t$ test, $\left.\mathrm{t}_{(54)}=4.476, P<0.001\right)$ months of age. Data are means \pm s.e.m. of $n$ mice, where $n$ denotes the number of recording sites sampled from 3 to 5 mice per genotype; ${ }^{* *} P<0.01 ;{ }^{* *} P$ $<0.001$ for WT DAT-Cre vs. PERK ${ }^{\mathrm{f} / \mathrm{f}}$ DAT-Cre mice. Values with $\mathrm{R}^{2}<0.95$, indicating goodness-of-fit were excluded from the data reported here.

Figure 7. In vivo pharmacological targeting of DA machinery reveals the impact of PERK deletion in DA neurons in 3-month old mice. (a-c) Acute i.p. injection of the D1 antagonist $(\mathrm{SCH} 23390 ; 0.01 \mathrm{mg} / \mathrm{kg})$ affects locomotor activity phenotype in WT DAT-Cre mice, but does not alter locomotor activity of PERK ${ }^{\mathrm{f} / \mathrm{f}}$ DAT-Cre mice. Conversely, high-dose SCH $23390(0.2$ $1232 \mathrm{mg} / \mathrm{kg}$ ) impairs locomotor activity in both genotypes. (a) Summary plot of average number of steps during drag test (two-way ANOVA, genotype $F_{(1,51)}=93.91, P<0.0001$, treatment $F_{(2,51)}$ $=41.83, \mathrm{P}<0.0001)$. (b) Summary plot of latency to fall from the rotating rod measured as average of two days ( 4 trials/day) test (two-way ANOVA, genotype $F_{(1,51)}=112.8, P<0.0001$, 
1236 treatment $\left.\mathrm{F}_{(2,51)}=18.19, \mathrm{P}<0.0001\right)$. (c) Summary plot of spontaneous locomotor activity 1237 expressed as distance moved $(\mathrm{cm})$ during the open field test (two-way ANOVA, genotype; $F_{(1,}$ $123851)=46.80, P<0.0001$, treatment $\left.F_{(2,51)}=34.66, P<0.0001\right)$. Mice were analyzed using two-way 1239 ANOVA followed by the Bonferroni's test for multiple comparisons. ${ }^{*} P<0.05$, ${ }^{* *} P<0.01$, ${ }^{* * *} P$ $1240<0.001$. (d-f) Acute DAT blockade causes no changes in behavioral responses in PERK ${ }^{\mathrm{f} / \mathrm{f}}$ 1241 DAT-Cre mice, whereas increases locomotor activity in WT DAT-Cre mice at a lower dose. 1242 High-dose GBR12783 effect is consistent with greater DA uptake in PERK ${ }^{\mathrm{f} / \mathrm{f}}$ DAT-Cre mice. (d) 1243 Summary plot of average number of steps during drag test (two-way ANOVA, genotype $x$ 1244 treatment, $\left.F_{(2,51)}=6.63, P=0.0028\right)$. (e) Summary plot of latency to fall from the rotating rod 1245 measured as average of two days (4 trials/day) test (two-way ANOVA, genotype $\mathrm{x}$ treatment, $\left.1246 \mathrm{~F}_{(2,51)}=4.12, \mathrm{P}=0.0221\right)$. (f) Summary plot of spontaneous locomotor activity expressed as 1247 distance moved $(\mathrm{cm})$ during the open field test (two-way ANOVA, genotype $x$ treatment; $F_{(2,51)}$ $1248=5.59, \mathrm{P}=0.0051) .(\mathbf{g}-\mathbf{i})$ VMAT2 blockade with i.p. administration of reserpine results in blunted 1249 behavioral responses in PERK ${ }^{\mathrm{f} / \mathrm{f}} \mathrm{DAT}-\mathrm{Cre}$ mice, in contrast to its impact on locomotor activity in 1250 control mice. (g) Summary plot of average number of steps during drag test (two-way ANOVA, 1251 genotype $x$ treatment, $\left.F_{(2,51)}=7.59, P=0.0013\right)$. (h) Summary plot of latency to fall from the 1252 rotating rod measured as average of two days (4 trials/day) test (two-way ANOVA, genotype $1253 \mathrm{~F}_{(1,51)}=39.58, \mathrm{P}<0.0001$; treatment $\left.\mathrm{F}_{(2,51)}=21.66, \mathrm{P}<0.0001\right)$. (i) Summary plot of 1254 spontaneous locomotor activity expressed as distance moved $(\mathrm{cm})$ during the open field test 1255 (two-way ANOVA, genotype $x$ treatment; $F_{(2,51)}=4.118, P=0.0220$ ). All data are shown as 1256 mean \pm s.e.m. of $n=10\left(\right.$ WT DAT-Cre) or $9\left(P^{2} K^{f / f}\right.$ DAT-Cre) mice/treatment.

Figure 8. Mice lacking PERK in DA neurons of the SNc exhibit motor phenotypes similar 1259 to those displayed by the PERK ${ }^{\mathrm{f} / \mathrm{f}}$ DAT-Cre mice. (a) Schematic for experiments shown in e1260 j. Either AAV2/10 TH-dsRED (control) or AAV2/10 TH-iCre (AAV-TH Cre) was injected bilaterally into the SNc of PERK ${ }^{\mathrm{f} / \mathrm{f}}$ mice. Representative low magnification immunofluorescence 1262 images showing the injection sites (scale bar represents $500 \mu \mathrm{m}$ ). (b) Immunofluorescence 1263 detection of TH-IR (green) and either PERK or dsREd (red) in the SNc of PERK ${ }^{\mathrm{f} / f}$ TH-Cre-AAV 1264 and PERK ${ }^{\mathrm{f} / \mathrm{f}}$ TH-dsRED AAV control mice (scale bars represent $50 \mu \mathrm{m}$ ). (c) Summary data 1265 showing the ratio of $\mathrm{TH}^{+}$cells in the SNc that co-labeled for PERK in PERK ${ }^{\mathrm{f} / \mathrm{f}} \mathrm{TH}-\mathrm{Cre}-\mathrm{AAV}$ vs. 1266 PERK $^{\mathrm{f} / \mathrm{f}}$ TH-dsRED AAV control mice $\left(n=4\right.$ mice each, unpaired t test, $\left.\mathrm{t}_{(6)}=9.373, P<0.001\right)$. 1267 (d) Summary data showing the overall number of $\mathrm{TH}^{+}$cells in the SNc that co-labeled for 1268 PERK in PERK ${ }^{\mathrm{f} / \mathrm{f}} \mathrm{TH}-\mathrm{Cre}-\mathrm{AAV}$ vs. PERK ${ }^{\mathrm{f} / \mathrm{f}} \mathrm{TH}-\mathrm{dsRED}$ AAV control mice $(n=4$ mice each, 
1269 unpaired t test, $\left.\mathrm{t}_{(6)}=0.599, P=0.571\right) .(\mathbf{e}-\mathrm{j}) \mathrm{PERK}^{\mathrm{f} / \mathrm{f}} \mathrm{TH}-\mathrm{Cre}-\mathrm{AAV}$ and PERK ${ }^{\mathrm{f} / \mathrm{f}}$ TH-dsRED AAV 1270 control mice were subjected to a set of tests including the bar $(\mathbf{e}, \mathbf{0})$, drag $(\mathbf{f}, \mathbf{p})$, rotarod $(\mathbf{g}, \mathbf{q})$, 1271 novel home cage (h,r), and open field (i-j, s-t) tests to investigate locomotor activity at 3 (3M) 1272 and 12 (12M) months of age. (e) Summary plot of immobility time (sec) during bar test in 1273 PERK ${ }^{\mathrm{f} / \mathrm{f}}$ TH-Cre-AAV vs. PERK ${ }^{\mathrm{f} / \mathrm{f}}$ TH-dsRED AAV control mice (unpaired $t$ test, 3M: $\mathrm{t}_{(16)}=$ $12742.500, P<0.05 ; 12 \mathrm{M}$ : n.s.). (f) Summary plot of average number of steps during drag test 1275 (unpaired $t$ test, $\left.3 \mathrm{M}: \mathrm{t}_{(16)}=7.660, P<0.001 ; 12 \mathrm{M}: \mathrm{n} . \mathrm{s}\right)$. (g) Summary plot of latency to fall from 1276 the rotating rod measured as average of two days ( 4 trials/day) test (unpaired $t$ test, 3M: $\mathrm{t}_{(16)}=$ $12772.439, P<0.05 ; 12 \mathrm{M}$ : n.s). (h) Summary plot of the novelty-induced locomotor activity 1278 expressed as a distance moved $(\mathrm{cm})$ in the first 10 minutes interval of a 60 minutes test during 1279 novel home cage test (unpaired $t$ test, $3 \mathrm{M}: \mathrm{t}_{(16)}=3.586, P<0.01 ; 12 \mathrm{M}$ : $\mathrm{n} . \mathrm{s}$ ). (i-j) Summary plot 1280 of (i) spontaneous locomotor activity expressed as distance moved (cm) and (j) vertical activity 1281 (number of counts) during the open field test (unpaired $t$ test; i, n.s. at both 3M and 12M; j, 3M: $1282 \mathrm{t}_{(16)}=2.300, P<0.05 ; 12 \mathrm{M}$ : n.s.). (k) Schematic for experiment shown in o-t. Either AAV2/10 1283 TH-dsRED (control) or AAV2/10 TH-iCre (AAV-TH Cre) was injected into the VTA of PERK ${ }^{\mathrm{f} / \mathrm{f}}$ 1284 mice. Representative low magnification immunofluorescence images showing the injection 1285 sites (scale bar represents $500 \mu \mathrm{m}$ ). (I) Immunofluorescence detection of TH-IR (green) and 1286 PERK or dsRED (red) in the VTA of PERK ${ }^{\mathrm{f} / \mathrm{f}}$ TH-Cre-AAV and PERK ${ }^{\mathrm{f} / \mathrm{f}}$ TH-dsRED AAV control 1287 mice (scale bars represent $50 \mu \mathrm{m}$ ). ( $\mathbf{m}$ ) Summary data showing the ratio of $\mathrm{TH}^{+}$cells in the 1288 VTA that co-labeled for PERK in PERK ${ }^{\mathrm{f} / \mathrm{f}} \mathrm{TH}-\mathrm{Cre}-\mathrm{AAV}$ vs. PERK ${ }^{\mathrm{f} / \mathrm{f}} \mathrm{TH}-\mathrm{dsRED}$ AAV control mice $1289\left(n=4\right.$ mice each, unpaired $\mathrm{t}$ test, $\left.\mathrm{t}_{(6)}=9.120, P<0.001\right)$. (n) Summary data showing the 1290 overall number of $\mathrm{TH}^{+}$cells in the VTA that co-labeled for PERK in PERK ${ }^{\mathrm{f} / \mathrm{f}}$ TH-Cre-AAV vs. 1291 PERK ${ }^{\mathrm{f} / \mathrm{f}}$ TH-dsRED AAV control mice ( $n=4$ mice each, unpaired t test, $\mathrm{t}_{(6)}=0.849, P=0.429$ ). 1292 (o) Summary plot of immobility time (sec) during bar test in PERK $\mathrm{f}^{\mathrm{f} / \mathrm{f}} \mathrm{TH}-\mathrm{Cre}-\mathrm{AAV}$ vs. PERK ${ }^{\mathrm{f} / \mathrm{f}}$ 1293 TH-dsRED AAV control mice (unpaired $t$ test, n.s. at both 3M and 12M). (p) Summary plot of 1294 average number of steps during drag test (unpaired $t$ test, n.s. at both $3 \mathrm{M}$ and 12M). (q) 1295 Summary plot of latency to fall from the rotating rod measured as average of two days (4 1296 trials/day) test (unpaired $t$ test, n.s. at both 3M and 12M). (r) Summary plot of the novelty1297 induced locomotor activity expressed as a distance moved (cm) in the first 10 minutes interval 1298 of a 60 minutes test during novel home cage test (unpaired $t$ test, n.s. at both $3 \mathrm{M}$ and 12M). (s1299 t) Summary plot of (s) spontaneous locomotor activity expressed as distance moved (cm) and 1300 (t) vertical activity (number of counts) during the open field test (unpaired $t$ test; n.s. at both $3 \mathrm{M}$ 1301 and 12M). All data are shown as mean \pm s.e.m. of $n=9-7$ PERK $^{\mathrm{f} / \mathrm{f}} \mathrm{TH}-\mathrm{Cre}-\mathrm{AAV}$ and $n=9-7$ 
PERK $^{\mathrm{f} / \mathrm{f}} \mathrm{TH}-\mathrm{dsRED}$ AAV mice injected in the SN at $3 \mathrm{M}$ and $12 \mathrm{M}$, respectively; $n=11-8 \mathrm{PERK}^{\mathrm{f} / \mathrm{f}}$ TH-Cre-AAV mice and $n=8-7$ PERK $^{\mathrm{f} / \mathrm{f}}$ TH-dsRED AAV mice injected in the VTA at $3 \mathrm{M}$ and $12 \mathrm{M}$, respectively. ${ }^{*} P<0.05,{ }^{* *} P<0.01$ and ${ }^{* *} P<0.001$ different from age-matched control.

\section{References}

13071 Aguzzi, A. \& O'connor, T. Protein aggregation diseases: pathogenicity and therapeutic perspectives.

1308

1309

1310

1311

1312

1313

1314

1315

1316

1317

1318

1319

1320

1321

1322

1323

1324

1325

1326

1327

1328

1329

1330

1331

1332

1333

1334

1335

1336

1337

1338

1339

1340

1341

1342

1343

1344

1345

1346

1347

1348

1349

Nature reviews Drug discovery 9, 237 (2010).

2 Ellgaard, L. \& Helenius, A. Quality control in the endoplasmic reticulum. Nature reviews Molecular cell biology 4, 181 (2003).

3 Martínez, G., Duran-Aniotz, C., Cabral-Miranda, F., Vivar, J. P. \& Hetz, C. Endoplasmic reticulum proteostasis impairment in aging. Aging Cell 16, 615-623 (2017).

4 Walter, P. \& Ron, D. The unfolded protein response: from stress pathway to homeostatic regulation. Science 334, 1081-1086 (2011).

5 Klann, E. \& Dever, T. E. Biochemical mechanisms for translational regulation in synaptic plasticity. Nature Reviews Neuroscience 5, 931 (2004).

6 Urra, H., Dufey, E., Lisbona, F., Rojas-Rivera, D. \& Hetz, C. When ER stress reaches a dead end. Biochimica et Biophysica Acta (BBA)-Molecular Cell Research 1833, 3507-3517 (2013).

7 Bandopadhyay, R. \& de Belleroche, J. Pathogenesis of Parkinson's disease: emerging role of molecular chaperones. Trends in molecular medicine 16, 27-36 (2010).

8 Soto, C. Unfolding the role of protein misfolding in neurodegenerative diseases. Nature Reviews Neuroscience 4, 49 (2003).

9 Smith, H. L. \& Mallucci, G. R. The unfolded protein response: mechanisms and therapy of neurodegeneration. Brain 139, 2113-2121, doi:10.1093/brain/aww101 (2016).

10 Hoozemans, J. J., Van Haastert, E. S., Nijholt, D. A., Rozemuller, A. J. \& Scheper, W. Activation of the unfolded protein response is an early event in Alzheimer's and Parkinson's disease. Neurodegenerative Diseases 10, 212-215 (2012).

11 Saxena, S. \& Caroni, P. Selective neuronal vulnerability in neurodegenerative diseases: from stressor thresholds to degeneration. Neuron 71, 35-48 (2011).

12 Mercado, G. et al. Targeting PERK signaling with the small molecule GSK2606414 prevents neurodegeneration in a model of Parkinson's disease. Neurobiology of disease 112, 136-148 (2018).

13 Schicknick, H. et al. Dopaminergic modulation of auditory cortex-dependent memory consolidation through mTOR. Cerebral Cortex 18, 2646-2658 (2008).

14 Broussard, J. I. et al. Dopamine regulates aversive contextual learning and associated in vivo synaptic plasticity in the hippocampus. Cell reports 14, 1930-1939 (2016).

15 Rosen, Z. B., Cheung, S. \& Siegelbaum, S. A. Midbrain dopamine neurons bidirectionally regulate CA3CA1 synaptic drive. Nature neuroscience 18, 1763 (2015).

16 Ma, T. \& Klann, E. PERK: a novel therapeutic target for neurodegenerative diseases? Alzheimer's research \& therapy 6, 30 (2014).

$17 \mathrm{Ma}, \mathrm{T}$. et al. Suppression of elF2 $\alpha$ kinases alleviates Alzheimer's disease-related plasticity and memory deficits. Nature neuroscience 16, 1299 (2013).

18 Moreno, J. A. et al. Sustained translational repression by elF2 $\alpha-\mathrm{P}$ mediates prion neurodegeneration. Nature 485, 507 (2012).

19 Hughes, D. \& Mallucci, G. R. The unfolded protein response in neurodegenerative disorders-therapeutic modulation of the PERK pathway. The FEBS journal (2018).

20 Hetz, C. \& Saxena, S. ER stress and the unfolded protein response in neurodegeneration. Nature Reviews Neurology 13, 477 (2017).

21 Bäckman, C. M. et al. Characterization of a mouse strain expressing Cre recombinase from the 3' untranslated region of the dopamine transporter locus. genesis 44, 383-390 (2006). 
Zhang, P. et al. The PERK eukaryotic initiation factor $2 \alpha$ kinase is required for the development of the skeletal system, postnatal growth, and the function and viability of the pancreas. Molecular and cellular biology 22, 3864-3874 (2002).

23 Madisen, L. et al. A robust and high-throughput Cre reporting and characterization system for the whole mouse brain. Nature neuroscience 13, 133 (2010).

24 Costa-Mattioli, M. et al. elF2 $\alpha$ phosphorylation bidirectionally regulates the switch from short-to longterm synaptic plasticity and memory. Cell 129, 195-206 (2007).

25 Trinh, M. A. et al. Brain-specific disruption of the elF2 $\alpha$ kinase PERK decreases ATF4 expression and impairs behavioral flexibility. Cell reports 1, 676-688 (2012).

26 Sharma, V. et al. Local inhibition of PERK enhances memory and reverses age-related deterioration of cognitive and neuronal properties. Journal of Neuroscience 38, 648-658 (2018).

27 Nobili, A. et al. Dopamine neuronal loss contributes to memory and reward dysfunction in a model of Alzheimer's disease. Nature communications 8, 14727 (2017).

28 Scheuner, D. et al. Translational control is required for the unfolded protein response and in vivo glucose homeostasis. Molecular cell 7, 1165-1176 (2001).

29 Tritsch, N. X. \& Sabatini, B. L. Dopaminergic modulation of synaptic transmission in cortex and striatum. Neuron 76, 33-50 (2012).

30 Chen, J. Y., Wang, E. A., Cepeda, C. \& Levine, M. S. Dopamine imbalance in Huntington's disease: a mechanism for the lack of behavioral flexibility. Frontiers in neuroscience 7, 114 (2013).

31 Björklund, A. \& Dunnett, S. B. Dopamine neuron systems in the brain: an update. Trends in neurosciences 30, 194-202 (2007).

32 Zhou, F.-M., Liang, Y. \& Dani, J. A. Endogenous nicotinic cholinergic activity regulates dopamine release in the striatum. Nature neuroscience 4, 1224 (2001).

33 Rice, M. E. \& Cragg, S. J. Nicotine amplifies reward-related dopamine signals in striatum. Nature neuroscience 7, 583 (2004).

34 Cachope, R. et al. Selective activation of cholinergic interneurons enhances accumbal phasic dopamine release: setting the tone for reward processing. Cell reports 2, 33-41 (2012).

35 Threlfell, S. et al. Striatal dopamine release is triggered by synchronized activity in cholinergic interneurons. Neuron 75, 58-64 (2012).

36 Viaro, R., Calcagno, M., Marti, M., Borrelli, E. \& Morari, M. Pharmacological and genetic evidence for pre-and postsynaptic D2 receptor involvement in motor responses to nociceptin/orphanin FQ receptor ligands. Neuropharmacology 72, 126-138 (2013).

37 Miller, G. W., Gainetdinov, R. R., Levey, A. I. \& Caron, M. G. Dopamine transporters and neuronal injury. Trends in pharmacological sciences 20, 424-429 (1999).

38 Calabresi, P. et al. Abnormal synaptic plasticity in the striatum of mice lacking dopamine D2 receptors. Journal of Neuroscience 17, 4536-4544 (1997).

39 Yin, H. H., Davis, M. I., Ronesi, J. A. \& Lovinger, D. M. The role of protein synthesis in striatal long-term depression. Journal of Neuroscience 26, 11811-11820 (2006).

40 Lüscher, C. \& Huber, K. M. Group 1 mGluR-dependent synaptic long-term depression: mechanisms and implications for circuitry and disease. Neuron 65, 445-459 (2010).

41 Calabresi, P., Picconi, B., Tozzi, A. \& Di Filippo, M. Dopamine-mediated regulation of corticostriatal synaptic plasticity. Trends in neurosciences 30, 211-219 (2007).

42 Goldberg, M. S. et al. Nigrostriatal dopaminergic deficits and hypokinesia caused by inactivation of the familial Parkinsonism-linked gene DJ-1. Neuron 45, 489-496 (2005).

43 Russo, S. J. \& Nestler, E. J. The brain reward circuitry in mood disorders. Nature Reviews Neuroscience 14, 609-625 (2013).

44 Gompf, H. S., Budygin, E. A., Fuller, P. M. \& Bass, C. E. Targeted genetic manipulations of neuronal subtypes using promoter-specific combinatorial AAVs in wild-type animals. Frontiers in behavioral neuroscience 9, 152 (2015). 
139945 Edwards, N. J. et al. Circuit specificity in the inhibitory architecture of the VTA regulates cocaine-induced

1400

1401

1402

1403

1404

1405

1406

1407

1408

1409

1410

1411

1412

1413

1414

1415

1416

1417

1418

1419

1420

1421

1422

1423

1424

1425

1426

1427

1428

1429

1430

1431

1432

1433

1434

1435

1436

1437

1438

1439

1440

1441

1442

1443

1444

1445

1446

1447 behavior. Nature neuroscience 20, 438 (2017).

46 Lee, H. J., Gallagher, M. \& Holland, P. C. The central amygdala projection to the substantia nigra reflects prediction error information in appetitive conditioning. Learning \& Memory 17, 531-538 (2010).

47 Hetz, C. \& Mollereau, B. Disturbance of endoplasmic reticulum proteostasis in neurodegenerative diseases. Nature Reviews Neuroscience 15, 233 (2014).

48 Duran-Aniotz, C. et al. IRE1 signaling exacerbates Alzheimer's disease pathogenesis. Acta neuropathologica 134, 489-506 (2017).

49 Cooper, A. A. et al. $\alpha$-Synuclein blocks ER-Golgi traffic and Rab1 rescues neuron loss in Parkinson's models. Science 313, 324-328 (2006).

50 Costa-Mattioli, M. et al. Translational control of hippocampal synaptic plasticity and memory by the elF2 $\alpha$ kinase GCN2. Nature 436, 1166 (2005).

51 Jiang, Z. et al. elF2 $\alpha$ phosphorylation-dependent translation in CA1 pyramidal cells impairs hippocampal memory consolidation without affecting general translation. Journal of Neuroscience 30, 2582-2594 (2010).

52 Sidrauski, C. et al. Pharmacological brake-release of mRNA translation enhances cognitive memory. Elife 2, e00498 (2013).

53 Tsaytler, P., Harding, H. P., Ron, D. \& Bertolotti, A. Selective inhibition of a regulatory subunit of protein phosphatase 1 restores proteostasis. Science 332, 91-94 (2011).

54 Bond, S., Lopez-Lloreda, C., Gannon, P. J., Akay-Espinoza, C. \& Jordan-Sciutto, K. L. The Integrated Stress Response and Phosphorylated Eukaryotic Initiation Factor $2 \alpha$ in Neurodegeneration. Journal of Neuropathology \& Experimental Neurology (2020).

55 Rittiner, J. E. et al. Functional genomic analyses of mendelian and sporadic disease identify impaired elF2 $\alpha$ signaling as a generalizable mechanism for dystonia. Neuron 92, 1238-1251 (2016).

56 Buffington, S. A., Huang, W. \& Costa-Mattioli, M. Translational control in synaptic plasticity and cognitive dysfunction. Annual review of neuroscience 37, 17-38 (2014).

57 Brichta, L. \& Greengard, P. Molecular determinants of selective dopaminergic vulnerability in Parkinson's disease: an update. Frontiers in neuroanatomy 8, 152 (2014).

58 Liljeholm, M. \& O'Doherty, J. P. Contributions of the striatum to learning, motivation, and performance: an associative account. Trends in cognitive sciences 16, 467-475 (2012).

59 Kreitzer, A. C. \& Malenka, R. C. Endocannabinoid-mediated rescue of striatal LTD and motor deficits in Parkinson's disease models. Nature 445, 643-647 (2007).

60 Shen, W., Flajolet, M., Greengard, P. \& Surmeier, D. J. Dichotomous dopaminergic control of striatal synaptic plasticity. Science 321, 848-851 (2008).

61 Haber, S. N., Fudge, J. L. \& McFarland, N. R. Striatonigrostriatal pathways in primates form an ascending spiral from the shell to the dorsolateral striatum. Journal of Neuroscience 20, 2369-2382 (2000).

62 Yang, K. \& Dani, J. A. Dopamine D1 and D5 receptors modulate spike timing-dependent plasticity at medial perforant path to dentate granule cell synapses. Journal of Neuroscience 34, 15888-15897 (2014).

63 Lemon, N. \& Manahan-Vaughan, D. Dopamine D1/D5 receptors gate the acquisition of novel information through hippocampal long-term potentiation and long-term depression. Journal of Neuroscience 26, 7723-7729 (2006).

64 Swant, J. \& Wagner, J. J. Dopamine transporter blockade increases LTP in the CA1 region of the rat hippocampus via activation of the D3 dopamine receptor. Learning \& Memory 13, 161-167 (2006).

65 McNamara, C. G., Tejero-Cantero, Á., Trouche, S., Campo-Urriza, N. \& Dupret, D. Dopaminergic neurons promote hippocampal reactivation and spatial memory persistence. Nature neuroscience 17, 1658 (2014).

66 Li, S., Cullen, W. K., Anwyl, R. \& Rowan, M. J. Dopamine-dependent facilitation of LTP induction in hippocampal CA1 by exposure to spatial novelty. Nature neuroscience 6, 526 (2003). 
144867 Hagena, H. \& Manahan-Vaughan, D. Dopamine D1/D5, but not D2/D3, receptor dependency of synaptic

1449

1450

1451

1452

1453

1454

1455

1456

1457

1458

1459

1460

1461

1462

1463

1464

1465

1466

1467

1468

1469

1470

1471

1472

1473

1474

1475

1476

1477

1478

1479

1480

1481

1482

1483

1484

1485

1486

1487

1488

1489

1490

1491

1492

1493

1494

1495

plasticity at hippocampal mossy fiber synapses that is enabled by patterned afferent stimulation, or spatial learning. Frontiers in synaptic neuroscience 8, 31 (2016).

68 Guzmán-Ramos, K. et al. Restoration of dopamine release deficits during object recognition memory acquisition attenuates cognitive impairment in a triple transgenic mice model of Alzheimer's disease. Learning \& memory 19, 453-460 (2012).

69 Colla, E. et al. Accumulation of toxic $\alpha$-synuclein oligomer within endoplasmic reticulum occurs in $\alpha$ synucleinopathy in vivo. Journal of Neuroscience 32, 3301-3305 (2012).

70 Das, l. et al. Preventing proteostasis diseases by selective inhibition of a phosphatase regulatory subunit. Science 348, 239-242 (2015).

71 Wang, L., Popko, B., Tixier, E. \& Roos, R. P. Guanabenz, which enhances the unfolded protein response, ameliorates mutant SOD1-induced amyotrophic lateral sclerosis. Neurobiology of disease 71, 317-324 (2014).

72 Back, S. H. et al. Translation attenuation through elF2 $\alpha$ phosphorylation prevents oxidative stress and maintains the differentiated state in $\beta$ cells. Cell metabolism 10, 13-26 (2009).

73 Longo, F., Russo, I., Shimshek, D. R., Greggio, E. \& Morari, M. Genetic and pharmacological evidence that G2019S LRRK2 confers a hyperkinetic phenotype, resistant to motor decline associated with aging. Neurobiol Dis 71, 62-73, doi:10.1016/j.nbd.2014.07.013 (2014).

74 Bhattacharya, A. et al. Genetic removal of p70 S6 kinase 1 corrects molecular, synaptic, and behavioral phenotypes in fragile X syndrome mice. Neuron 76, 325-337, doi:10.1016/j.neuron.2012.07.022 (2012).

75 Errico, F. et al. The GTP-binding protein Rhes modulates dopamine signalling in striatal medium spiny neurons. Mol Cell Neurosci 37, 335-345, doi:10.1016/j.mcn.2007.10.007 (2008).

76 Santini, E. et al. Exaggerated translation causes synaptic and behavioural aberrations associated with autism. Nature 493, 411-415, doi:10.1038/nature11782 (2013).

77 Pick, J. E., Malumbres, M. \& Klann, E. The E3 ligase APC/C-Cdh1 is required for associative fear memory and long-term potentiation in the amygdala of adult mice. Learn Mem 20, 11-20, doi:10.1101/Im.027383.112 (2012).

78 Huynh, T. N., Santini, E. \& Klann, E. Requirement of Mammalian target of rapamycin complex 1 downstream effectors in cued fear memory reconsolidation and its persistence. $J$ Neurosci 34, 90349039, doi:10.1523/JNEUROSCI.0878-14.2014 (2014).

79 Bowling, H. et al. BONLAC: A combinatorial proteomic technique to measure stimulus-induced translational profiles in brain slices. Neuropharmacology 100, 76-89, doi:10.1016/j.neuropharm.2015.07.017 (2016).

80 Schmidt, E. K., Clavarino, G., Ceppi, M. \& Pierre, P. SUnSET, a nonradioactive method to monitor protein synthesis. Nature methods 6, 275 (2009).

81 Hou, L. et al. Dynamic translational and proteasomal regulation of fragile $\mathrm{X}$ mental retardation protein controls mGluR-dependent long-term depression. Neuron 51, 441-454 (2006).

82 Stouffer, M. A. et al. Insulin enhances striatal dopamine release by activating cholinergic interneurons and thereby signals reward. Nature communications 6, 8543 (2015).

$83 \mathrm{Li}, \mathrm{X}$. et al. Enhanced striatal dopamine transmission and motor performance with LRRK2 overexpression in mice is eliminated by familial Parkinson's disease mutation G2019S. Journal of Neuroscience 30, 17881797 (2010).

84 Schmitz, Y., Lee, C. J., Schmauss, C., Gonon, F. \& Sulzer, D. Amphetamine distorts stimulation-dependent dopamine overflow: effects on D2 autoreceptors, transporters, and synaptic vesicle stores. Journal of Neuroscience 21, 5916-5924 (2001).

85 O'Neill, B., Patel, J. C. \& Rice, M. E. Characterization of optically and electrically evoked dopamine release in striatal slices from digenic knock-in mice with DAT-driven expression of channelrhodopsin. ACS chemical neuroscience 8, 310-319 (2017). 
a

slice preparation 120' recovery 150' AHA incubation

b

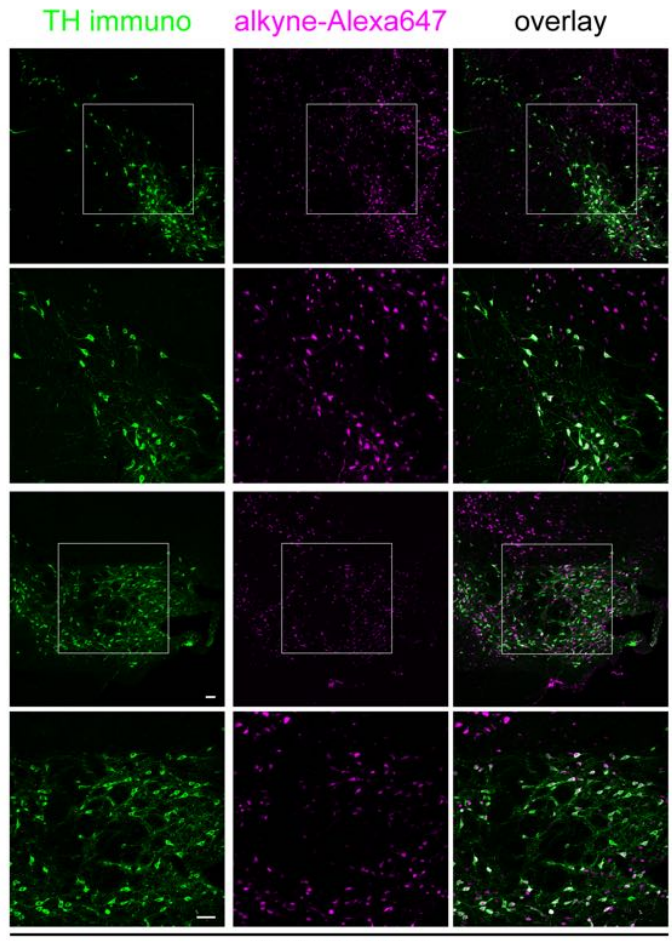

WT DAT-Cre

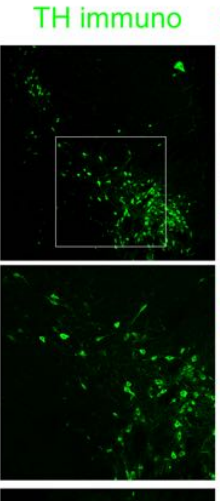

alkyne-Alexa647
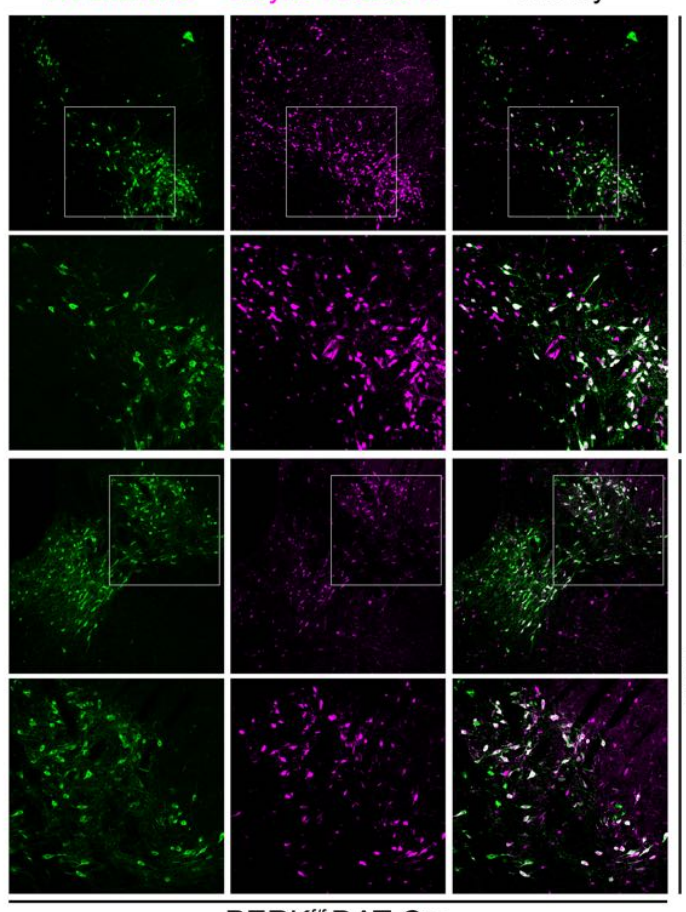

PERK $^{f / f}$ DAT-Cre

overlay
¿

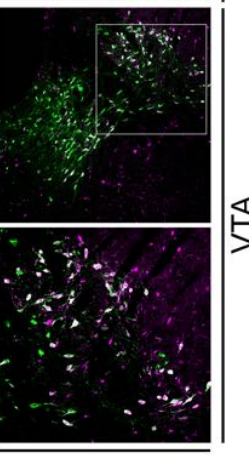

$\stackrel{5}{5}$

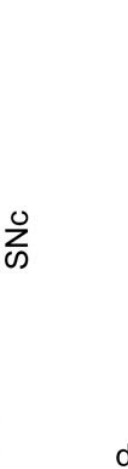

d
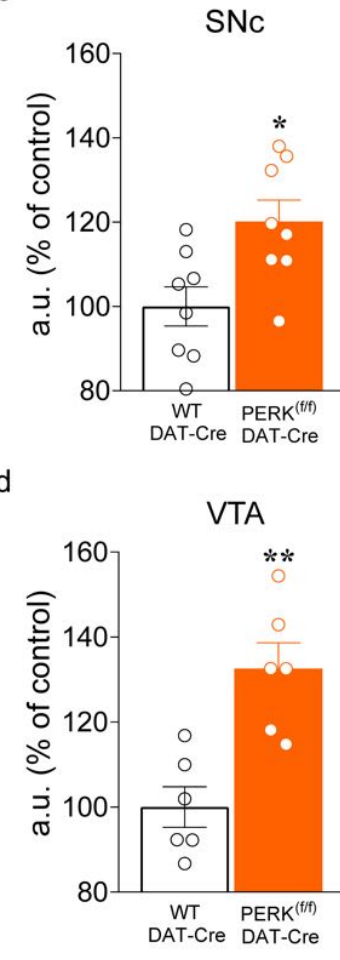


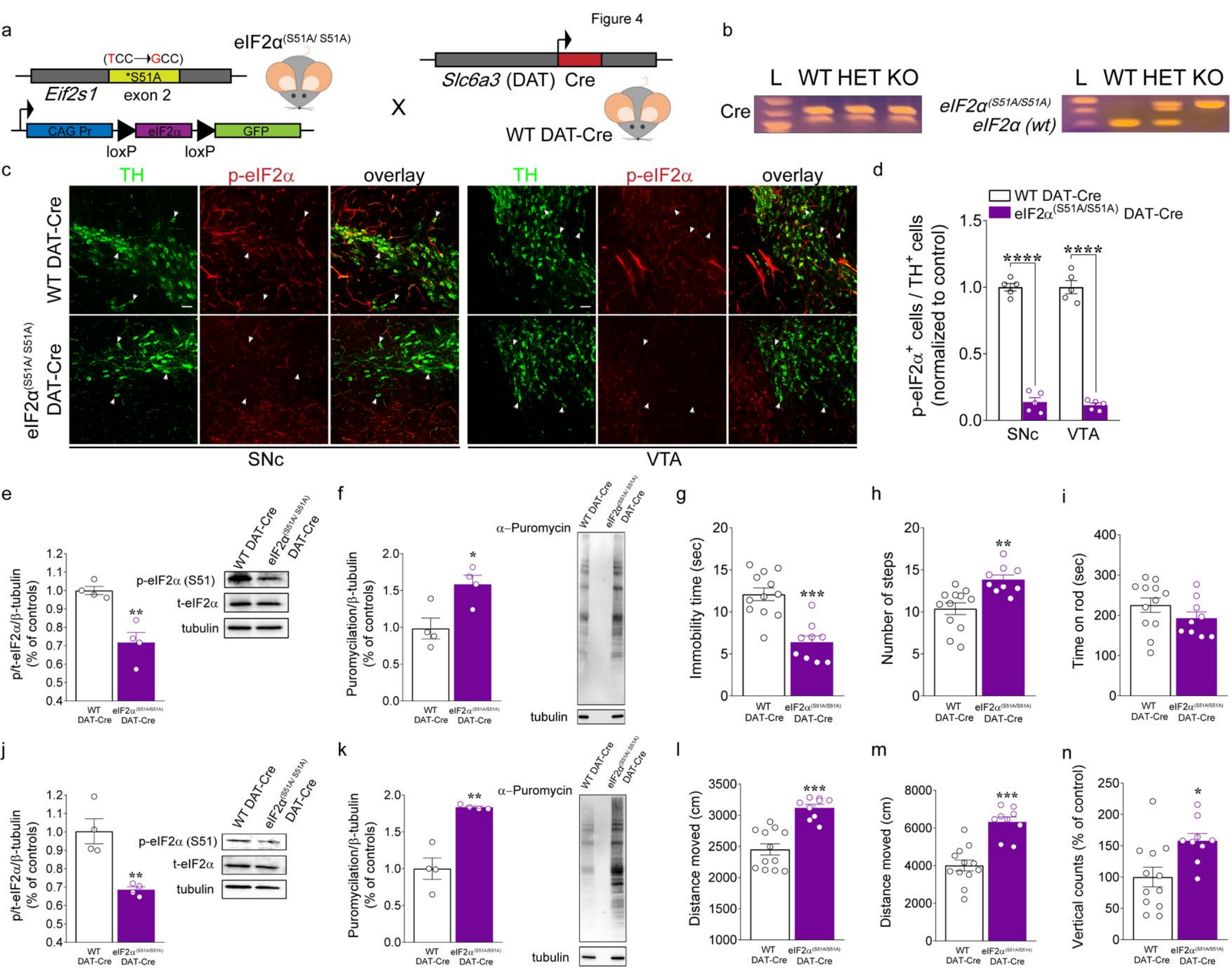


Figure 7

b

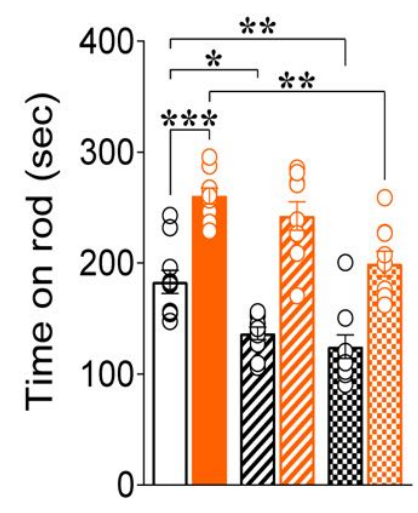

e

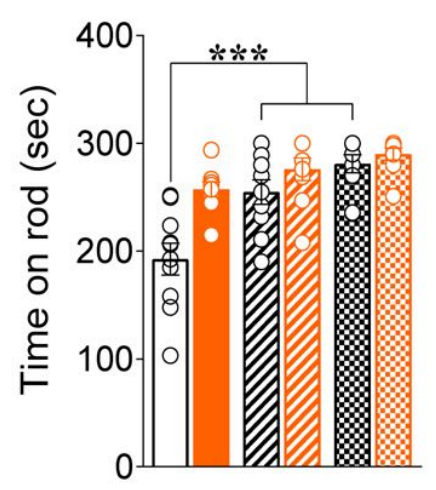

$\mathrm{h}$

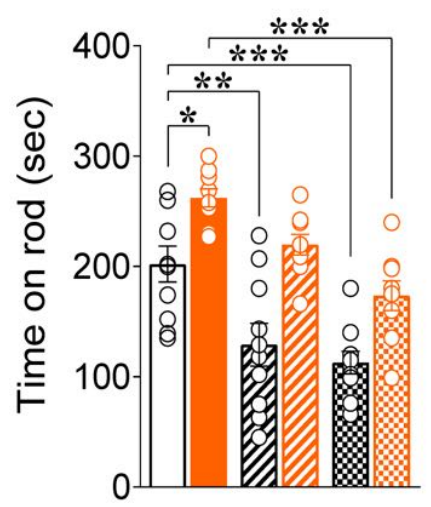

C

f

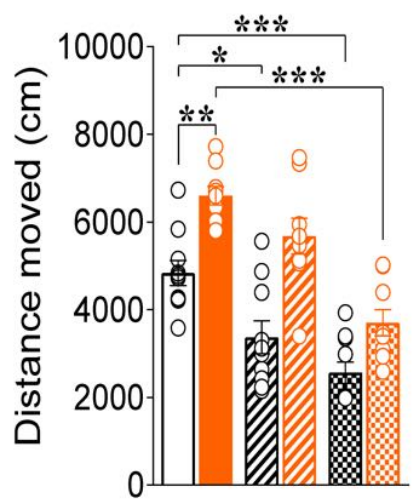

$\square$ WT DAT-Cre + Vehicle PERK $^{\mathrm{flf}}$ DAT-Cre + Vehicle WI WT DAT-Cre + SCH 23390 (0.01 mg/kg) WIA PERK ${ }^{\mathrm{f} / \mathrm{f}}$ DAT-Cre + SCH $23390(0.01 \mathrm{mg} / \mathrm{kg})$ $\$$ WT DAT-Cre + SCH $23390(0.2 \mathrm{mg} / \mathrm{kg})$ \% PERK ${ }^{\mathrm{f} / \mathrm{f}}$ DAT-Cre + SCH 23390 (0.2 mg/kg)

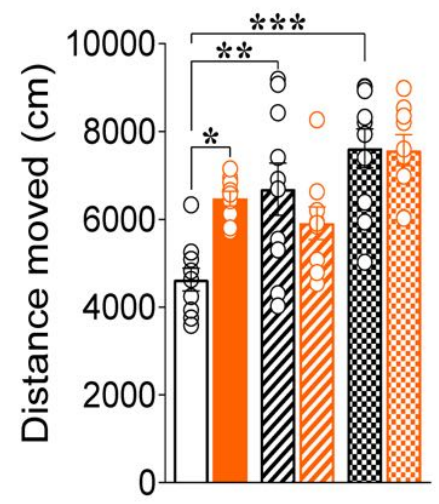

WT DAT-Cre + Vehicle

PERK $K^{6 / f}$ DAT-Cre + Vehicle WII WT DAT-Cre + GBR12783 (6 mg/kg) WIA PERK ${ }^{f / f}$ DAT-Cre + GBR12783 (6 mg/kg) \& WT DAT-Cre + GBR12783 (10 mg/kg) PERK ${ }^{\mathrm{f} / \mathrm{f}}$ DAT-Cre + GBR12783 (10 mg/kg)

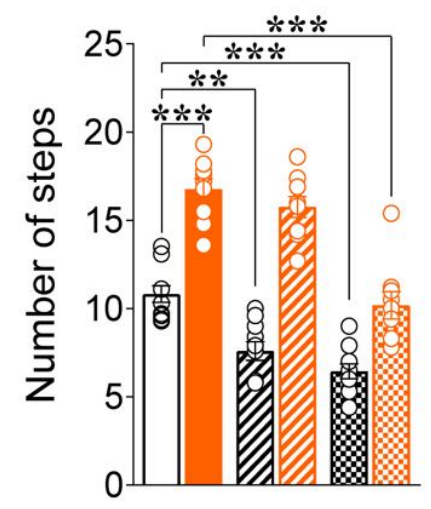

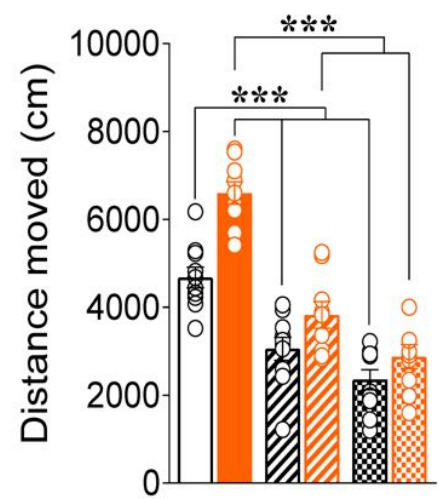

$\square$ WT DAT-Cre + Vehicle

PERK $^{\text {f/f }}$ DAT-Cre + Vehicle

WIA WT DAT-Cre + Reserpine (1 mg/kg) IIA PERK $^{\mathrm{f} / \mathrm{f}}$ DAT-Cre + Reserpine (1 mg/kg) $\$$ WT DAT-Cre + Reserpine (1.5 mg/kg) KERK PER $^{\mathrm{f} / \mathrm{f}}$ DAT-Cre + Reserpine $(1.5 \mathrm{mg} / \mathrm{kg})$ 

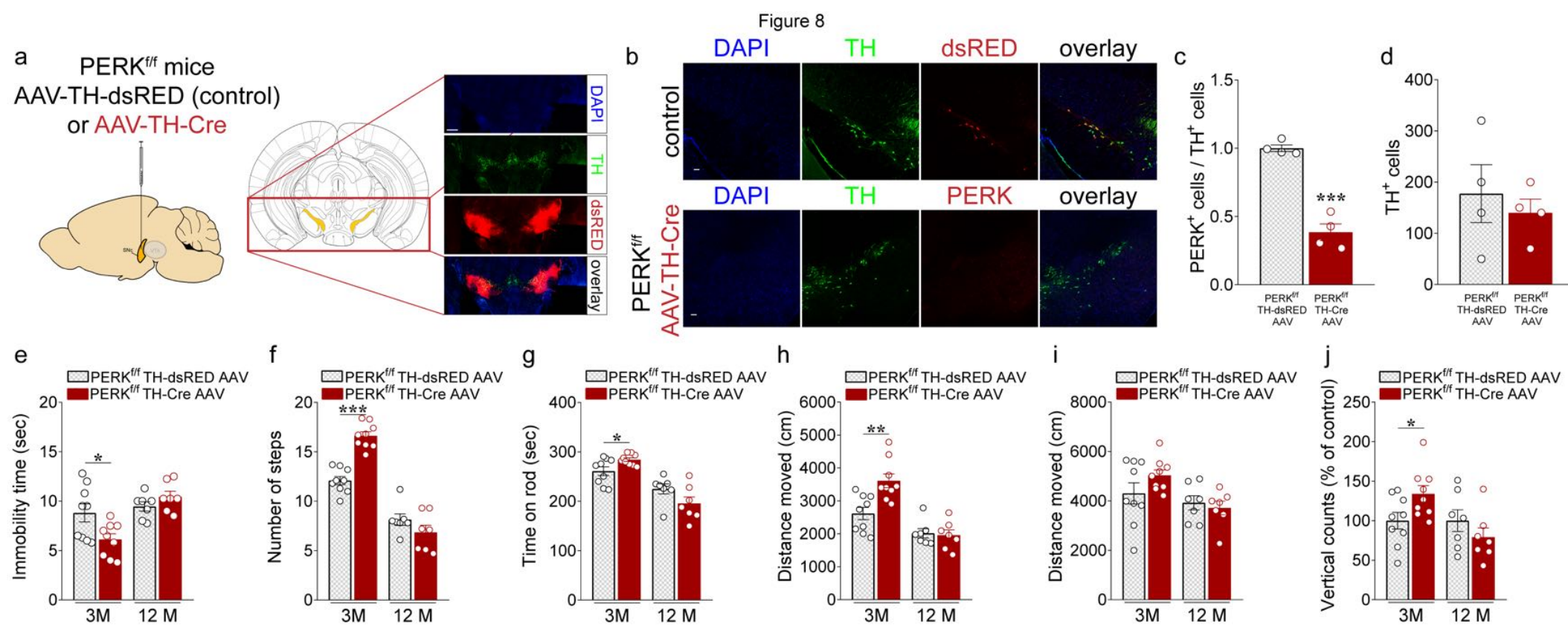

\section{k $\quad$ PERK ${ }^{\mathrm{flf}}$ mice} AAV-TH-dsRED (control) or AAV-TH-Cre
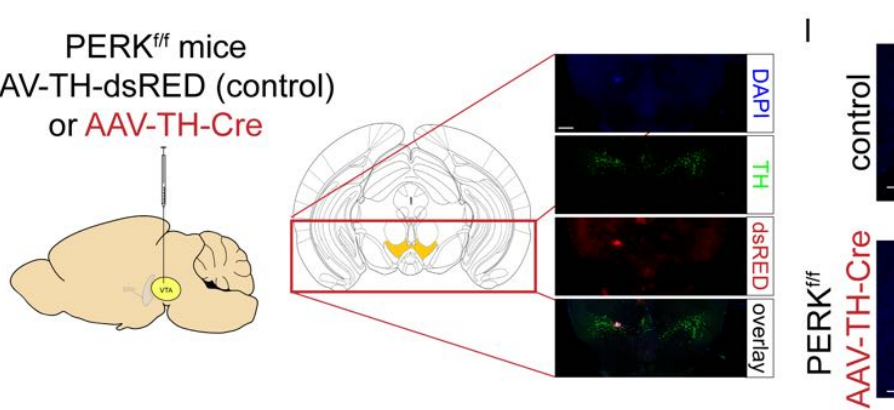

$p$

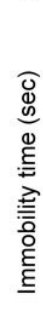

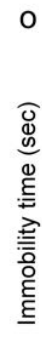

$\square$ PERK $^{f / f} \mathrm{TH}$-dsRED AAV DERK ${ }^{\text {fff }}$ TH-Cre AAV

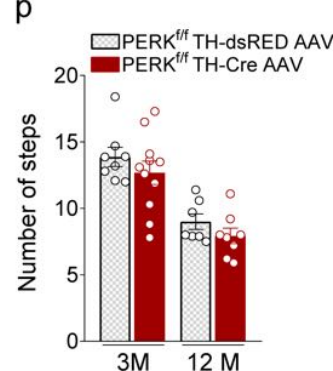

\section{q}

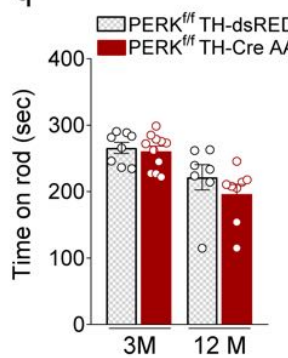

DAPI

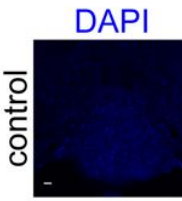

DAPI

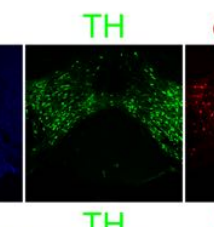

dsRE

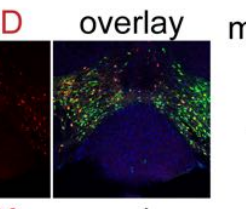

PERK
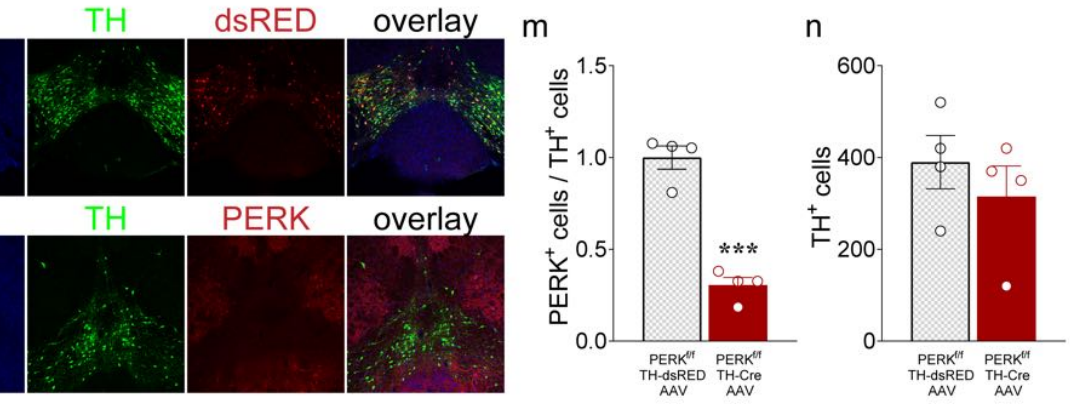

S

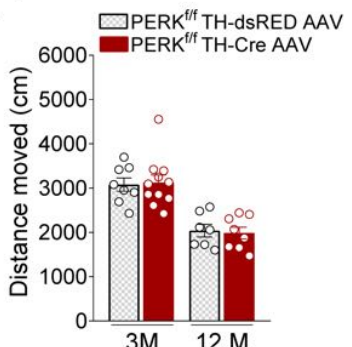

\section{$\mathrm{t}$}

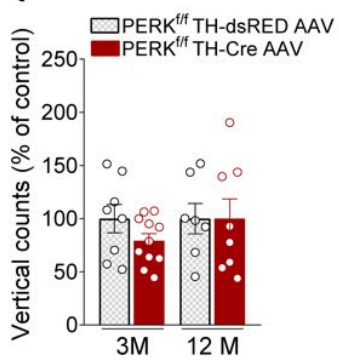




\section{Supplementary Figure 1}
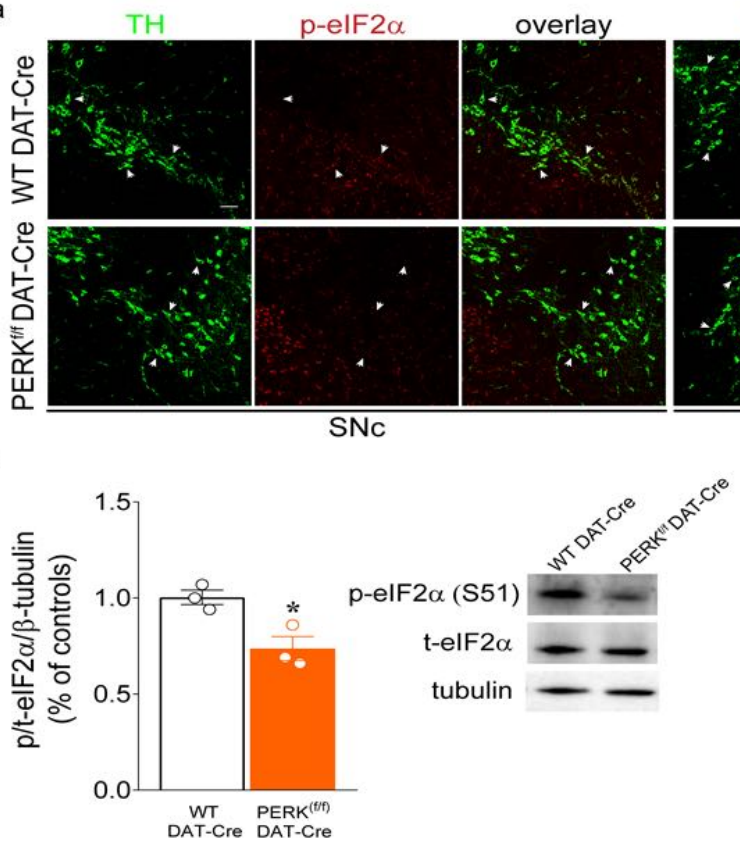
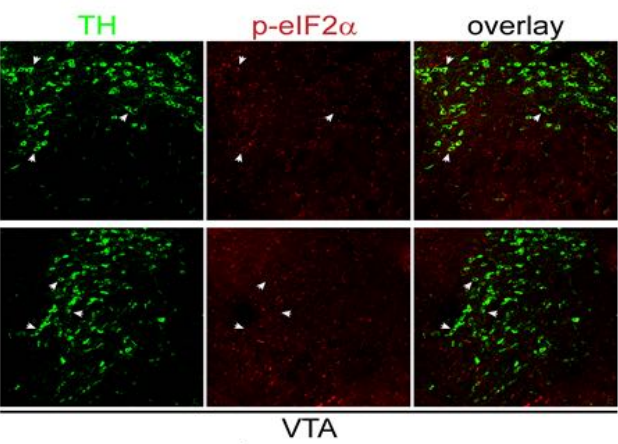

d
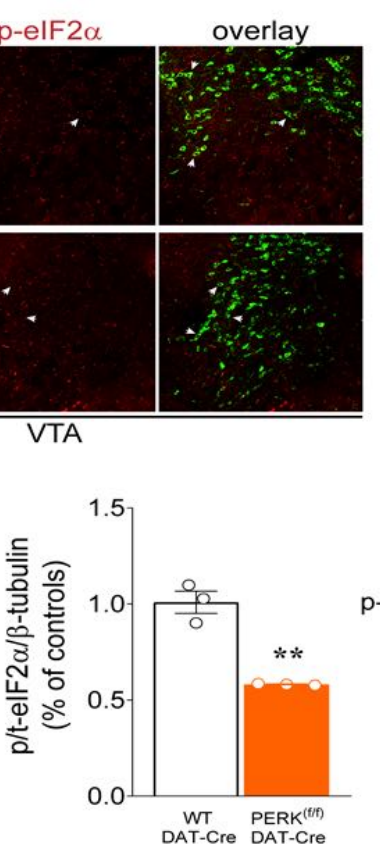

b

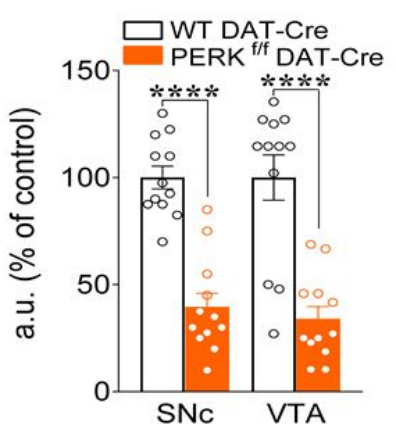

e
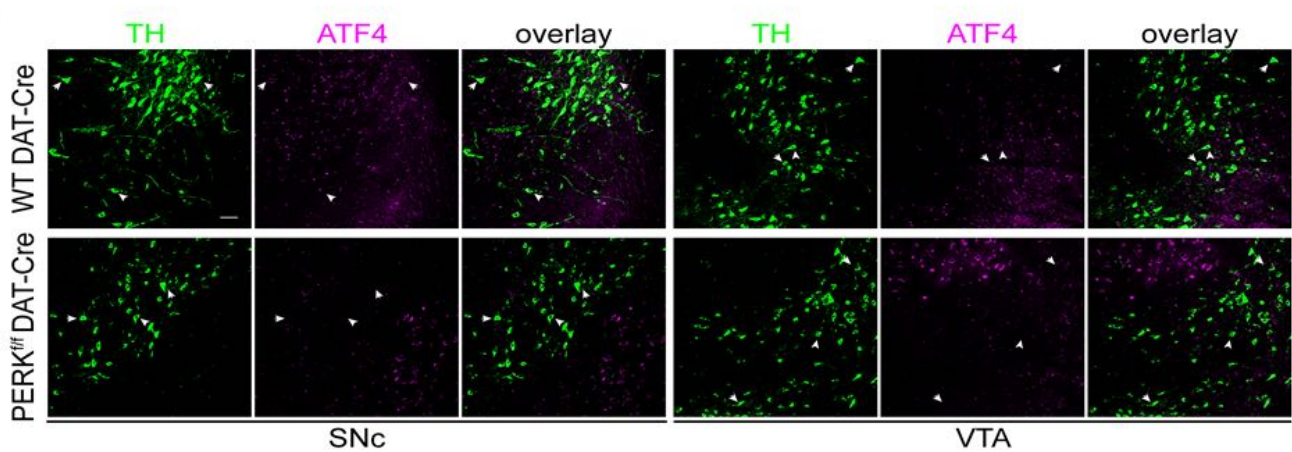

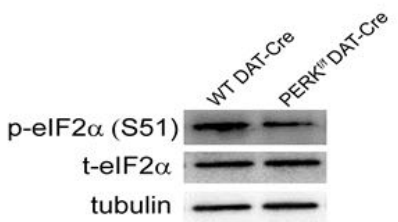

tubulin

Supplementary Figure 1. Cell-specific deletion of PERK in VTA and SNc DA neurons results in reduced UPR after thapsigargin-induced ER-stress (a) Immunofluorescent detection of $\mathrm{TH}^{+}$neuron (green) and phosphorylated elF2 $\alpha$ (red) in SNc and VTA DA neurons of PERK ${ }^{\mathrm{fff}}$ DAT-Cre and WT DAT-Cre mice, in thapsigargin-treated brain slices (scale bars represent $50 \mu \mathrm{m}$ ). Arrows indicate dopaminergic neurons (green) and p-elF2a (red) co-stain. (b) Summary plot showing reduced p-elF2 $\alpha$ signal after ER-stress induction, expressed as fluorescent arbitrary units (a.u.; \% of control) in $\mathrm{TH}+$ neurons from SNc and VTA of PERK ${ }^{\mathrm{ff}}$ DAT-Cre vs. WT DAT-Cre mice. Cell soma intensity was measured in ImageJ. Statistical significance was determined by using Student's $t$ test (PERK ${ }^{\mathrm{fff}}$ DAT-Cre vs. WT DAT-Cre mice; unpaired test; SNc, $\mathrm{t}_{(22)}=7.277, P<0.0001 ;$ VTA, $\left._{(22)}=5.496, P<0.0001\right)$. Data are shown as mean \pm s.e.m. of $\mathrm{n}=12$ slices per group (average of $n=40$ somas per slice, $n=2$ slices per mouse, from three independent experiments) ${ }^{* * * *} P<0.0001$. (c,d) Representative western blots (right panel) and quantification of phosphorylation of elF2 $\alpha$ in SNc (c) and VTA (d) of PERK $^{\text {fff }}$ DAT-Cre and WT DAT-Cre mice. Summary plot showed a significant decrease in the phosphorylation of elF2 $\alpha$ in both SNc (c; unpaired $\mathrm{t}$ test, $\mathrm{t}_{(4)}=3.667, P=0.023 ; \mathrm{n}=3$ independent lysates from 3 mice per group) and VTA (d; unpaired $\mathrm{t}$ test, $\mathrm{t}_{(4)}=7.414, P=0.002 ; \mathrm{n}=3$ independent lysates from 3 mice per group) of PERK ${ }^{\mathrm{f} / \mathrm{f}}$ DAT-Cre mice compared with controls after treatment with thapsigargin. (e) Immunofluorescent detection of $\mathrm{TH}^{+}$neuron (green) and ATF4 (magenta) in SNc and VTA DA neurons of PERK ${ }^{\mathrm{fff}}$ DAT-Cre and WT DAT-Cre mice, in thapsigargin-treated brain slices (scale bars represent $50 \mu \mathrm{m}$ ). Arrows indicate dopaminergic neurons (green) and ATF4 (magenta) co-stain. (f) Summary plot showing reduced ATF4 signal after ER-stress induction, expressed as fluorescent arbitrary units (a.u.; \% of control) in TH+ neurons from SNc and VTA of PERK ${ }^{\mathrm{f} / \mathrm{f}}$ DAT-Cre vs. WT DAT-Cre mice. Cell soma intensity was measured in ImageJ. Statistical significance was determined by using Student's $t$ test (PERK ${ }^{\mathrm{f} / f}$ DAT-Cre vs. WT DAT-Cre mice; unpaired $\mathrm{t}$ test; $\left.\mathrm{SNc}, \mathrm{t}_{(12)}=9.407, P<0.0001 ; \mathrm{VTA}, \mathrm{t}_{(12)}=13.66, P<0.0001\right)$. Data are shown as mean $\pm \mathrm{s}$.e. $\mathrm{m}$. of $\mathrm{n}=7$ slices per group (average of $\mathrm{n}=40$ somas per slice, $\mathrm{n}=2-3$ slices per mouse, from three independent experiments) ${ }^{* * * *} P$ $<0.0001$. 


\section{Supplementary Figure 2}

a

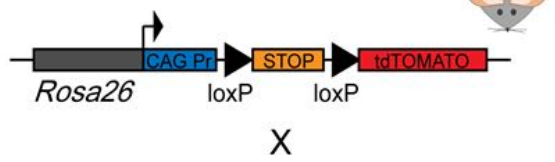

PERK $^{f /+}$ DAT-Cre mice

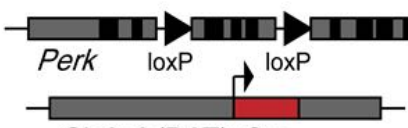

S/c6a3 (DAT) Cre
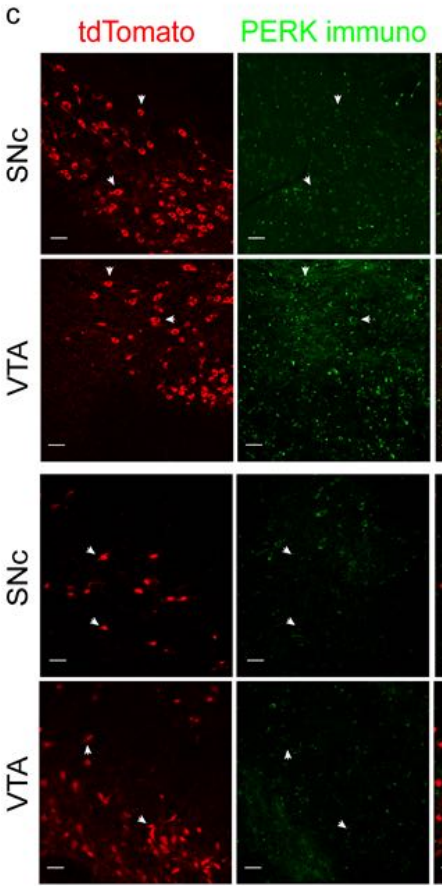
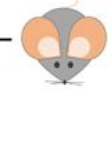

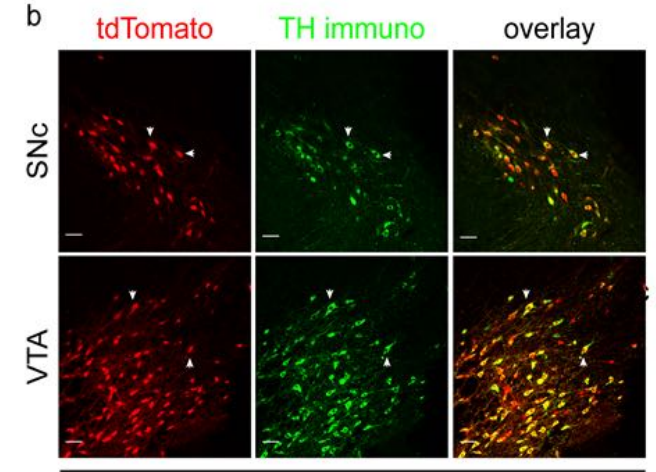

CAG ${ }^{\text {floxStop-totomato }}$ DAT-Cre

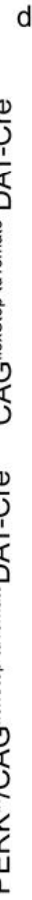

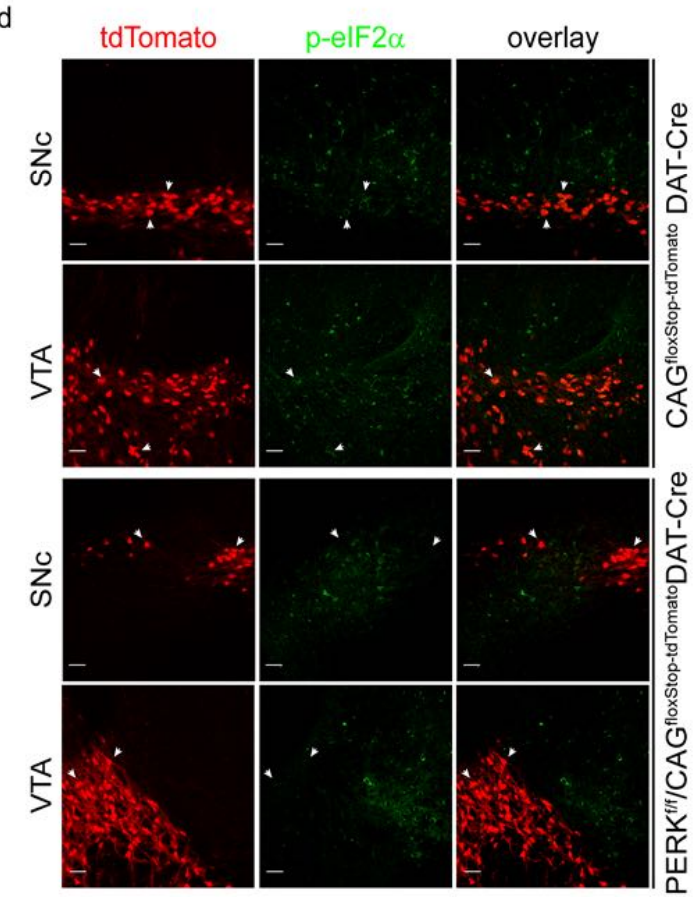
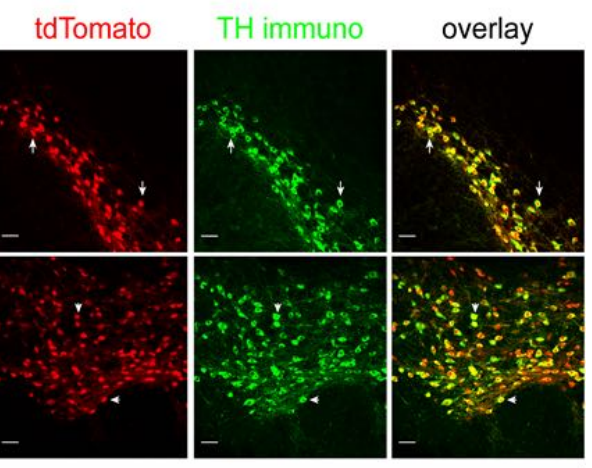

PERK ${ }^{\text {ff }} / \mathrm{CAG}^{\text {floxStop-tdTomato } D A T-C r e ~}$

e
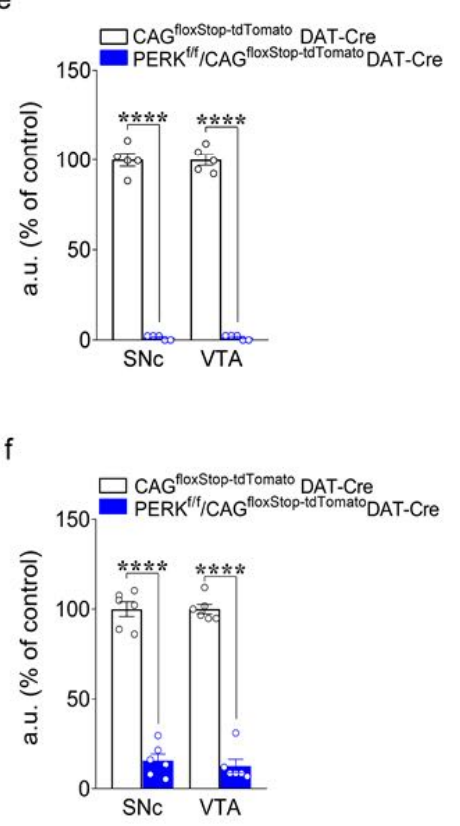

Supplementary Figure 2. Gt(ROSA)26Sor ${ }^{\mathrm{tm} 14(\mathrm{CAG}-\mathrm{tdT} T o m a t o) H z e}$ Cre-dependent reporter mice crossed with PERK ${ }^{\mathrm{f} /+}$ DAT-Cre mice confirm positive targeting of $\mathrm{DAT}^{+}$neurons for the deletion of PERK and reduction of phosphorylated elF2 $\alpha$ in VTA and SNc DA neurons (a) Schematic representation of DAT ${ }^{+}$neuron-specific expression of tdTomato in DAT-Cre mice crossed with Gt(ROSA)26Sor ${ }^{\text {tm14(CAG-tdTomato)Hze }}$ Cre-dependent reporter mice. (b) Immunofluorescent detection of tdTomato (red) $\mathrm{DAT}^{+}$neurons and TH-IR (green) in SNc and VTA DA neurons of $\mathrm{PERK}^{\mathrm{f} / \mathrm{f}} / \mathrm{CAG}{ }^{\text {floxStop-tdTomato } D A T-C r e}$ and WT/CAG ${ }^{\text {floxStop-tdTomato }} \mathrm{DAT}$-Cre (control) mice, confirming specificity of the Cresystem (scale bars represent $50 \mu \mathrm{m}$ ). Arrows indicate dopaminergic neurons (green) and tdTomato (red) co-stain. (c) Immunofluorescent detection of tdTomato (red) DAT ${ }^{+}$neurons and PERK (green) expression in SNc and VTA DA neurons of $\mathrm{PERK}^{\mathrm{f} / \mathrm{f}} / \mathrm{CAG}^{\text {floxStop-tdTomato }} \mathrm{DAT}$-Cre and WT/CAG ${ }^{\text {floxStop-tdTomato }} \mathrm{DAT}$-Cre mice, confirming positive targeting of DAT neurons for the deletion of PERK (scale bars represent $50 \mu \mathrm{m}$ ). Arrows indicate dopaminergic neurons (tdTomato; red) and PERK (green) co-stain. (d) Immunofluorescent detection of tdTomato (red) DAT ${ }^{+}$neurons and phosphorylated elF2 $\alpha$ (green) expression in SNc and VTA DA neurons of PERK ${ }^{\text {f/f }} /$ CAG $^{\text {floxStop-tdTomato }}$ DAT-Cre and WT/CAG ${ }^{\text {floxStop-tdTomato }}$ DAT-Cre mice, confirming reduction of phosphorylated elF2 $\alpha$ following deletion of PERK in DA neurons (scale bars represent 50 $\mu \mathrm{m})$. Arrows indicate dopaminergic neurons (tdTomato; red) and p-elF2a (green) co-stain. (e,f) Summary plot showing reduced PERK (e) and p-elF2a (f) signal expressed as fluorescent arbitrary units (a.u.; \% of control) in tdTomato ${ }^{+}$ (dopaminergic) neurons from SNc and VTA of PERK ${ }^{\mathrm{f} / \mathrm{f}} / \mathrm{CAG}^{\text {floxStop-tdTomato }}{ }^{\mathrm{DAT}-C r e}$ vs. WT/CAG ${ }^{\text {floxStop-tdTomato }}$ DAT-Cre mice. Cell soma intensity was measured in ImageJ. Statistical significance was determined by using Student's $t$ test $\left(\right.$ PERK $^{\mathrm{f} / \mathrm{f}} / \mathrm{CAG}^{\text {floxStop-tdTomato } D A T-C r e ~ v s . ~ W T / C A G ~}{ }^{\text {floxStop-tdTomato } D A T-C r e ~ m i c e ; ~ e, ~ u n p a i r e d ~} t$ test, SNc, $\mathrm{t}_{(8)}=27.04$, $P<$ 0.0001 ; VTA, $\mathrm{t}_{(8)}=31.14, P<0.0001 ; \mathbf{f}$, unpaired $t$ test, $\mathrm{SNc}, \mathrm{t}_{(10)}=15.31, P<0.0001 ;$ VTA, $\left.\mathrm{t}_{(10)}=19.00, P<0.0001\right)$ Data are shown as mean \pm s.e.m. of $n=5-6$ slices per group (average of $n=40$ somas per slice, $n=2-3$ slices per mouse, from three independent experiments) ${ }^{* * * *} P<0.0001$. 


\section{Supplementary Figure 3}

a

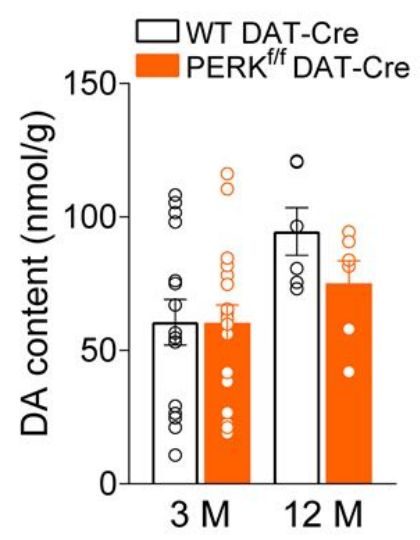

d

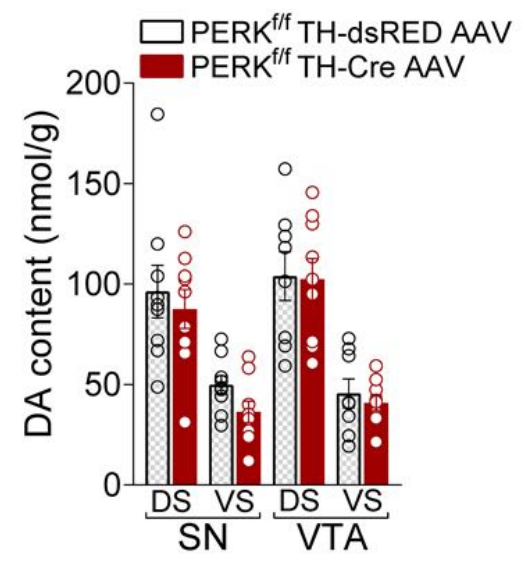

b

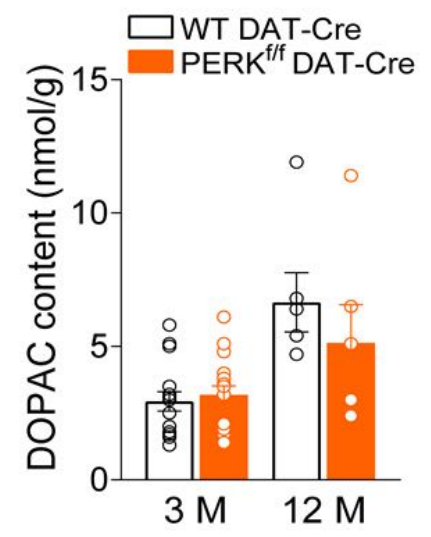

e

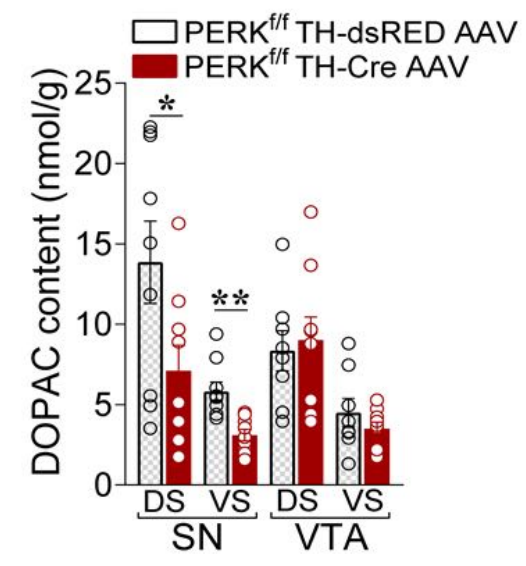

C

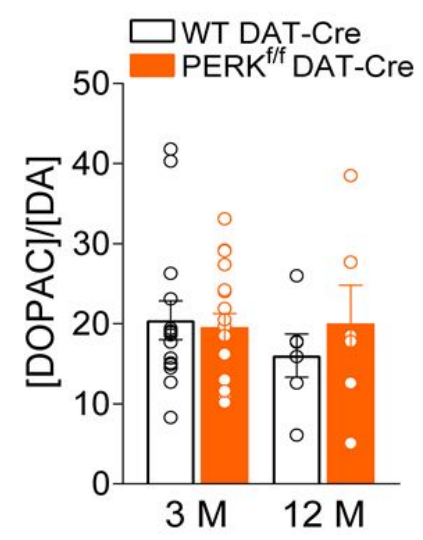

f

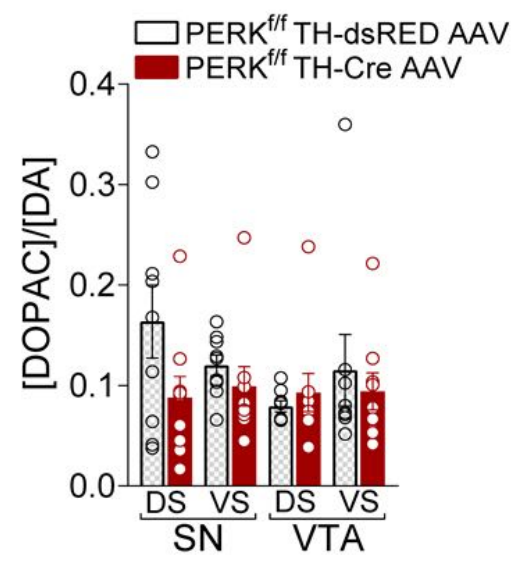

Supplementary Figure 3. Deletion of PERK from DA neurons does not affect DA content in either 3- or 12-month old mice. Tissue content (nmoles/g tissue wet weight) of DA (a,d), its metabolite DOPAC (b,e), was performed using HPLC with electrochemical detection in experimental striatal slices. The analysis of the metabolite/DA ratio ([DOPAC/DA]; $\mathbf{c , f})$ is also reported. (a-b) Summary plot of average DA (a) and DOPAC (b) content in both dorsal (DS) and ventral (VS) striatum of WT DAT-Cre vs. PERK ${ }^{\text {fif }}$ DAT-Cre mice (unpaired $t$-test, n.s. in both 3 and 12-month old mice). (c) Summary plot of average [DOPAC/DA] ratio (unpaired $t$-test, n.s. in both 3 and 12-month old mice). (d) Summary plot of average DA content in either DS or VS of PERK ${ }^{\mathrm{f} / \mathrm{f}}$ TH-Cre-AAV vs. PERK ${ }^{\mathrm{flf}}$ TH-dsRED AAV mice injected in either the SN (unpaired ttest, n.s. in both DS and VS) or the VTA (unpaired t-test, n.s. in both DS and VS). (e) Summary plot of average DOPAC content in either in both DS or VS of PERK ${ }^{f / f}$ TH-Cre-AAV vs. PERK ${ }^{\mathrm{f} / \mathrm{f}}$ TH-dsRED AAV mice injected in either the SN (unpaired t-test, DS, $\mathrm{t}_{(16)}=2.234, P<0.05$; VS, $\mathrm{t}_{(16)}=3.936, P<0.01$ ) or the VTA (unpaired t-test, $\mathrm{n}$.s. in both DS and VS) at 12 months of age. (f) Summary plot of average [DOPAC/DA] ratio in either DS or VS of PERK ${ }^{f / f}$ TH-Cre-AAV vs. PERK $^{f / f}$ TH-dsRED AAV mice injected in either the SN (unpaired t-test, n.s. in both DS and VS) or the VTA (unpaired ttest, n.s. in both DS and VS). All data are shown as mean \pm s.e.m. of $n=15-18$ mice per genotype at 3 months of age and $n=6$ mice per genotype at 12 months of age (a-c); or $n=8-9$ TH-Cre AAV-injected 12-month PERK ${ }^{\mathrm{t} / \mathrm{f}}$ mice. 


\section{1}

\section{Supplementary Figure 4}

3

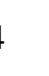
6 (7)

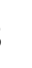

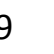
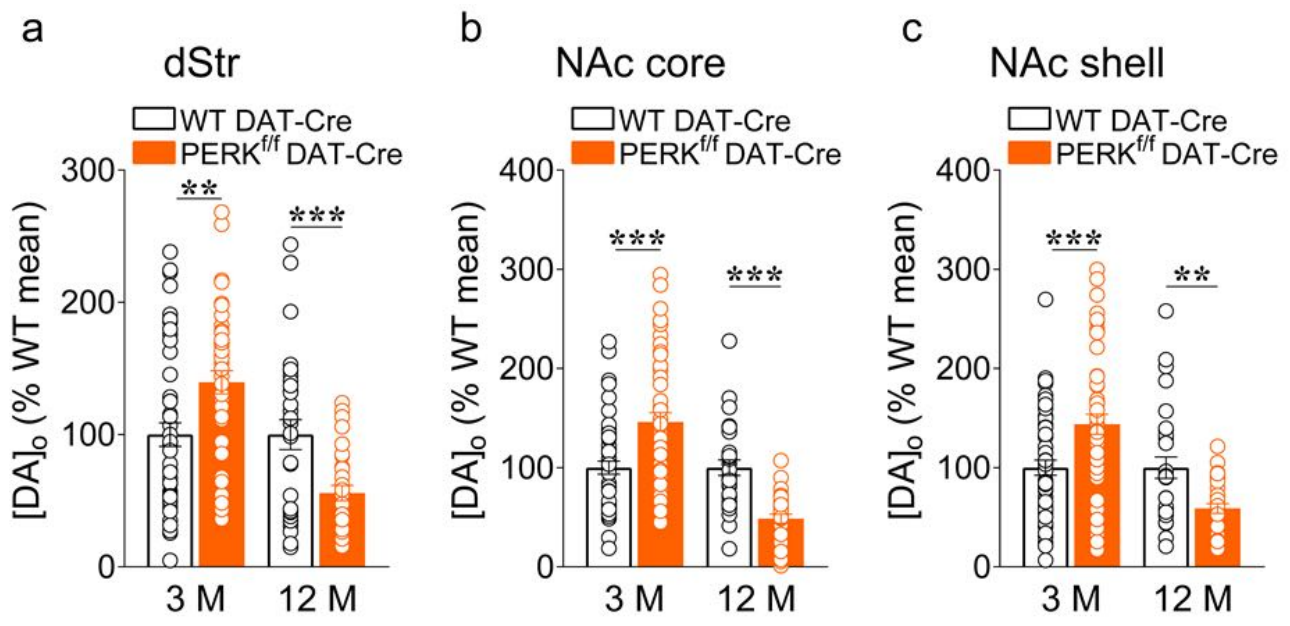

Supplementary Figure 4. Effect of PERK deletion on DA release in DA neurons does not involve ACh and nAChRs. (a-c) Average single-pulse-evoked $[D A]_{\circ}$ in dStr (a, unpaired $t$-test: $\mathrm{t}_{(91)}=3.160, P<0.01 ; \mathrm{t}_{(58)}=3.466, P=$ 0.001 , respectively at 3 and 12 months), NAc core (b, unpaired $t$-test: $\mathrm{t}_{(96)}=4.045, P<0.001 ; \mathrm{t}_{(58)}=5.619, P<0.001$, respectively at 3 and 12 months), and NAc shell (c, unpaired $t$-test: $\mathrm{t}_{(96)}=4.491, P<0.001 ; \mathrm{t}_{(58)}=3.466, P=0.001$, respectively at 3 and 12 months) in the presence of dihydro- $\beta$-erythroidine (Dh $\beta E ; 1 \mu \mathrm{M})$, a selective antagonist for $\beta 2$ subunit-containing $\left(\beta 2^{*}\right)$ nAChRs that are enriched on DA axons. Data are are means \pm s.e.m. normalized to $100 \%$ mean WT control for each region. ${ }^{* *} P<0.01 ;{ }^{* * *} P<0.001$ for WT DAT-Cre vs. PERK ${ }^{\mathrm{f} / f}$ DAT-Cre mice, where $n$ denotes the number of recording sites in each region sampled from 3 to 5 mice per genotype. 


\section{Supplementary Figure 5}

a

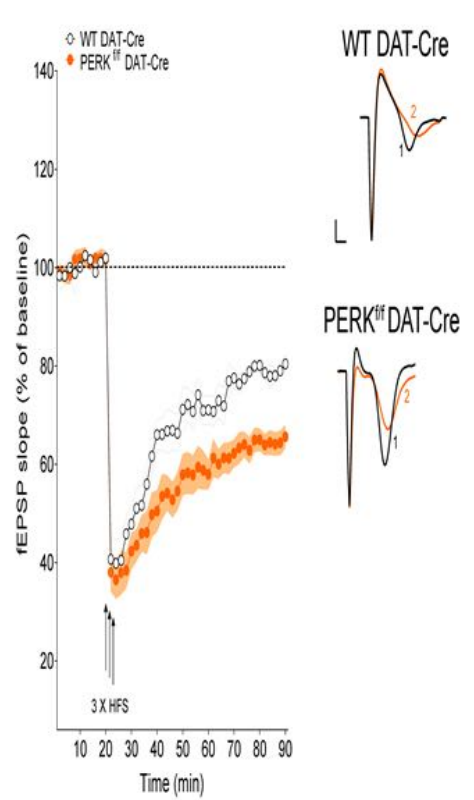

b

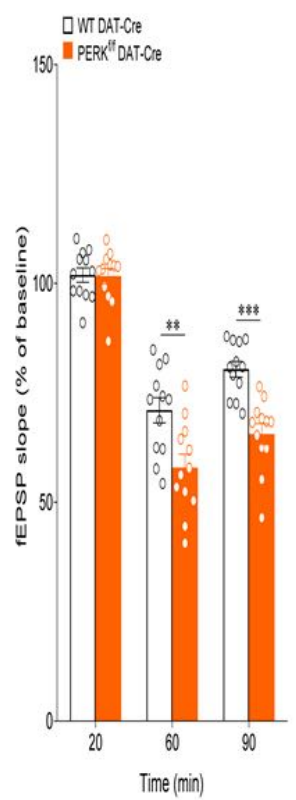

C

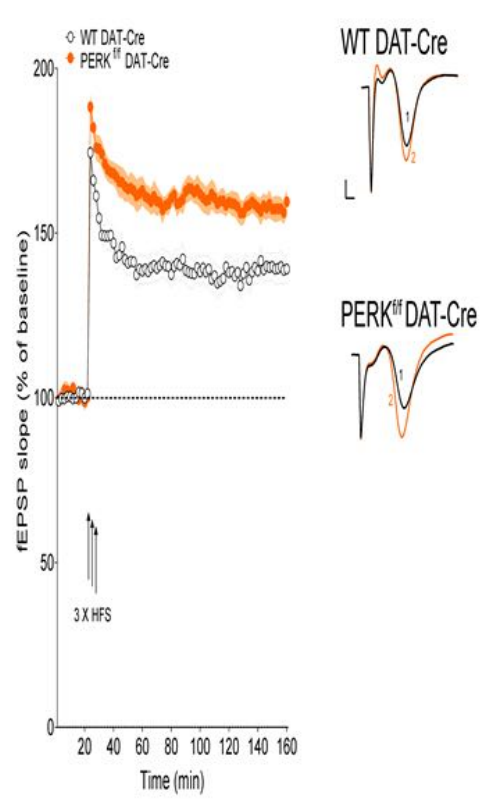

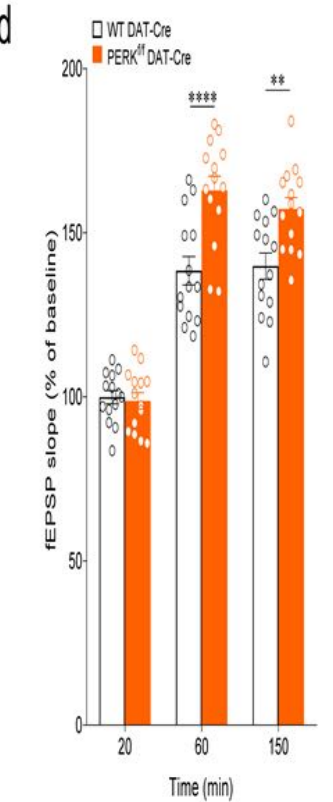

Supplementary Figure 5. Deletion of PERK in DA neurons alters both striatal and hippocampal synaptic plasticity. $(\mathbf{a}, \mathbf{b})$ Striatal long-term depression (LTD) in 3-month old PERK ${ }^{\mathrm{f} / \mathrm{f}}$ DAT-Cre vs. WT DAT-Cre mice. (a) Plot showing normalized fEPSP mean slope ( \pm s.e.m. displayed every $2 \mathrm{~min}$ ) recorded from striatal slices. (b) Mean fEPSPs at baseline (20 min), at 60 (40 min after tetanus) and at $90 \mathrm{~min}$ (70 min after tetanus). LTD evoked by 3 trains of high frequency stimulation (HFS) was significantly enhanced in PERK ${ }^{\mathrm{k} / \mathrm{f}}$ DAT-Cre striatal slices at both 60 min and 90 min (two-way RM ANOVA, followed by Bonferroni's multiple comparisons test, time $x$ genotype, $\mathrm{F}_{(2,44)}=6.71, P=0.003$; time, $\mathrm{F}_{(2,44)}=$ 161.60, $P<0,0001$; genotype $\mathrm{F}_{(1,22)}=19.85, P=0,0002 ; \mathrm{n}=12$ slices from 7 mice/genotype). Data are shown as mean \pm s.e.m. ${ }^{* *} P<0.01$ and ${ }^{* * *} P<0.001$ PERK $^{\mathrm{f} / f}$ DAT-Cre versus WT DAT-Cre mice. (c,d) Hippocampal late-phase long-term potentiation (L-LTP) in 3-month old PERK ${ }^{\mathrm{f} / \mathrm{f}}$ DAT-Cre vs. WT DAT-Cre mice. (c) Plot showing normalized fEPSP mean slope ( \pm s.e.m. displayed every $2 \mathrm{~min}$ ) recorded from hippocampal slices. (d) Mean fEPSPs at baseline (20 min), at 60 (40 min after tetanus) and at $150 \mathrm{~min}$ (130 min after tetanus). L-LTP evoked by 3 trains of high frequency stimulation (HFS) was significantly increased in PERK ${ }^{\mathrm{f} / \mathrm{f}}$ DAT-Cre hippocampal slices at both $60 \mathrm{~min}$ and 150 min (two-way RM ANOVA, followed by Bonferroni's multiple comparisons test, time $x$ genotype, $F_{(2,52)}=8.36, P=0.0007$; time, $F_{(2,52)}=162, P$ $<0,0001$; genotype $\mathrm{F}_{(1,26)}=162, P=0,0004 ; \mathrm{n}=14$ slices from 8 mice/genotype). Representative traces (a,c left panels) are superimposed fEPSPs (scale bars represent $1 \mathrm{mv} / \mathrm{msec}$ ) recorded during baseline (1) and 60 min after HFS train (2). Arrows indicate delivery of HFS. 


\section{Supplementary Figure 6}

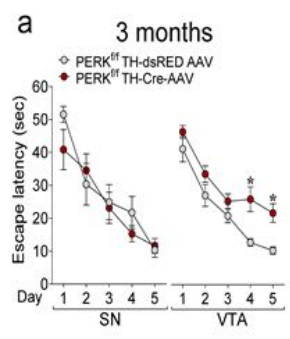

b

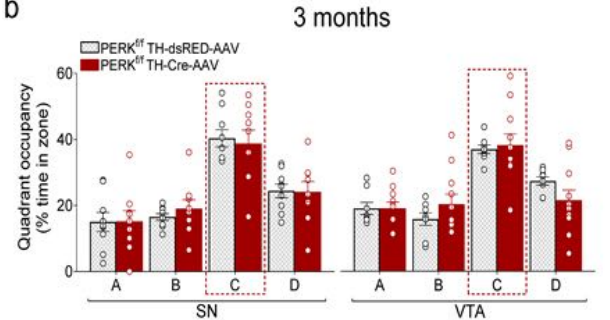

3 months

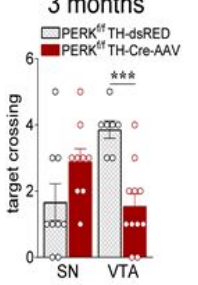

$f$

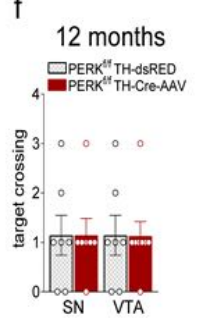

g

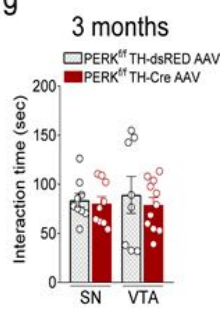

$\mathrm{h}$

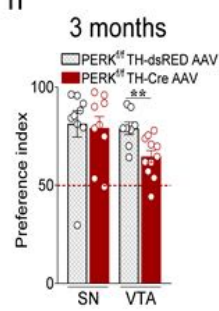

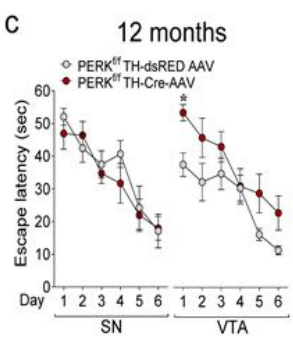

d

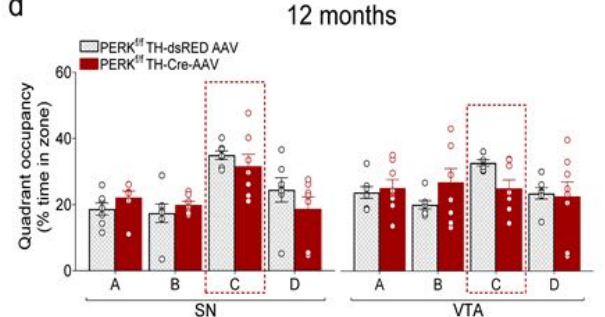

i
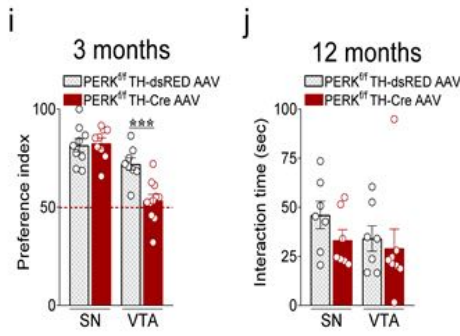

$\mathrm{k}$

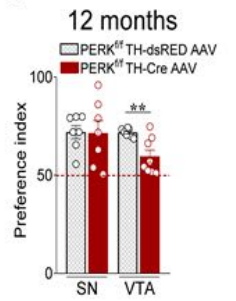

I
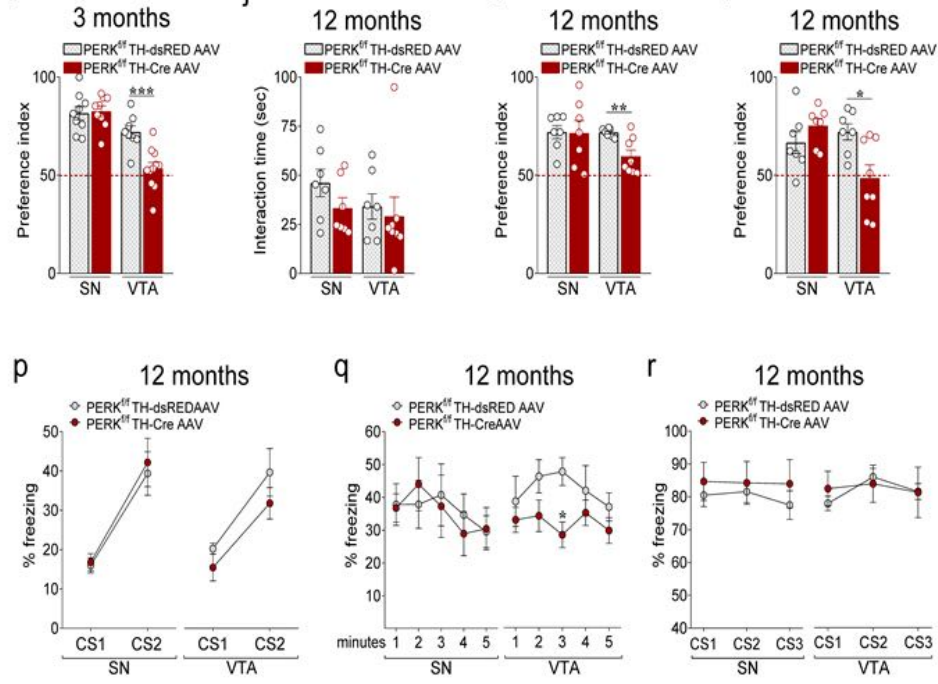
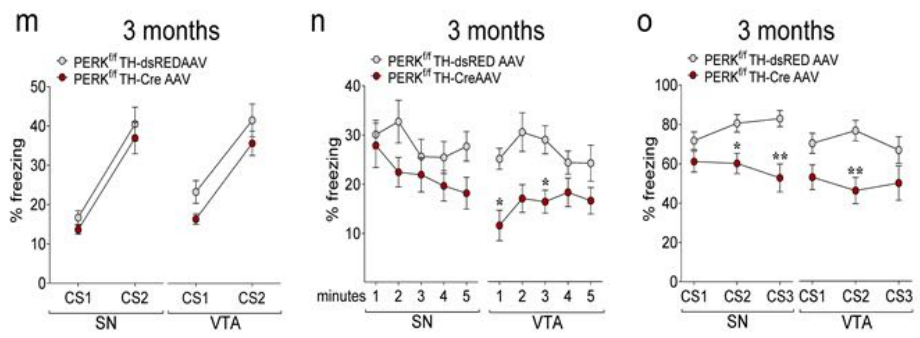

Supplementary Figure 6. Mice lacking PERK in DA neurons of the VTA exhibit cognitive phenotypes similar to those displayed by the PERK ${ }^{f / f}$ DAT-Cre mice. (a-f) Summary plots of $(\mathbf{a}, \mathbf{c})$ average latency to find the hidden platform during a 5 (a) and 6-day (c) training protocol, (b,d) percentage of total time spent in each quadrant, and (e-f) average number of times spent crossing the location of the previously hidden platform during probe tests in 3-month old and 12month old PERK ${ }^{\mathrm{f} / \mathrm{T}}$ TH-Cre-AAV versus PERK ${ }^{\mathrm{f} / \mathrm{f}}$ TH-dsRED AAV control mice injected in either SN or VTA in the MWM test (a, two-way RM ANOVA, followed by Bonferroni's multiple comparisons test, SN: n.s; VTA: genoype, $\mathrm{F}_{(1,17)}=15.22, P<$ 0.01; b, two-way RM ANOVA, followed by Bonferroni's multiple comparisons test, quadrant $x$ genotype, n.s., in both SN and VTA; c, two-way RM ANOVA, followed by Bonferroni's multiple comparisons test, SN: n.s; VTA: genoype, $\mathrm{F}_{(1,13)}=$ 5.404, $P=0.037$; d, two-way RM ANOVA, followed by Bonferroni's multiple comparisons test, quadrant $x$ genotype, n.s., in both SN and VTA; e, unpaired $t$ test, SN: n.s.; VTA: $\mathrm{t}_{(17)}=4.927, P<0.001$; f, unpaired $t$ test, SN: n.s.; VTA: n.s.). (g-I) Summary plots of $(\mathbf{g}, \mathbf{j})$ interaction time with familiar objects, and $(\mathbf{e}, \mathbf{f})$ preference indices of mice toward a novel object introduced in the novel object recognition test in (h-i) 3-month old and (k-I) 12-month old PERK ${ }^{f / f}$ TH-Cre-AAV versus PERK $^{\mathrm{f} / \mathrm{f}}$ TH-dsRED AAV control mice injected in either SN or VTA (unpaired t test; $\mathbf{g}$, n.s. in both SN and VTA; $\mathbf{h}, \mathrm{SN}$ : n.s., VTA: $\mathrm{t}_{(17)}=3.173, P<0.01$; $\mathbf{i}$, SN: n.s., VTA: $\mathrm{t}_{(17)}=4.102, P<0.001$; $\mathbf{j}$, n.s. in both SN and VTA; $\mathbf{k}$, SN: n.s., VTA: $\mathrm{t}_{(13)}=$ $3.435, P<0.01$; I, SN: n.s., VTA: $\left.\mathrm{t}_{(13)}=2.866, P<0.05\right)$. $(\mathbf{m}-\mathbf{r})$ Summary plots of average percentage of freezing during $(\mathbf{m}, \mathbf{p})$ training, $(\mathbf{n}, \mathbf{q})$ exposure to the context 24 hours after training, and $(\mathbf{o}, \mathbf{r})$ exposure to 3 CS presentations in a novel context in the associative threat memory test in $(\mathbf{m}-\mathbf{o})$ 3-month old and $(\mathbf{p}-\mathbf{r})$ 12-month old PERK ${ }^{\mathrm{f} / \mathrm{f}}$ TH-Cre-AAV versus PERK $^{\mathrm{f} / \mathrm{f}}$ TH-dsRED AAV control mice injected in either SN or VTA ( $\mathbf{m}$, two-way RM ANOVA, followed by Bonferroni's multiple comparisons test, n.s. in both SN and VTA; $\mathbf{n}$, two-way RM ANOVA, followed by Bonferroni's multiple comparisons test, genotype, SN: n.s., VTA: genotype, $\mathrm{F}_{(1,17)}=10.97, P<0.01$; o, two-way RM ANOVA, followed by Bonferroni's multiple comparisons test, $S N$ : time $x$ genotype, $F_{(2,32)}=5.837 P<0.01$, VTA: time $\times$ genotype, $F_{(2,34)}=2.79$ $P=0.075$; $\mathbf{p}$, two-way RM ANOVA, followed by Bonferroni's multiple comparisons test, n.s. in both SN and VTA; q, twoway RM ANOVA, followed by Bonferroni's multiple comparisons test, genotype, SN: n.s., VTA: genotype, $\mathrm{F}_{(1,13)}=11.22$, $P$ $<0.01$; r, two-way RM ANOVA, followed by Bonferroni's multiple comparisons test, n.s. in both SN and VTA). All data are shown as mean \pm s.e.m. of $n=9$ (3-month old) or 7 (12-month old) PERK ${ }^{\mathrm{t} / \mathrm{f}}$ TH-Cre-AAV and PERK ${ }^{\mathrm{t} / \mathrm{f}}$ TH-dsRED AAV mice injected in the SN; $n=11$ (3-month old) or 8 (12-month old) PERK ${ }^{\mathrm{t} / \mathrm{f}}$ TH-Cre-AAV mice and $n=8$ (3-month old) or 7 (12-month old) PERK ${ }^{f / f}$ TH-dsRED AAV mice injected in the VTA. ${ }^{*} P<0.05$, ${ }^{* *} P<0.01$ and ${ }^{* * *} P<0.001 \mathrm{PERK}^{\mathrm{fff}}$ TH-CreAAV versus PERK ${ }^{\mathrm{fff}}$ TH-dsRED AAV mice. 


\section{1}

172

173

174

175

176

177

178

179

180

181

182

183

184

185

186

187

188

\section{Supplementary Figure 7}

a

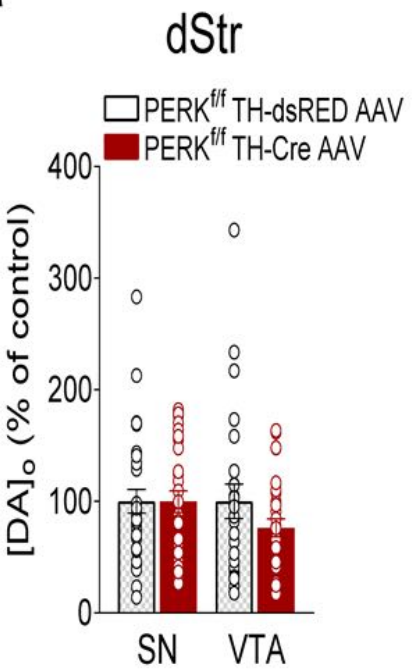

b

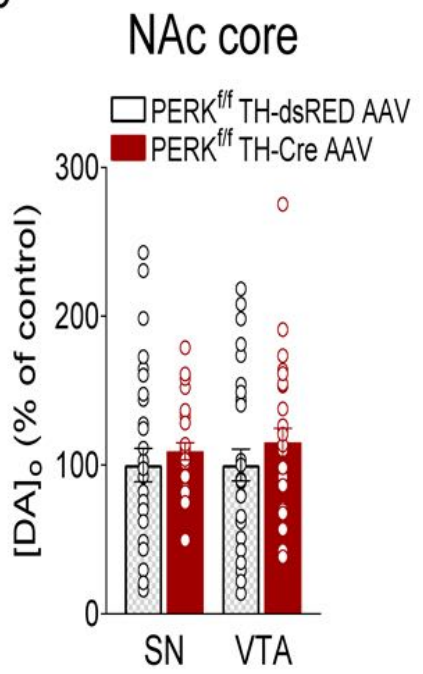

C

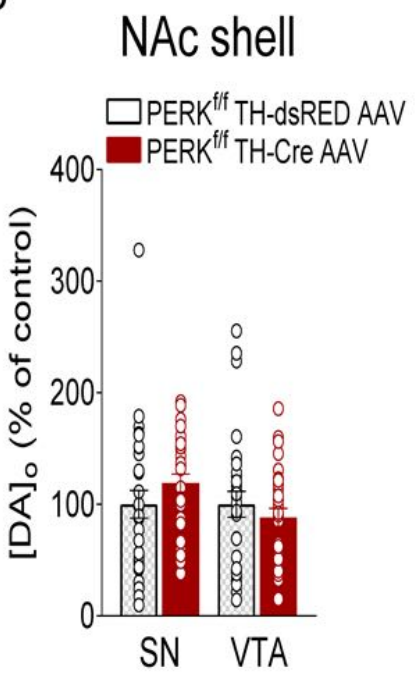

Supplementary Figure 7. Selective deletion of PERK in DA neurons of either the VTA or the SN does not affect DA release and DAT activity in TH-Cre AAV-injected 12-month PERK ${ }^{f / f}$ mice. (a-c) Summary plot of evoked [DA]。 peak expressed as \% of control in dStr (a, unpaired $t$-test, n.s. for either SN or VTA), NAc core (b, unpaired $t$-test, n.s. for either SN or VTA), and NAc shell (c, unpaired $t$-test, n.s. in either SN or VTA) in 12-month old mice. Data are means \pm s.e.m. of $n$ mice, where $n$ denotes the number of recording sites sampled from 3 to 5 mice per genotype. Values with $\mathrm{R}^{2}<0.95$, indicating goodness-of-fit were excluded from the data reported here. 